AUGUSTO OTTO MOLKE

\title{
MINIMIZAÇÃO DO ATRASO TOTAL PONDERADO NA PROGRAMAÇÃO DE MÁQUINAS DIFERENTES EM PARALELO COM ELEGIBILIDADE
}




\title{
MINIMIZAÇÃO DO ATRASO TOTAL PONDERADO NA PROGRAMAÇÃO DE MÁQUINAS DIFERENTES EM PARALELO COM ELEGIBILIDADE
}

\author{
Dissertação apresentada à Escola Po- \\ litécnica da Universidade de São Paulo para \\ obtenção do Título de Mestre em Ciências. \\ Área de Concentração: \\ Engenharia de Sistemas Logísticos
}

Orientador:

Prof Dr Miguel Cezar Santoro 
Autorizo a reprodução e divulgação total ou parcial deste trabalho, por qualquer meio convencional ou eletrônico, para fins de estudo e pesquisa, desde que citada a fonte.

Este exemplar foi revisado e corrigido em relação à versão original, sob responsabilidade única do autor e com a anuência de seu orientador.

São Paulo, de de

Assinatura do autor:

Assinatura do orientador:

\section{Catalogação-na-publicação}

Molke, Augusto Otto

Minimização do atraso total ponderado na programação de máquinas diferentes em paralelo com elegibilidade / A. O. Molke -- versão corr. -- São Paulo, 2018.

$106 \mathrm{p}$.

Dissertação (Mestrado) - Escola Politécnica da Universidade de São Paulo. Departamento de Engenharia de Produção.

1.Scheduling 2.Geração de Colunas 3.Pesquisa Operacional 4.Máquinas em Paralelo I.Universidade de São Paulo. Escola Politécnica. Departamento de Engenharia de Produção II.t. 
À minha familia, fonte de carinho e apoio 


\section{AGRADECIMENTOS}

Muitas pessoas contribuíram direta e indiretamente para o desenvolvimento desta pesquisa. Gostaria de deixar registrado a minha gratidão a algumas delas: Prof. Miguel Santoro - orientador, amigo e incentivador, pela condução segura, ponderada e sobremaneira dedicada a esta pesquisa e pelo apoio contínuo em todos os momentos; Professores André Bergsten e Débora Ronconi, pelo importante apoio durante as etapas da minha formação acadêmica; Hanna Pamplona, Sérgio Bassi, Fernanda Rocha e Bruna Carvalho - colegas do grupo de Gestão de Operações Logísticas, pelo apoio, incentivo mútuo e amizade; Família - pais e avós pelo carinho e apoio permanente. 


\section{RESUMO}

Este trabalho trata do problema de sequenciamento e programação de atividades em máquinas diferentes em paralelo, considerando elegibilidade de máquina, e tempo de liberação das máquinas e das atividades com o objetivo de minimizar o custo de atraso total. Tal problema é descrito pela literatura como NP-hard. Foi proposto um método otimizante que envolve modelagem matemática, um algoritmo de geração de colunas e, além disso, uma heurística para tratar problemas com instancias maiores. O algoritmo de geração de colunas é baseado no método proposto por Akker, Hurkens e Savelsbergh (2000), que foi adaptado para o problema de múltiplas máquinas diferentes. Assim, o método foi aplicado em instâncias da literatura e em instâncias geradas para este trabalho de até 25 atividades e 4 máquinas. Os resultados foram analisados e observou-se que o modelo de programação inteira mista é eficiente para encontrar limitantes superiores de boa qualidade. Por outro lado, o algoritmo de geração de colunas é eficiente para encontrar limitantes inferiores para o problema. Desta forma, o método proposto utiliza o modelo MILP e o algoritmo de geração de colunas de maneira a se complementar. Assim, soluções ótimas foram encontradas para 84\% das instancias geradas, sendo que o GAP médio para as instancias restantes foi de $2,1 \%$. A heurística proposta é baseada na ideia de heurística construtiva probabilística, que foi apresentada por Arcus (1965). Ela foi executada na massa de dados gerada, resultando em um GAP médio de 10,6\%.

Palavras-Chave programação de atividades, máquinas diferentes em paralelo, atraso total, geração de colunas, heurística construtiva. 


\section{ABSTRACT}

This paper deals with the problem of scheduling activities in unrelated parallel parallel, considering machine eligibility, and machine and activity release time in order to minimize total weighted tardiness.Such a problem is described in the literature as NPhard. It has been proposed an optimizing method that involves mathematical modeling and a column generation algorithm, in addition, it is proposed a heuristic to treat problems with larger instances. The column generation algorithm was based on the method proposed by Akker, Hurkens e Savelsbergh (2000), which has been adapted to the problem of multiple different machines. Thus, the method was applied in instances of the literature and in instances generated for this paper up to 25 jobs and 4 machines. The results were analyzed and it was noted that the mixed integer programming model is efficient to find good quality upper bounds. On the other hand, the column generation algorithm is efficient to find lower bounds for the problem. Therefore, the proposed method uses the MILP model and the column generation algorithm to complement each other. Thus, optimal solutions were found for $84 \%$ of the generated instances, with the mean GAP for the remaining instances being $2.1 \%$. The proposed heuristic is based on the idea of probabilistic constructive heuristics, which was presented by Arcus (1965). It was run on the mass of data generated, resulting in an average GAP of $10,6 \%$.

Keywords scheduling, unrelated parallel machines, tardiness, column generation, constructive heuristic. 


\section{LISTA DE FIGURAS}

1 Esquema do problema de máquinas em paralelo . . . . . . . . . . . . . . 16

2 Fluxograma do método proposto . . . . . . . . . . . . . . . . . . 29

3 Exemplo de rede de caminho mínimo . . . . . . . . . . . . . . . . 40

4 Fluxograma da Geração de colunas . . . . . . . . . . . . . . . . . . . 41

5 Gráfido de Probabilidades . . . . . . . . . . . . . . . . . . . 49

6 Gráfico de Gantt da solução fornecida pelo modelo matemático para a instância 21. . . . . . . . . . . . . . . . . . . . . 60

$7 \quad$ Gráfico da evolução do Limitante Superior e Inferior para a Instância 158, 63

8 Gráfico da evolução do Limitante Superior e Inferior para a Instância 158, 64

9 Gráfico de Gantt da solução fornecida pelo modelo matemático para a instância 158. . . . . . . . . . . . . . . . . . . . . . . 65

10 Histograma de GAPs das melhores soluções encontradas para as instâncias do conjunto $2 \ldots \ldots \ldots \ldots$. . . . . . . . . . . . . 66

11 Gráfico de Gantt da solução fornecida pela para a instância 158. . . . . . . 70 


\section{LISTA DE TABELAS}

1 Parâmetros do Modelo de Zhu e Heady (2000) . . . . . . . . . . . . . . . . 22

2 Variáveis do Modelo de Zhu e Heady (2000) . . . . . . . . . . . . . . . . 22

3 Dados de entrada do modelo proposto . . . . . . . . . . . . . . . 30

4 Variáveis de Decisão do modelo proposto . . . . . . . . . . . . . . . 30

$5 \quad$ Variáveis de Decisão . . . . . . . . . . . . . . . . . . . 34

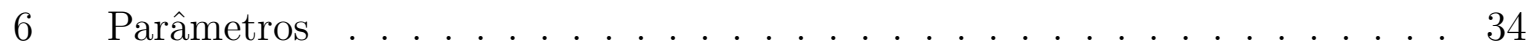

7 Instância Exemplo . . . . . . . . . . . . . . . . . . . . . . 45

8 Instância Exemplo - Lista de pares $(j, m)$ Ordenada por $c_{j m}$ decrescente . . 46

9 Instância Exemplo - Lista após a alocação da primeira atividade . . . . . . 46

10 Instância Exemplo - Lista de pares $(j, m)$ Ordenada por $\operatorname{prob}_{j m}$, conside-

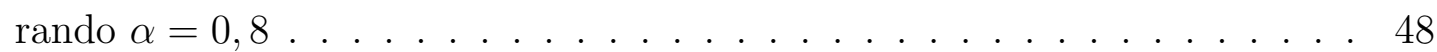

11 Parâmetros das instâncias do primeiro conjunto . . . . . . . . . . . . . 52

12 Parâmetros das instâncias do segundo conjunto . . . . . . . . . . . . . 55

13 Quantidade de instâncias que tiveram soluções ótimas encontradas em até 1800 segundos pelo MILP, por quantidade de máquinas e atividades. . . . . 58

14 Quantidade de instâncias que foram resolvidas em até 1800 segundos pelo MILP, por R e T. . . . . . . . . . . . . . . . . . 58

$15 G A P_{M I L P}$ resultante para instâncias que não tiveram soluções ótimas encontradas em até 1800 segundos pelo MILP. . . . . . . . . . . . . . . . . 58

$16 G A P_{M I L P}$ resultante para todas a instâncias por T e R. . . . . . . . . . . 59

17 Tempo médio de processamento do MILP em segundos para todas as instâncias. . . . . . . . . . . . . . . . . . . . . 59

18 Quantidade de instâncias que tiveram soluções ótimas comprovadas pelo algoritmo de geração de colunas por quantidade de máquinas e atividades. 
19 Quantidade de instâncias que tiveram soluções ótimas comprovadas pelo algoritmo de geração de colunas por fator T e R. . . . . . . . . . . . . . . . 61

$20 G A P_{G C}$ médio final das instâncias que não tiveram soluções ótimas comprovadas pelo algoritmo de geração de colunas por fator T e R. . . . . . . . 62

21 Quantidade de instâncias com solução ótima por fator de elegibilidade. . 67

22 Quantidade de instâncias com solução ótima por fator amplitude (R). . . . 67

23 GAP final médio das instâncias que não tiveram soluções ótimas encontradas pelo método por quantidade de máquinas e atividades. . . . . . . . . . . 67

24 Tempo médio de execução do método em segundos, por fator R e T. . . . . 67

$25 G A P_{H E U}$ médio das instâncias resultante da heurística construtiva probabilística, por quantidade de atividades e máquinas. . . . . . . . . . . . . 68

$26 G A P_{H E U}$ médio das instâncias resultante da heurística construtiva probabilística, por fator R e T. . . . . . . . . . . . . . . . . . . . . 69

27 Tempo médio de execução da heurística construtiva probabilística em segundos, por quantidade de atividades e máquinas. . . . . . . . . . . . . . . 69

28 Tempo médio de execução da heurística construtiva probabilística em segundos, por fator $\mathrm{R}$ e $\mathrm{T}$. 


\section{LISTA DE SIGLAS}

MILP: Mixed Integer Linear Programming

VNS: Variable Neighborhood Search

GRASP: Greedy Randomized Adaptative Search Procedure 


\section{SUMÁRIO}

1 Introdução 12

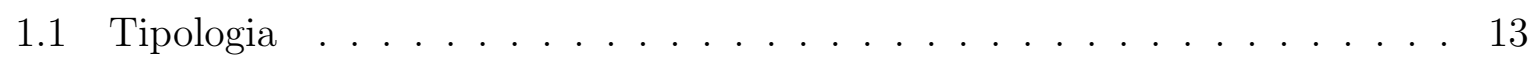

1.2 Definição e características do Problema . . . . . . . . . . . . . . . . 14

1.3 Objetivos do Trabalho . . . . . . . . . . . . . . . 16

2 Revisão Bibliográfica $\quad 18$

2.1 Formulação Matemática . . . . . . . . . . . . . . . . . . 21

2.2 Lower Bounds . . . . . . . . . . . . . . . . . . . 23

2.3 Métodos de Solução . . . . . . . . . . . . . . . . . . . . . 24

2.3.1 Meta-Heurísticas . . . . . . . . . . . . . 25

2.3.2 Métodos Exatos . . . . . . . . . . . . . . 26

2.3.3 Geração de Colunas . . . . . . . . . . . . . . . . . 26

2.3.4 Outros Métodos ...................... 27

3 Método $\quad 29$

3.1 Modelo de Programação Inteira Mista . . . . . . . . . . . . . . . . . . 29

3.2 Lower Bound . . . . . . . . . . . . . . . . . . . . . 33

3.2.1 Reformulação e Decomposição de Dantzig-Wolfe . . . . . . . . . . . 34

3.2 .2 Geração de Colunas . . . . . . . . . . . . . . . . . . . 38

3.2 .3 Solução Inicial . . . . . . . . . . . . . . . . . . . . . . . . 43

3.3 Método Heurístico . . . . . . . . . . . . . . . . . . . . . 43

3.3.1 Heurística Construtiva Determinística . . . . . . . . . . . . . 44

3.3.2 Heurística Construtiva Probabilística . . . . . . . . . . . . . 48 
4.1 Validação do Método . . . . . . . . . . . . . . . . . . . . . 51

4.1.1 Instâncias do conjunto de validação do Método . . . . . . . . . . . 51

4.1.2 Resultados das instâncias do Conjunto de Validação do método . . 52

4.2 Instâncias do Conjunto de Teste . . . . . . . . . . . . . . . . . . . . 54

5 Análise dos Resultados $\quad 56$

5.1 Resultados do modelo matemático . . . . . . . . . . . . . . . . . . 57

5.2 Resultados da geração de colunas . . . . . . . . . . . . . . . . . . . . . 61

5.3 Resultados do método como um todo . . . . . . . . . . . . . . . . . . 66

5.4 Resultados da Heurística Construtiva Probabilística . . . . . . . . . . . . 68

6 Conclusão $r 1$

Referências $\quad 73$

Apêndice A - Modelo de Programação Inteira Mista no CPLEX 77

Apêndice B - Código Fonte da Heurística Construtiva Probabilística $\quad 81$

Apêndice C - Codigo Fonte do Método de Geração de Colunas $\quad 87$

Apêndice D - Exemplo de Estrutura de Dados $\quad 91$

Apêndice E - Resultado das Instâncias para os três métodos (MILP, Geração de Colunas e Heurística Construtiva Probabilística) 97 


\section{INTRODUÇÃO}

Em uma economia de recursos limitados e competitividade elevada, o sistema Toyotismo de produção tem se mostrado efetivo para gerenciar a industria de manufatura (CHENG; HUANG, 2017). O conceito chamado JIT, ou Just-in-Time, é componente critico do Toyotismo e trás à tona os problemas relacionados ao atraso na produção. Dentre outros pontos tocados pelo sistema, o atraso acarreta insatisfação com o nível de serviço oferecido aos clientes incorrendo em problemas com a reputação da companhia. O Toyotismo é componente chave para o sucesso da fabricante de automóveis, como mostra a mídia. Um exemplo de publicação abordando este tema pode ser visto a seguir.

"Pode parecer estranho para o público brasileiro, onde a Toyota tem um discreto oitavo lugar no mercado, mas nesta semana a fabricante japonesa de automóveis chegou à liderança do mercado mundial de automóveis e caminhões: a empresa vendeu 2,348 milhões de veículos no mundo todo, no primeiro trimestre de 2007, e passou a tradicional líder GM, que estava à frente do mercado havia 70 anos. No centro do crescimento da Toyota está seu método de produção, apelidado de "toyotismo" [...] o sistema de produção da Toyota procura eliminar desperdícios do processo de produção, como forma de atingir a melhor qualidade, o menor custo e o menor tempo de produção, explica o engenheiro de produção."

$(\mathrm{G} 1,2007)$

De maneira similar, o atraso está presente em situações mais recorrentes na vida cotidiana. Como exemplo, o atraso em vôos é um dos principais problemas de companhias aéreas. Em um levantamento publicado pela Fundação de Proteção e Defesa do Consumidor (Procon-SP) em 2012, foi mostrado que os vôos com atrasos de 60 minutos ou mais chegam a $32 \%$ do total de vôos em algumas empresas aéreas do mercado brasileiro.

Desta forma, não é incomum encontrar empresas colocando esforços na redução do atraso em suas atividades. A literatura científica também acompanha este movimento e 
observa-se uma grande quantidade de trabalhos sendo publicado acerca deste tema.

O problema abordado neste trabalho, conhecido como sequenciamento e programação e de tarefas em máquinas diferentes em paralelo, se relaciona com as situações mencionadas. Ele consiste em alocar diversas atividades que devem ser processadas em máquinas diferentes que podem trabalhar simultaneamente. Cada atividade deve ser processada apenas uma vez e procura-se sequenciá-las de maneira a minimizar o atraso total das atividades considerando a data de entrega prevista para cada uma delas ou o ultimo instante de término das atividades.

Este cenário pode ser facilmente associado ao exemplo de atrasos de voos mencionado acima, onde cada portão de embarque representa uma máquina que deve processar as atividades, ou embarques, em determinada ordem de modo a minimizar o atraso. Neste contexto, pode-se acrescentar características que tornam o problema mais aderente à realidade, como diferentes velocidades de máquina e setup dependente de sequência. Em adição, cada atividade pode ter um custo diferente de atraso, que deve ser considerado no objetivo do problema.

É possível perceber que trata-se de um problema combinatório com características semelhantes à outros problemas, como roteamento de veículos e corte e empacotamento, que compõem um conjunto de problemas classificados como NP-hard (GRAHAM et al., 1979), de grande relevância para o contexto econômico e acadêmico atual.

\subsection{Tipologia}

Para descrever um problema de programação e sequenciamento, é utilizada a notação de Graham et al. (1979). Os três campos propostos ( $\alpha, \beta$ e $\gamma)$ representam, nesta ordem, informações sobre máquinas, informações sobre as atividades, e o objetivo a ser minimizado. No que se trata de máquinas em paralelo, o campo $\alpha$ pode assumir as notações $P, Q$ ou $R$. Onde $P$ denota máquinas idênticas, $Q$ denota máquinas uniformes e $R$ denota máquinas diferentes. Considerando-se que a máquina $i$ processa a atividade $j$ na velocidade $s_{i j}$, segundo Blazewicz, Dror e Weglarz (1991), tem-se que:

- Máquinas Idênticas: todos $s_{i j}$ são iguais e podem ter seu valor igual a 1 ;

- Máquinas Uniformes: toda máquina $i$ processa todas as atividades $j$ na mesma velocidade $s_{i}$, de forma que se pode assumir $s_{1} \geq s_{2} \geq \ldots \geq s_{m}$;

- Máquinas diferentes: não existe relação entre os valores de $s_{i j}$. 
O nível de generalização, assim como a complexidade do problema, aumenta à medida que nos aproximamos do cenário $R$. Grande parte da literatura a respeito deste tema trabalha com o cenário de máquinas idênticas.

O campo $\beta$ contém as informações e características do programa de produção. Algumas dessas características, de acordo com Li e Yang (2009), podem ser:

- $r_{j}$ : tempo de liberação da atividade;

- $r_{m}$ : tempo de liberação da máquina;

- pmtn: o processamento da atividade pode ser interrompido e continuado posteriormente na mesma máquina ou em máquina diferente;

- prec: restrições de precedência;

- $S T_{s i}$ : tempo de setup independente da sequência;

- $S T_{s d}$ : tempo de setup dependente da sequência;

Por fim, o campo $\gamma$ contém informações sobre o critério de desempenho, em outras palavras, o objetivo a ser minimizado. Neste trabalho, considera-se a classificação utilizada por Cheng e Sin (1990) que categoriza os critérios de desempenho em: baseado no instante de término, como $C_{\max }$ (makespan) e baseado na data de entrega, como $\sum w_{j} T_{j}$ (atraso total ponderado).

\subsection{Definição e características do Problema}

Considere um conjunto de máquinas diferentes $m=\{1,2,3 \ldots M\}$ e um conjunto de atividades $j=\{1,2,3 \ldots J\}$ que devem ser processadas uma vez por qualquer uma das máquinas elegíveis para processar tal atividade. Cada máquina possui uma data de liberação, e cada atividade possui uma data de liberação, um tempo de processamento dependente da máquina, uma data de entrega e um custo de atraso. Todos os dados são determinísticos e conhecidos previamente. O problema de programação e sequenciamento tratado neste trabalho consiste em designar uma máquina à cada atividade e sequenciar as atividades designadas a cada máquina de maneira a minimizar o atraso total ponderado. Interrupções não são permitidas, em outra palavras, uma vez que a atividade começa a ser processada, ela deve permanecer na máquina até o término de seu processamento.

A seguinte notação é utilizada neste trabalho: 
- $m$ - Número de máquinas em paralelo;

- $n$ - Número de atividades a serem sequenciadas;

- $D_{j}$ - Data de entrega da atividade $j$. Cada unidade de tempo que a atividade $j$ requisitar para ser processada além de $D_{j}$ será definido como atraso.

- $r_{j}$ - Data de liberação da atividade $j$, antes da qual ela não pode começar a ser processada;

- $r_{m}$ - Data de liberação da máquina $m$, antes da qual ela não pode processar nenhuma atividade;

- $p_{j m}$ - Tempo de processamento da atividade $j$ na máquina $m$;

- $t_{j}$ - Custo de atraso da atividade $j$.

- $C_{j}$ - Instante de término da atividade $j$;

- $T_{j}$ - Atraso da atividade $j$, definido como $\max \left\{0, C_{j}-D_{j}\right\}$;

- $C_{\max }$ - Horizonte de processamento, ou makespan, é definido pelo último instante de término das atividades.

Assim, o objetivo primário deste trabalho consiste na minimização do atraso total ponderado, representado a seguir:

$$
\min \sum_{1}^{j} t_{j} T_{j}
$$

A solução deste problema, ou seja, a programação e sequenciamento das atividades que minimiza (1.1), pode ser representada como um conjunto de sequências $S=$ $\left\{S_{1}, S_{2}, S_{3} \ldots S_{m}\right\}$, onde

$$
S_{k}=\left\{S_{k}^{1}, S_{k}^{2}, S_{k}^{3} \ldots S_{k}^{n k}\right\}
$$

Representa a sequência de atividades designadas para a máquina $k, n_{k}$ é o número de atividades designadas para a máquina $k$ e $S_{k}^{i}$ representa a atividade alocada na posição $i$ daquela máquina. Um modelo esquemático deste problema é mostrado na Figura 1.

Utilizando a notação $\alpha|\beta| \gamma$ de Graham et al. (1979), este problema pode ser pesquisado como $R_{m}\left|r_{j}, r_{m}, e\right| \sum t_{j} T_{j}$. Segundo o mesmo autor, o problema $1 \| \sum T_{j}$ é NP-Hard. 


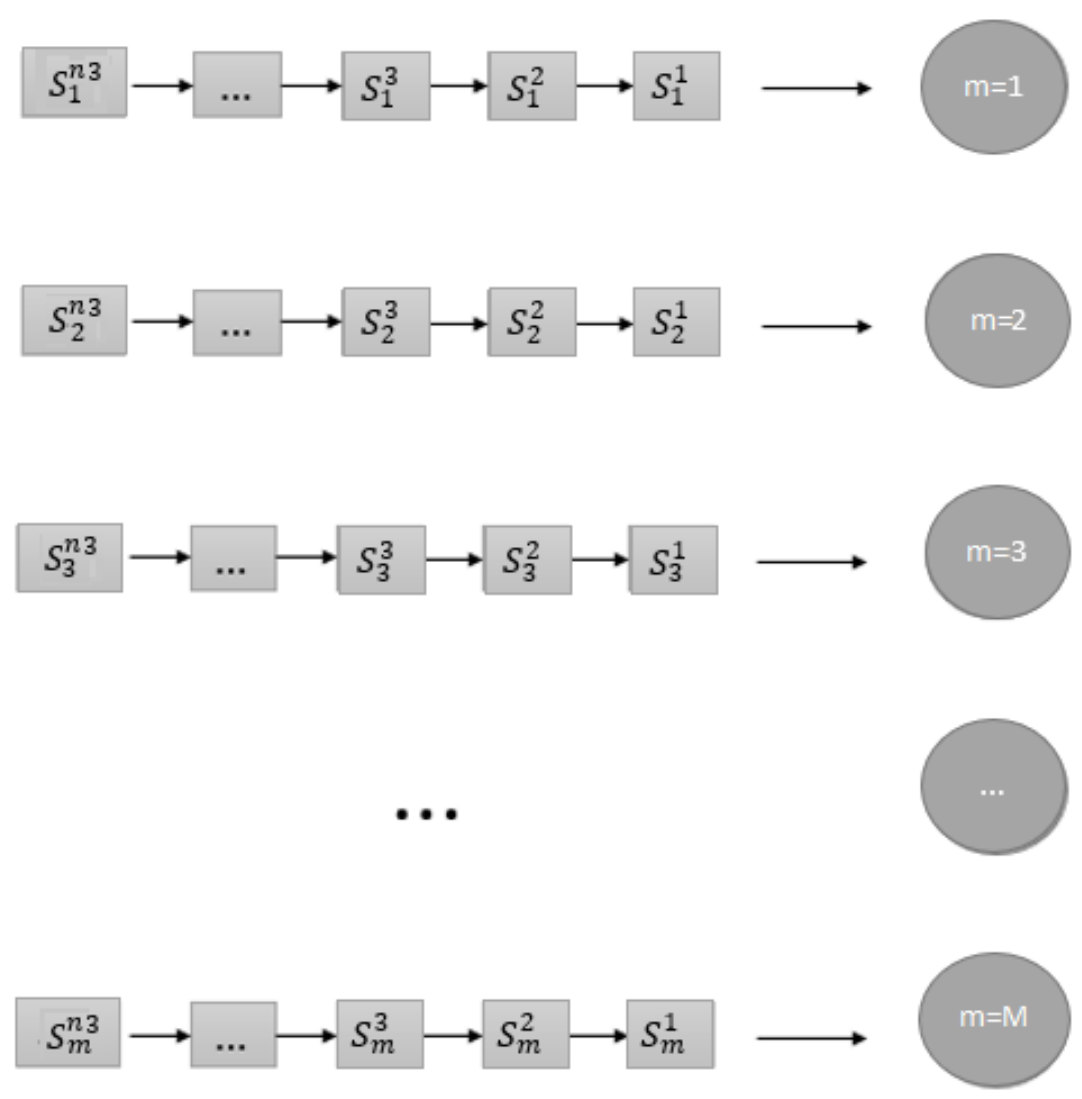

Figura 1: $m$ sequencias de tarefas, com $n_{m}$ atividades cada uma, sequenciadas de maneira a minimizar o atraso total ponderado.

Como o problema aqui apresentado é uma generalização deste ultimo, podemos dizer que $R_{m}\left|r_{j}, r_{m}, e\right| \sum t_{j} T_{j}$ é NP-Hard.

\subsection{Objetivos do Trabalho}

Este trabalho tem como objetivo geral tratar o problema de minimização de atraso total ponderado em máquinas diferentes em paralelo com elegibilidade, considerando tempos de liberação da atividade e da máquina, como apresentado na seção anterior. Para isto, será utilizada a modelagem matemática, será proposto um método para encontrar lower bound (LB) e uma heurística para o problema.

A metodologia proposta foi aplicada em instâncias selecionadas da literatura e os resultados foram analisados com base nas características de cada instância. Os objetivos específicos deste trabalho englobam:

- Propor um novo modelo de programação inteira mista, ou mixed integer linear programming (MILP), para o problema; 
- Discutir o método de geração de colunas e suas implicações para o problema, analisando as variáveis críticas para o algoritmo;

- Propor um método de geração de colunas para o problema;

- Propor uma heurística para tratar os problemas de instâncias maiores;

- Expor e discutir os resultados obtidos da aplicação do modelo, do método de geração de colunas e da heurística em instâncias encontradas na literatura, avaliando o desempenho dos mesmos.

O presente trabalho está estruturado em quatro seções. Primeiro a literatura acerca do tema será discutida. Logo após, o método proposto para resolver este problema será mostrado assim como a implementação computacional e os resultados encontrados. 


\section{REVISÃO BIBLIOGRÁFICA}

O problema de programação e sequenciamento de atividades em múltiplas máquinas pode ser analisado a partir do ponto de vista da pesquisa operacional. Essa linha de estudo busca modelar matematicamente problemas reais, afim de encontrar um valor ótimo para uma dada função de desempenho considerando as restrições deles. O problema de programação e sequenciamento de atividades lida com a construção de um programa de produção cujo objetivo é garantir o processamento de todas as atividades nas máquinas disponíveis considerando as restrições de recursos. Tais sistemas de máquinas podem estar configurados em série ou em paralelo (CHENG; SIN, 1990). Aqui, será abordada a configuração de máquinas em paralelo onde cada atividade pode ser processada em qualquer uma das máquinas elegíveis para ela e, uma vez terminado o processo, a máquina estará livre para processar outra atividade. De maneira genérica, seja dado um conjunto $N$ de atividades, $j_{1}, j_{2}, j_{3} \ldots j_{n}$, que precisam ser processados em um conjunto $M$ de máquinas, $M_{1}, M_{2}, M_{3} \ldots M_{m}$, em um tempo de processamento positivo $p_{j m}$, procura-se determinar a alocação e sequência das atividades nas máquinas de maneira a minimizar um critério de desempenho, por exemplo o atraso total, respeitando tempos de liberação de máquinas e atividades. Cada máquina pode processar somente uma atividade por vez e cada atividade pode ser processada somente por uma máquina.

São variados os exemplos de aplicações de problemas de sequenciamento de máquinas em paralelo. Podem ser citadas aplicações em ciências da computação, onde alguns microcomputadores possuem vários processadores em paralelo que ficam a cargo das operações dos programas. No ramo agrícola é comum haver vários maquinários que devem ser alocados para realizarem a colheita em diversos locais em um tempo razoável. Como estes, vários outros exemplos de aplicações podem ser citados nas mais diversas áreas do conhecimento. Assim, se justifica o crescente interesse na pesquisa sobre programação e sequenciamento em máquinas em paralelo. Uma média de mais de 40 artigos relacionados ao tema são adicionados anualmente à literatura (ALLAHVERDI et al., 2008).

Neste contexto, Cheng e Sin (1990) desenvolveram uma revisão do estado da arte 
da teoria de máquinas em paralelo com os principais resultados de pesquisa do assunto. Os autores estruturam seu trabalho em medidas de desempenho e métodos de resolução. Esta primeira classificação tange a função objetivo e contempla categorias como instante de término e datas de entrega. Como métodos de resolução, Cheng e Sin (1990) abordam algoritmos otimizantes e de aproximação.

Potts e Kovalyov (2000) desenvolveram uma revisão a respeito do sequenciamento atrelado ao tamanho de lote, passando pela configuração de máquinas em paralelo e apresentando algumas formulações encontradas na literatura.A análise dos autores sugere que em muitos casos, o problema de sequenciamento e programação pode ser tradado separadamente do problema de dimensionamento de lote.

Além deste trabalho, considerações sobre tamanho de lote foram feitas por Allahverdi, Gupta e Aldowaisan (1999), que se aprofundaram nos resultados de pesquisa de programação e sequenciamento de múltiplas máquinas envolvendo tempos de setup dependentes e independentes de sequência, discorrendo sobre a literatura em torno de máquinas em paralelo. Os autores identificaram uma carência de pesquisas acadêmicas envolvendo critérios de performance relacionados a data de entrega. Assim, segundo Allahverdi, Gupta e Aldowaisan (1999), existe uma lacuna na literatura de pesquisa operacional referente a problemas de minimização de atraso total, atraso total ponderado e numero de atividades atrasadas, por exemplo.

Logo após, em 2008, o autor publicou uma revisão sobre o mesmo tema para cobrir a literatura que surgiu após a publicação da primeira revisão. Neste último trabalho, o autor identificou e comparou métodos desenvolvidos de forma independente, classificando-os por tipo de setup, existência ou ausência de lotes, e ambiente de máquinas. Os autores identificaram que algumas configurações de problemas, como problemas de múltiplas máquinas em paralelo, receberam menos atenção da academia e apontaram como possíveis causa desta lacuna a complexidade do problema. As próximas seções deste capítulo irão discutir a literatura acerca da tipologia do problema, formulações matemáticas geralmente empregadas, métodos de encontrar lower bounds de soluções, englobando geração de colunas, meta-heurísticas, métodos exatos e outras metodologias.

Lee e Pinedo (1997) propuseram um método heurístico de três fases para o problema de minimização do atraso total ponderado em máquinas paralelas idênticas. Os autores apresentaram estatísticas descritivas das informações das instâncias trabalhadas. Nesta etapa, foram definidos parâmetros que descrevem a severidade dos tempos de setup e a quantidade média de atividades a serem processadas por máquina, por exemplo. Na etapa 
seguinte, uma heurística construtiva foi proposta, utilizando os parâmetros calculados na etapa anterior. O resultado desta heurística foi utilizada como solução inicial em um algorítimo de Simulated Annealing convencional, na terceira etapa.

Beezão et al. (2017) trabalhou com a minimização do makespan em um ambiente de máquinas idênticas em paralelo agregando restrições de ferramentas, propondo duas modelagens matemáticas e uma meta-heurística. A meta-heurística, denominada ALNS e baseada no algoritmo Simulated Annealing, consiste em a aplicação de dois operadores, um de destruição da solução e um de reconstrução da mesma, escolhidos através de um sorteio enviesado. O viés de cada operador é atualizado a cada iteração da meta-heurística de acordo com a evolução da solução.

Feng e Lau (2008) propõem um método heurístico para minimizar a soma do desvio ponderado, ou seja, a soma do atraso e do adiantamento em um cenário de máquinas idênticas em paralelo. Azizoglu e Kirca (1999) analisa o problema de minimização do Lead Time ponderado, discutindo as propriedades de uma solução ótima para os problemas de máquinas paralelas idênticas ou uniformes, propondo um lower bound e aplicando algoritmos de Branch and Bound ao problema.

Outros autores trabalharam com máquinas uniformes em paralelo, como SivrikayaŞerifoğlu e Ulusoy (1999), que propôs a minimização do atraso e adiantamento ponderado total através de Algoritmo Genético. Zhu e Heady (2000) propõe uma formulação matemática para minimizar o atraso e adiantamento ponderado total de máquinas diferentes, com a consideração de setups dependente de sequências. Li e Yang (2009) apresenta uma revisão bibliográfica sobre problemas de máquinas não idênticas com o objetivo de minimizar o makespan, apresentando formulações matemáticas e relaxações, assim como técnicas de otimização encontradas na literatura.

O tempo de setup dependente da sequência tem ganhado atenção na literatura por trazer ao problema uma maior aderência à realidade. Os principais resultados alcançados são abordados por Cheng e Sin (1990), Allahverdi, Gupta e Aldowaisan (1999), Potts e Kovalyov (2000). Em adição, pode-se citar Weng, Lu e Ren (2001), que abordou o problema real de um ambiente de indústria através de heurísticas e apresentou análises computacionais do resultado encontrado. Afzalirad e Rezaeian (2016), Ruiz e AndrésRomano (2011) abordaram este problema considerando, ainda, recursos extras além das máquinas e propuseram heurísticas e modelos matemáticos para encontrar boas soluções. 


\subsection{Formulação Matemática}

De maneira geral, as formulações matemáticas encontradas na literatura são divididas em modelos baseados em variáveis de designação e modelos baseados em variáveis indexadas no tempo (LI; YANG, 2009). Blazewicz, Dror e Weglarz (1991) nos dá uma revisão de literatura no tema de programação e sequenciamento de máquinas, discutindo sobre problemas de máquinas em paralelo idênticas, uniformes e não-idênticas e apresentando uma formulação baseada em variáveis de designação $x_{i j}^{k}=1$ se a atividade $j$ é processada na máquina $i$ na posição $k$ ). Assim, para o problema $P \| C_{\text {max }}$,Blazewicz, Dror e Weglarz (1991) propõem:

$$
\text { minimize } Y
$$

sujeito $a$ :

$$
\begin{gathered}
\sum_{k=1}^{n} \sum_{i=1}^{m} x_{i j}^{k}=1 \quad(j=1 \ldots n) \\
\sum_{j=1}^{n} x_{i j}^{k} \leq 1 \quad(k=1 \ldots n ; i=1 \ldots m) \\
\sum_{k=1}^{n} \sum_{j=1}^{n} p_{j} x_{i j}^{k} \leq Y \quad(i=1 \ldots m) \\
x_{i j}^{k} \in\{0,1\} \quad(j, k=1 . . n ; i=1 . . m)
\end{gathered}
$$

Onde $p_{j}$ é o tempo de processamento da atividade $j$. A equação (2.2) garante que todas as atividades sejam processadas somente uma vez, e pode ser vista como a restrição de demanda. Por outro lado, a restrição (2.3) garante que a capaciade seja respeitada, ou seja, cada máquina processe no máximo uma atividade por vez. A equação (2.4) define $Y$, ou makespan, e a restrição (2.5) define o domínio das variáveis de decisão.

Como constatam os autores, este problema é NP-hard para $m \geq 2$, que pode ser resolvido em $O(n \log n)$. Ainda são apresentadas generalizações deste modelo para máquinas uniformes, diferentes e para outras funções objetivo.

Ruiz e Andrés-Romano (2011) apresentam uma modelagem por variável de precedência que considera a utilização de recursos extras, e minimiza uma função multi- 
objetivo construída pela soma do tempo de término total e a utilização de recursos, ponderados por dois fatores $\alpha$ e $\beta$. Para isto, Ruiz e Andrés-Romano utilizam a variável $x_{i j k}=1$ se a atividade $i$ precede imediatamente a atividade $j$ na máquina $k, 0$ caso o contrário. Os autores também definem $C_{i k}$ e $R_{i j k}$ para o instante de término da atividade $i$ na máquina $k$ e para a utilização de recursos para setup entre as atividades $i$ e $j$ na máquina $k$.

Vredeveld e Hurkens (2002) apresentam algumas modelagens e relaxações para máquinas uniformes ou não idênticas por variáveis indexadas no tempo, encontram soluções reais e, logo após, uma heurística recupera a solução inteira factível.

Zhu e Heady (2000) apresentam um modelo de programação inteira mista para o problema $P / Q / R\left|S T_{s d}\right| \sum\left(E_{i} e_{i}+T_{i} t_{i}\right)$. Primeiro, os autores apresentam o modelo e, então, propõem uma série de métodos para torná-lo mais eficiente envolvendo simetrias e relaxações. Para o modelo original, os autores utilizam a seguinte notação:

Tabela 1: Parâmetros do Modelo de Zhu e Heady (2000)

\begin{tabular}{l|l}
\hline Notação & Significado \\
\hline$B$ & Um número grande; \\
$d_{i}$ & Data de entrega da atividade $i ;$ \\
$e_{i}$ & Custo de adiantamento por unidade de tempo da atividade $i ;$ \\
$p_{i m}$ & Tempo de processamento da atividade $i$ na máquina $m ;$ \\
$M$ & Número de máquias disponíveis; \\
$N$ & Número de atividades a serem programadas; \\
$s_{i j}$ & Tempo de setup quando a atividade $i$ precede imediatamente a atividade $j ;$ \\
$s_{0 i}$ & Tempo de setup da atividade $i$ quando ela é a primeira a ser processada; \\
$t_{i}$ & Custo de atraso por unidade de tempo da atividade $i ;$ \\
\hline
\end{tabular}

Tabela 2: Variáveis do Modelo de Zhu e Heady (2000)

\begin{tabular}{l|l}
\hline Notação & Significado \\
\hline$E_{i}$ & Período de adiantamento da atividade $i ;$ \\
$T_{i}$ & Tempo de atraso da atividade $i ;$ \\
$X_{i}$ & Instante de término da atividade $i ;$ \\
$Y_{i j m}$ & 1 se a atividade $i$ precede a atividade $j$ na máquina $m, 0$ caso contrário; \\
$Z_{i m}$ & 1 se a atividade $i$ é feita na máquina $m, 0$ caso contrário; \\
\hline
\end{tabular}

Desta forma, o modelo de programação inteira mista é proposto:

$$
\begin{gathered}
\min \sum_{i=1}^{N}\left(e_{i} E_{i}+t_{i} T_{i}\right) \\
X_{i}-T_{i}+E_{i}=d_{i} \quad(i=1, \ldots, N)
\end{gathered}
$$




$$
\begin{gathered}
\sum_{m=1}^{M} Z_{i m}=1 \quad(i=1, \ldots, N) \\
\sum_{j=1}^{N} Y_{i j m} \leq Z_{i m} \quad(j \neq i, i=0 \ldots N, m=1, \ldots, M) \\
\sum_{j=0}^{N} Y_{i j m}=Z_{j m} \quad(j \neq i, i=1, \ldots, N, m=1, \ldots, M)
\end{gathered}
$$

$$
X_{i}-X_{j}-B Y i j m \geq p_{i m}+s_{i j}-B \quad(j \neq i, i=1, \ldots, N ; j=0, \ldots, N ; m=1, \ldots, M)
$$

Todas as variáveis de decisão são não negativas e $Y_{i j m}$ e $Z_{i m} \in\{0,1\}$ A restrição (2.7) define o atraso e o adiantamento de cada atividade, as equações (2.8),(2.9) e (2.10) garantem que cada atividade seja processada em apenas uma máquina e seja precedida e sucedida por apenas uma outra atividade. A equação (2.11) garante a consistência dos tempos de processamente e setup. Zhu e Heady (2000) propõem uma melhoria ao modelo ao substituirem as restrições (2.9) e (2.10) por:

$$
\begin{gathered}
X_{j}-X_{i}-B Y i j-B Z_{i m}-B Z_{j m} \geq p_{j m}+s_{i j}-3 B \\
(j \neq i, i=1, \ldots, N ; j=i+1, \ldots, N ; m=1, \ldots, M) \\
X_{i}-X_{j}+B Y i j-B Z_{i m}-B Z_{j m} \geq p_{j m}+s_{i j}-2 B \\
(j \neq i, i=0, \ldots, N ; j=i+1, \ldots, N ; m=1, \ldots, M)
\end{gathered}
$$

Com as equações (2.12) e (2.13), $Y_{i j m}$ pode ser substituído por $Y_{i j}$, reduzindo o número de variáveis de decisão. Os autores, ainda, constatam que há ganho em forçar que todas as máquinas sejam utilizadas, inserindo a restrição (2.14) a seguir.

$$
\sum_{i=1}^{N} Z_{i m} \geq 1 \quad(m=1, \ldots, M)
$$

\subsection{Lower Bounds}

Devido à natureza complexa do problema discutido neste trabalho, poucos artigos se direcionam a algoritmos exatos e lower bounds. Apesar disso, lower bounds são peça-chave 
para avaliação de heurísticas e bom desempenho de alguns algoritmos (LI; YANG, 2009).

Liaw et al. (2003) propõe um método para encontrar lower bound para o problema de máquinas diferentes em paralelo e com o objetivo de minimizar o atraso total ponderado. O trabalho não considerou elegibilidade de máquinas. Os autores trabalham em um modelo matemático com variáveis de designação para o problema, onde o tempo de término de processamento da atividade $i$ quando é processada na máquina $k$ na posição $t\left(C_{i k}^{t}\right)$ é definido em função da variável de decisão. O lower bound proposto se baseia na substituição de $C_{i k}^{t}$ por uma aproximação $C_{i k}^{\prime t}$ que é resultado de um problema de designação atividade-máquina resolvido pelo método Húngaro (KUHN, 2005).

Mensendiek, Gupta e Herrmann (2015) aborda o problema de máquinas idênticas e atividades com datas de entrega fixas, em outras palavras, cada atividade só pode ser entregue em certas datas pré-determinadas. Para minimizar o atraso total, o autor suporta seu método com um lower bound definido como a soma de outros três. Cada um destes três lower bounds é baseado em um possível aspecto do problema:

- Existem atividades que irão, inevitávelmente, atrasar;

- Existem várias atividades com datas de entregas relativamente grandes;

- Relaxando o problema, existe alguma parcela de atividade que será atrasada.

O maior destes lower bound listados compõe o lower bound final que foi considerado nos métodos de solução proposto pelo autor.

Yalaoui e Chu (2002) trabalha com o problema de máquinas idênticas e propõe um lower bound a partir do sequenciamento de todas as atividades em todas as máquinas pela regra do menor tempo de processamento. A partir dessa programação parcial, o menor instante de término de cada atividade é utilizado para construir o lower bound.

\subsection{Métodos de Solução}

Diversas abordagens são adotadas na literatura para resolver problemas de sequenciamento e programação de máquinas em paralelo. Nesta seção, serão revisados os algoritmos exatos, meta-heurísticas e outros métodos. Esta classificação foi proposta por Li e Yang (2009) em sua revisão de literatura, e engloba os métodos mais comuns para instâncias de diferentes ordens de grandezas e problemas com peculiaridades que proporcionam maior ou menor complexidade no processo de solução. 


\subsubsection{Meta-Heurísticas}

Meta-heurísticas são métodos de solução que utilizam tecnologias de busca local para encontrar boas soluções para problemas complexos (LI; YANG, 2009), requerendo menor aprofundamento nas propriedades e regras de dominância do problema. Grande parte da literatura aborda este tema através de meta-heurísticas para encontrar soluções boas de instâncias maiores, sem abrir mão de um tempo computacional adequado. Rambod e Rezaeian (2014) propõem três meta-heurísticas para a minimização do horizonte de processamento considerando retrabalho, elegibilidade de máquinas e setup dependente de sequência e de máquina. O autor apresenta um Algoritmo Genético e duas versões do algoritmo Colônia de Abelhas para endereçar este problema. Afzalirad e Rezaeian (2016) considerou o problema de máquinas diferentes, com precedência, elegibilidade de máquina, setup dependente da sequência e restrição de recursos extra. Utilizando Algoritmo Genético, aliado ao método Taguchi para calibração dos parâmetros, encontrou soluções próximas do ótimo.

Bilyk, Mönch e Almeder (2014) propõem duas meta-heurísticas para o problema de máquinas idênticas com restrições de precedência, com o objetivo de minimizar o atraso total ponderado. O autor trabalha com algoritmos de VNS (Variable Neighborhood Search) e GRASP (Greedy Randomized Adaptative Search Procedure). Para o algoritmo VNS, a busca na vizinhança foi dividida em duas etapas que consistem em operações de busca com atividades,na primeira etapa, e operações de busca com lotes. Para o algoritmo GRASP, cinco heurísticas construtivas foram propostas. Os autores identificaram que o algoritmo VNS encontra soluções de boa qualidade rapidamente, sendo sutilmente melhor do que o algoritmo GRASP. Porém, este ultimo pode ser facilmente paralelizado, ganhando vantagem para a resolução de um número variado de instâncias.

Schaller (2014) apresenta um comparativo entre várias meta-heurísticas para o problema de máquinas idênticas com setup de famílias. O autor discorre sobre a Busca Tabu e Algoritmo Genético, totalizando cinco algoritmos diferentes para este problema. O autor realizou testes computacionais e demonstrou estatisticamente que o Algoritmo Genético é mais eficiente.

Chaudhry e Drake (2009) trabalharam com a minimização do atraso total em máquinas idênticas utilizando Algoritmo Genético, utilizando ambiente de planilha e apresentou diversas análises sobre o efeito dos parâmetros na eficiência do algoritmo. 


\subsubsection{Métodos Exatos}

Devido à complexidade de problemas $P / Q / R|\ldots| \sum w_{j} T_{j}$, algoritmos exatos ficam restritos pela capacidade computacional, sendo utilizado em instâncias pequenas em grande parte da literatura. Liaw et al. (2003) apresentou um algoritmo Branch and Bound para resolver o problema de sequenciamento de atividades independentes em máquinas diferentes, discutindo propriedades e considerando regras de dominância. O autor incorpora um upper bound proveniente de uma heurística proposta e um lower bound proveniente de um problema de designação. Com este método, Liaw et al. (2003). promoveu uma grande redução nos nós explorados no Branch and Bound. Em 2016, o autor apresentou um algoritmo de 'Branch and Bound para o problema de máquinas idênticas e propôs heurísticas para instâncias maiores. Em ambos os trabalhos, o autor buscou minimizar o atraso total. Logo em seguida, Ozturk, Begen e Zaric (2017) também trabalharam com a minimização do horizonte de processamento em máquinas idênticas, apresentando regras de dominância que foram introduzidas no algoritmo de Branch and Bound desenvolvido. Hassan et al. (2016) discutiu sobre a estrutura do problema de máquinas não idênticas com restrições de precedência e propôs algoritmos de Branch and Cut para encontrar soluções em tempos de processamento razoáveis.

\subsubsection{Geração de Colunas}

A geração de colunas tem sido aplicada com sucesso na literatura em problemas com um número muito grande de variáveis. Considerando-se que uma variável de decisão é associada a uma coluna do modelo e, consequentemente, a um custo, o método consiste em selecionar um subconjunto de colunas em oposição à listar todas as possíveis variáveis (WILHELM, 2001).

Segundo Wilhelm (2001), existem três tipos de geração de colunas. Todos eles envolvem um MP, ou "Master Problem", que deve ser otimizado após a adição das colunas selecionadas. O autor menciona que o tipo I envolve modelos auxiliares que identificarão colunas atrativas para o problema sem ter interação com o MP. O tipo II geralmente envolve técnicas de precificação que interagem com o MP para identificar as colunas que melhorarão a função objetivo. Por sua vez, o tipo III envolve a decomposição do problema e, assim, a criação de um ou mais subproblemas que resultarão na seleção das colunas promissoras. Este ultimo tipo de Geração de Colunas utiliza a decomposição de Dantzig-Wolfe (DANTZIG; WOLFE, 1960) e será o foco deste trabalho. 
Para o problema tratado neste trabalho, a decomposição de Dantzig-Wolfe associada à geração de colunas se mostra promissora pois converte um problema com muitas restrições a um problema com muitas colunas. Segundo Akker, Hurkens e Savelsbergh (2000), a quantidade de colunas é, no entanto, um desafio superado pela geração de colunas. Os mesmos autores aplicaram este método para encontrar lower bounds relevantes para o problema de minimização do atraso em máquina única. A decomposição de Dantzig-Wolfe aplicada por Akker, Hurkens e Savelsbergh consistiu na criação de um subproblema que considerou somente a restrição de capacidade de máquina, enquanto o problema mestre considerou as restrições de demanda. O subproblema foi, então, reduzido à um problema de caminho mínimo que resultava na coluna mais promissora para o problema mestre. Assim, esta era adicionada ao modelo principal e uma iteração era completada.

Desrosiers e Lübbecke (2005) discutiram os usos mais comuns da geração de colunas e apresentaram exemplos dos principais conceitos, discorrendo sobre a decomposição de Dantzig-Wolfe e outras técnicas empregadas na literatura.

Barnhart et al. (1998) discutiu sobre as formulações de programação inteira e as aplicações da geração de colunas. Além disso, o autor discorreu sobre as questões computacionais da implementação deste método.

Rahmani et al. (2016) aplicou com sucesso o método para o problema de coleta e entrega, associando o subproblema a uma heurística de precificação que gerou as rotas viáveis. O tempo de viagem e espera eram apropriadamente penalizados na função objetivo. Este método apresentou bons resultados em tempos computacionais adequados.

Castaño e Sevaux (2016) discutiram os problemas de adotar a geração de colunas para endereçar programação matemática e propuseram a aplicação da geração de colunas associada a meta-heurísticas. Os autores discutem as vantagens do método, aplicações e obtém bons resultados através de meta-heurísticas como GRASP e VNS.

\subsubsection{Outros Métodos}

Não é incomum encontrar na literatura outras abordagens para endereçar este problema, como heurísticas construtivas, algoritmos de aproximação e decomposições. Aqui, discute-se alguns trabalhos que utilizaram estes métodos.

Weng, Lu e Ren (2001) propõem sete procedimentos construtivos para o sequenciamento em máquinas diferentes, considerando o setup e com o objetivo de minimizar o tempo total de término ponderado. O autor encontra resultados de instâncias até 120 ati- 
vidades e 12 máquinas em tempos rápidos de processamentos. Além disso, após realizar testes computacionais, os autores discutem os resultados das heurísticas propostas.

Fanjul-Peyro, Perea e Ruiz (2017) apresentam métodos híbridos para o problema de máquinas diferentes com recursos adicionais. O autor propõe três Matheuristics, ou seja, métodos híbridos de heurísticas e otimização matemática, que decompõe o problema em problemas menores, para reduzir a complexidade e o tempo computacional. 


\section{$3 \quad$ MÉTODO}

Como mencionado na seção 1, o sequenciamento de atividades em múltiplas máquinas paralelas diferentes consiste em um problema combinatorial NP-Hard, em outras palavras, não pode ser resolvido em tempo polinomial (KARP, 1972). Considerando isto, a metodologia utilizada neste trabalho para endereçar o problema envolve programação inteira mista e definição de lower bounds através de geração de colunas.

Devido à natureza do problema, viu-se a necessidade de propor lower bounds de qualidade, a fim de suportar a medida de performance em instâncias maiores, cujas soluções ótimas serão dificilmente encontradas. Para estas instâncias, uma heurística construtiva será proposta nas seções posteriores. Abaixo, na figura 2, o fluxograma do método proposto é apresentado.

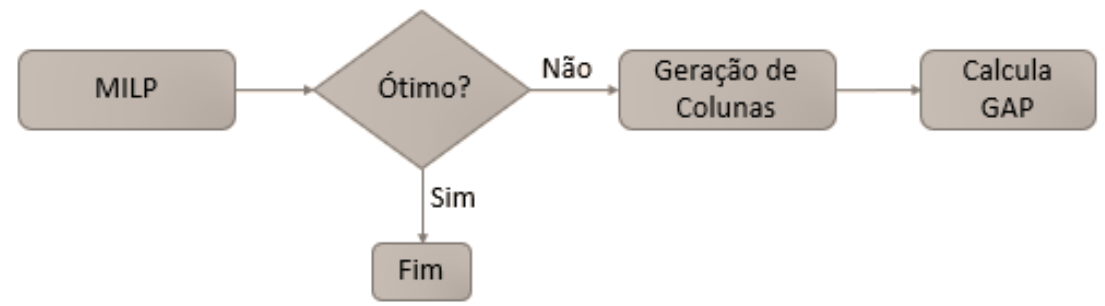

Figura 2: Fluxograma do método proposto.

A seguir, o modelo MILP será discutido e, logo após, o processo de definição do lower bound através de geração de colunas.

\subsection{Modelo de Programação Inteira Mista}

O modelo de programação linear inteira mista (MILP) proposto neste trabalho é inspirado no problema de corte e empacotamento, em que as peças bidimensionais precisam ser "encaixadas" em uma área menor possível. Essas peças precisam ser empacotadas vertical e horizontalmente de maneira que não haja sobreposição. No caso de sequenciamento de 
máquinas em paralelo, as atividades podem ser vistas como peças retangulares de altura unitária e comprimento igual ao tempo de processamento.

Neste contexto, para o problema de sequenciar $j$ atividades em $m$ máquinas diferentes, seja $j=\{1 \ldots J\}$ e $m=\{1 \ldots M\}$, o modelo matemático apresentado neste trabalho considera os dados de entrada mostrados na Tabela 3 e as variáveis de decisão mostradas na Tabela 6.

Tabela 3: Dados de entrada do modelo proposto

\begin{tabular}{l|l}
\hline Notação & Significado \\
\hline$r_{m}$ & Data de liberação da máquina $m$ \\
$r_{j}$ & Data de liberação da atividade $j$ \\
$D_{j}$ & Data de entrega da atividade $j$ \\
$t_{j}$ & Custo de atraso da atividade $j$ \\
$P_{j m}$ & Tempo de processamento da atividade $j$ na máquina $m$ \\
\hline
\end{tabular}

Tabela 4: Variáveis de Decisão do modelo proposto

\begin{tabular}{l|l}
\hline Variável & Significado \\
\hline$Z_{j m}$ & 1 se a atividade $j$ for alocada na máquina $m, 0$ caso contrário \\
$C_{j}$ & Instante de término da atividade $j$ \\
$Z 1_{i j}$ & 1 se a atividade $i$ for sequenciada antes da atividade $j, 0$ caso contrário \\
$Z 2_{i j}$, & 1 se a atividade $j$ for sequenciada antes da atividade $i, 0$ caso contrário \\
\hline
\end{tabular}

Para a execução do modelo, alguns cálculos são desenvolvidos previamente, como mostrado a seguir.

$$
\begin{gathered}
P_{j}^{M A X}=\max \left\{P_{j m} \quad \forall m=1 \ldots M\right\} \quad \forall j=1 \ldots J \\
M^{M A X}=\max \left\{\min \left\{r_{j}\right\}, \max \left\{r_{m}\right\}\right\}+\frac{\sum_{j=1}^{J} P_{j}^{M A X}}{m * e} \\
C_{j m}^{M I N}=\max \left\{r_{j}, r_{m}\right\}+P_{j m} \quad \forall j=1 \ldots J, m=1 \ldots M
\end{gathered}
$$

A equação 3.1 define o tempo de processamento da máquina mais lenta para a atividade $j$. A equação 3.2 define o maior valor que o horizonte de processamento dessa instância pode apresentar sem tempo ocioso. Por fim, a equação 3.3 define o menor valor 
que o instante de término de uma atividade $j$ pode apresentar se for alocada na máquina $m$. Esses dados calculados dão suporte ao modelo MILP ao definirem melhor o domínio das variáveis de decisão, e serão referenciados como dados secundários neste trabalho.

Considerando os dados de entrada e secundários, o modelo de programação inteira mista é proposto da seguinte forma:

$$
\text { minimize } \sum_{j=1}^{J}\left(t_{j} T_{j}\right)
$$

sujeito a:

$$
\begin{aligned}
& \sum_{m=1}^{M} Z_{j m}=1 \quad \forall j=1 \ldots J \\
& P_{j}=\sum_{m=1}^{M}\left(Z_{j m} * P_{j m}\right) \quad \forall j=1 \ldots J \\
& C_{j} \geq \sum_{m=1}^{M}\left(Z_{j m} * C_{j m}^{M I N}\right) \quad \forall j=1 \ldots J \\
& C_{j} \geq C_{i}+P_{j}-\left(1-Z 1_{i j}\right) * M^{M A X} \quad \forall i, j=1 \ldots J: j>i, m=1 \ldots M \\
& C_{i} \geq C_{j}+P_{i}-\left(1-Z 2_{i j}\right) * M^{M A X} \quad \forall i, j=1 \ldots J: j>i, m=1 \ldots M \\
& Z 1_{i j}+Z 2 i j \geq Z_{i m}+Z_{j m}-1 \quad \forall i, j=1 \ldots J: j>i, m=1 \ldots M \\
& T_{j} \geq C_{j}-D_{j} \quad \forall j=1 \ldots J \\
& T_{j} \geq 0 \quad \forall j=1 \ldots J \\
& Z 1_{i j}, Z 2 i j, Z_{j m} \in\{0,1\}, \quad C_{j} \in R
\end{aligned}
$$


Como mencionado anteriormente, o problema é composto por um conjunto de atividades que devem ser processadas somente uma vez, sem interrupções, por uma das máquinas elegíveis para tal atividade. Desta forma, a restrição 3.5 é responsável por atribuir cada atividade $j$ a uma, e apenas uma, máquina $m$. Esta restrição garante tal condição atribuindo o valor 1 à soma de todas as variáveis $Z_{j m}$, ou seja, apenas um par $(j, m)$ poderá corresponder à $Z_{j m}=1$.

De acordo com a definição do problema, cada máquina disponível processa cada atividade em um tempo independente. Não existe qualquer relação entre o tempo de processamento de qualquer atividade $j$ em qualquer máquina $m$ ou qualquer outro parâmetro da instância. Assim, é preciso garantir que a máquina escolhida para processar determinada atividade reserve o tempo necessário para processá-la. A restrição 3.6 define o tempo de processamento $P_{j}$ da atividade $j$ considerando a máquina na qual esta atividade foi alocada através da soma dos produtos $Z_{j m} * P_{j m}$. Como mencionado anteriormente, esta soma resultará no tempo de processamento correto para a máquina na qual a atividade será processada.

Em posse das informações referentes a qualquer instância, como os tempos de processamentos de cada máquina para cada atividade e os tempos de liberação das máquinas e atividades, é possível encontrar o instante de término de processamento mínimo possível para cada atividade em cada máquina. Para isto, a restrição 3.7 define que o instante de término da atividade $j$, nomeado de $C_{j}$, será maior do que $C_{j m}^{M I N}$, como definido na equação 3.3, se esta atividade for atribuída para a máquina $m$.

A restrição 3.10 garante que não existam atividades sendo processadas ao mesmo tempo na mesma máquina, embora isso possa acontecer em máquinas diferentes. Como mencionado, a variável binária $Z 1_{i j}$ vale 1 caso a atividade $i$ seja sequenciada antes da atividade $j$, enquanto a variável $Z 2_{i j}$ vale 1 caso a situação oposta seja verdadeira. É importante destacar que as equações disjuntivas se aplicam apenas ao conjunto $(i, j)$ em que $i<j$. Como esperado, caso algum par de atividades $(i, j)$ estejam alocados na mesma máquina, é indispensável que $Z 1_{i j}$ ou $Z 2_{i j}$ valha 1 , garantindo que as atividades $i$ e $j$ sejam programadas sequencialmente. Para isto, a equação 3.10 utiliza o termo $Z_{i m}+Z_{j m}-1$, que vale 1 caso $Z_{i m}$ e $Z_{j m}$ sejam 1 , em outras palavras, as atividades $i$ e $j$ foram alocadas na mesma máquina $m$. Nesta situação, a equação garante que a soma $Z 1_{i j}+Z 2_{i j}$ seja maior ou igual a 1 , porém, devido à natureza de minimização do modelo, o resultado desta soma nunca será maior do que 1 pois isto significaria obrigatoriamente uma solução de pior qualidade. 
Em outras palavras, a restrição 3.10 garante que não haja sobreposição de atividades informando a alocação das atividades nas máquinas e a sequência em que estas serão processadas em cada máquina. Com tal informação, as restrições 3.8 e 3.9 utilizam os tempos de processamento da instância e o termo $M$, definido na equação 3.2, para calcular os instantes de término das atividades garantindo, assim, aderência à realidade. É sabido, pela definição de $M$, que o horizonte de processamento da instância nunca será maior do que este valor. Portanto, caso a atividade $j$ seja processada antes da atividade $i$, o termo $\left(1-Z 1_{i j}\right) * M$ será igual a $M$, o que faz da equação 3.8 redundante. Por outro lado, a equação 3.9 se reduziria a $C_{i} \geq C_{j}+P_{i}$, sendo adequada para definir o instante de término da atividade $i$ como o instante de término da atividade anterior, $j$, somado do tempo de processamento correto. A situação inversa ocorreria caso a atividade $i$ for sequenciada antes da atividade $j$. Neste caso a equação 3.9 se tornaria menos restritiva enquanto a equação 3.8 definiria o instante de término adequado para a atividade $i$.

Uma vez conhecidos os instantes de término de processamento de cada atividade, as restrições 3.11 e 3.12 utilizam a data esperada de entrega da atividade, $D_{j}$, informado nos dados da instância, para definir o atraso daquela atividade seguindo o seguinte cálculo:

$$
T_{j}=\max \left(C_{j}-D_{j}, 0\right)
$$

Assim, a função objetivo define o atraso total ponderado da instância através da soma dos produtos $T_{j} * t_{j}$.

A equação 3.13 define o domínio das variáveis.

É importante notar que as restrições disjuntivas 3.8 e 3.9 consideram apenas $j>i$, uma vez que é redundante contemplar todo o conjunto de combinações de $i$ e $j$.

O modelo aqui apresentado possuem $2 * J(J-1)+J * M$ variáveis binárias e $J$ variáveis contínuas.

\subsection{Lower Bound}

Outro objetivo deste trabalho é propor um método de encontrar Lower Bounds para o problema tratado. Associado à decomposição de Dantzig-Wolfe (DANTZIG; WOLFE, 1960), o método de geração de colunas foi aplicado a um modelo matemático de sequenciamento de máquinas em paralelo com elegibilidade de máquinas e instante de liberação de atividades e máquinas. 
Neste contexto, um modelo diferente do apresentado na seção 3.1 é apresentado. Baseado no trabalho de Akker, Hurkens e Savelsbergh (2000), que trata do problema para máquina única, o modelo indexado no tempo é escolhido por apresentar um lower bound forte quando submetido à relaxação de integralidade (DYER; WOLSEY, 1990). Além disso, Akker, Hurkens e Savelsbergh (2000) também mencionam que a maior fraqueza dos modelos indexados no tempo, seu tamanho, é contornado pelo método de geração de colunas associado à decomposição de Dantzig-Wolfe. Em outras palavras, a decomposição resulta em um modelo com muito menos restrições, porém com um número muito maior de variáveis, o que não caracteriza um problema para o método de geração de colunas.

\subsubsection{Reformulação e Decomposição de Dantzig-Wolfe}

Esta técnica de decomposição, apresentada por Dantzig e Wolfe (1960), envolve a subpartição de um problema linear permitindo a solução deste problema através da resolução iterativa de diversos sub-problemas. Ela tem sido aplicada na literatura com sucesso para resolver problemas de grande porte, uma vez que é eficiente na redução da complexidade da formulação matemática (AKKER; HURKENS; SAVELSBERGH, 2000).

Neste contexto, apresenta-se o modelo matemático abaixo para o problema deste trabalho. Utiliza-se a mesma notação para dados de entrada mostrada na seção anterior. Sendo $j=\{1 \ldots J\}, m=\{1 \ldots M\}$ e $t=\{1 \ldots T\}$ os conjuntos de atividades, máquinas e instantes de tempo, respectivamente, tem-se:

Tabela 5: Variáveis de Decisão

\begin{tabular}{l|l}
\hline Variável & Significado \\
\hline$x_{j t}^{m}$ & 1 se a atividade $j$ for alocada no instante $t$ na máquina $m, 0$ caso contrário \\
\hline
\end{tabular}

Tabela 6: Parâmetros

\begin{tabular}{l|l}
\hline Variável & Significado \\
\hline$c_{j t}^{m}$ & custo de atraso se a atividade $j$ for alocada no instante $t$ na máquina $m$ \\
$T_{j m}^{m i n}$ & Instante de início mais cedo possível para a atividade $j$ na máquina $m$ \\
$P_{j m}$ & Tempo de processamento da atividade $j$ na máquina $m$ \\
$T$ & Horizonte de processamento máximo da instância \\
$r_{j}$ & Instante de liberação da atividade $j$ \\
$r_{m}$ & Instante de liberação da máquina $m$ \\
\hline
\end{tabular}




$$
\min \sum_{m=1}^{M} \sum_{j=1}^{J} \sum_{t=1}^{T-P_{j m}+1} c_{j t}^{m} x_{j t}^{m}
$$

Sujeito a:

$$
\begin{gathered}
\sum_{m=1}^{M} \sum_{t=T_{j m}^{\text {min }}}^{T-P_{j m}+1} x_{j t}^{m}=1 \quad \forall j=1 \ldots J \\
\sum_{j=1}^{J} \sum_{s=t-P_{j m}+1}^{t} x_{j s}^{m} \leq 1 \quad \forall t=1 \ldots T, \quad \forall m=1 \ldots M \\
T_{j m}^{\text {min }}=\max \left(r_{m}, r_{j}\right)+1 \quad \forall j=1 \ldots J, \quad \forall m=1 \ldots M
\end{gathered}
$$

Este é um modelo de programação inteira baseado em tempo discreto que foi adaptado do trabalho de Akker, Hurkens e Savelsbergh (2000). Nele, a variável de decisão $x_{j t}^{m}$ é uma binária igual a 1 caso a tarefa $j$ inicie seu processamento no instante $t$ na máquina $m$, ou igual a 0 caso contrario, e $c_{j t}^{m}$ é o custo de atraso resultante caso a tarefa $j$ inicie seu processamento no instante $t$ na máquina $m$, calculado por $\max \left(0,\left(t+P_{j m}-D_{j}\right) * t_{j}\right)$.

Deste modo, a restrição 3.16 garante que toda atividade seja processada uma vez, já que esta restrição só é respeitada se, para todo $j$, apenas uma variável $x_{j t}^{m}$ pode valer 1 . A equação 3.18 define um parâmetro que limita o instante de inicio de processamento de uma atividade em uma máquina ao valor mínimo possível. Perceba, portanto, que apenas conjuntos $(j, m, t)$ viáveis são contemplados na restrição 3.16, uma vez que o horizonte de processamento da instância é definido por $T$, não existe a possibilidade de iniciar o processamento de uma atividade em qualquer instante $t>T-P_{j m}+1$, ou menor do que $T_{j m}^{\text {min }}$. Adicionalmente, variáveis que representam máquinas não elegíveis para determinada atividade não existem neste modelo.

A restrição 3.17 é responsável por garantir que, em qualquer instante de tempo $t$, no máximo uma atividade seja processada na mesma máquina. Para todo conjunto $(j, m, t)$, existe um intervalo $\left(t-P_{j m}+1, t\right)$ no qual a máquina $m$ estará ocupada caso $x_{j, t-P_{j m}+1}^{m}=1$. A equação 3.17, portanto, restringe o somatório das variáveis $x_{j t}^{m}$ neste intervalo para todo conjunto $(j, m, t)$ a 0 ou 1 . Desta forma, nenhuma outra atividade será alocada a uma máquina enquanto o processamento da atividade já alocada não terminar.

A desvantagem desta formulação indexada no tempo é seu tamanho. O modelo possui $j+T * M+1$ restrições e aproximadamente $j * T * m$ variáveis. Adicionalmente, é 
essencial para o desenvolvimento do método aqui proposto que a discretização do tempo neste modelo seja coerente com o modelo apresentado na seção 3.1. Desta forma, caso os tempos considerados naquele modelo não sejam inteiros, a discretização deverá considerar a menor fração possível. Isto garante que o método de geração de colunas aqui proposto resulte em um limitante inferior coerente com o problema.

Apesar disso, segundo o trabalho de Akker, Hurkens e Savelsbergh (2000), a reformulação prossegue com a redução deste problema scheduling a um problema de alocação de programas de produção. Em outras palavras, considerando o conjunto de todos os programas de produção possíveis da instância, o novo problema consiste em escolher um conjunto de $m$ programas de produção, um para cada máquina, que minimizem o custo de atraso total.

A ideia fundamental da decomposição de Dantzig-Wolfe consiste em definir um conjunto convexo e limitado $k=1 \ldots K$ representado pelos seus valores extremos $\left\{x^{1}, \ldots, x^{K}\right\}$, em que cada vetor $\mathrm{x}$ contido em $K$ pode ser representado por:

$$
x=\sum_{k=1}^{K} \lambda_{k} x^{k}, \quad \text { com } \sum_{k=1}^{K} \lambda_{k}=1, \quad \lambda_{k} \geq 0, \quad(k=1, . ., K)
$$

Em outras palavras, seja $k=1 \ldots K$ o conjunto de todas as soluções possíveis do problema, é possível representar qualquer solução como uma combinação linear de um número finito de outras soluções do problema.

Neste trabalho, uma solução possível para o problema é entendida como um programa de produção. Portanto, para adaptarmos o modelo representado pelas equações 3.15 a 3.18 ao método de Akker, Hurkens e Savelsbergh (2000), temos a introdução da variável $y_{j t}^{k}$. Ela é igual a 1 se a atividade $j$ inicia seu processamento no instante $t$ no programa de produção $k$. Cada programa de produção está associado a somente uma máquina da instância, porém cada máquina pode estar associada a diversos programas de produção.

Assim, o denominado Problema Mestre é definido abaixo:

$$
\min \sum_{k=1}^{K} \sum_{m=1}^{M}\left(\sum_{j=1}^{J} \sum_{t=1}^{T-P_{j m}+1} c_{j t}^{k} y_{j t}^{k}\right) \lambda_{k}^{m}
$$

Sujeito a: 


$$
\begin{gathered}
\sum_{k=1}^{K} \sum_{m=1}^{M}\left(\sum_{t=1}^{T-P_{j m}+1} y_{j t}^{k}\right) \lambda_{k}^{m}=1 \quad \forall j=1 \ldots J \\
\sum_{k=1}^{K} \lambda_{k}^{m} \leq 1 \quad \forall m=1 \ldots M \\
\lambda_{k}^{m} \geq 0 \quad(k=1, \ldots, K)
\end{gathered}
$$

Esta formulação pode ser interpretada como a relaxação linear de um problema de partição de conjuntos, em que deve-se escolher programas de produção do conjunto $\{k=$ $1, \ldots, K\}$ para compor a solução, onde a variável de decisão $\lambda_{k}^{m}$ é real e representa quantas vezes aquele programa de produção foi selecionado para compor a solução final.

A equação 3.20 busca minimizar o custo de atraso dos programas de produção selecionados. Nesta equação, o fator $\sum_{j=1}^{n} \sum_{t=1}^{T-p_{j}+1} c_{j t} y_{j t}^{k}$ representa o custo de atraso do programa $k$ e será referenciado por $C_{k}$ nas próximas seções.

A equação 3.21 representa a restrição que garante a demanda do problema, ou seja, todas as atividades devem ser processadas uma vez. O fator $\sum_{t=1}^{T-p_{j}+1} y_{j t}^{k}$ desta equação representa a quantidade de vezes que a atividade $j$ foi processada no programa de produção $k$, e será referenciado por $A_{j k}$ neste trabalho.

A restrição 3.22 garante que a capacidade de cada máquina seja respeitada, permitindo a seleção de, no máximo, 1 programa de produção por máquina. Por sua vez, a equação 3.23 define o domínio das variáveis.

Portanto, o Problema Mestre que será trabalhado neste texto se dá por:

$$
\min \sum_{k=1}^{K} \sum_{m=1}^{M} C_{k} \lambda_{k}^{m}
$$

Sujeito a:

$$
\begin{gathered}
\sum_{k=1}^{K} \sum_{m=1}^{M} A_{j k} \lambda_{k}^{m}=1 \quad \forall j=1 \ldots J \\
\sum_{k=1}^{K} \lambda_{k}^{m} \leq 1 \quad \forall m=1 \ldots M
\end{gathered}
$$




$$
\lambda_{k}^{m} \geq 0 \quad(k=1, \ldots, K)
$$

Em outras palavras, uma pseudo-solução $k$ é representada por $\lambda_{k}^{m}$, possui um custo de atraso $C_{k}$ e um vetor $A_{k}=\left\{A_{k 1}, A_{k 2}, \ldots A_{k n}\right\}$, onde $A_{k j}$ representa a quantidade de vezes que a tarefa $j$ foi processada na pseudo-solução $k$.

Percebe-se que cada programa de produção $k$ representa uma pseudo-solução que respeita a capacidade de processamento das máquinas, mas não necessariamente atende à demanda da instancia. Por exemplo, uma pseudo-solução pode ser representada por um programa de produção que processa a mesma atividade cinco vezes, e deixa de processar outras atividades. Assim, uma solução do problema real pode ser representada como uma combinação linear de pseudo-soluções.

Esta formulação reduziu o número de restrições de $J+T * M+1$ para $J+m$. Apesar disso, o número de variáveis aumentou significativamente. O número de variáveis é finito, sendo possível listar todos os possíveis programas e produção $k$, representados por $\lambda_{k}^{m}$, e construir o modelo completo. Apesar disso, o poder de processamento computacional requerido para tal torna este modelo matemático inviável. A grande quantidade de variáveis, porém, não configura um problema pois será tratada com o processo de geração de colunas.

\subsubsection{Geração de Colunas}

O procedimento de geração de colunas consiste em selecionar um sub-conjunto de variáveis do modelo de programação linear, ou pseudo-soluções, para serem consideradas na solução do Problema Mestre (AKKER; HURKENS; SAVELSBERGH, 2000). Neste trabalho, o termo coluna se referirá aos vetores de coeficientes que compõem o modelo de programação inteira mostrado nas equações 3.24 a 3.27, e também pode ser interpretado como uma pseudo-solução. Para cada coluna adicionada ao modelo, exite uma variável de decisão associada a ela. Desta forma, de acordo com as equações 3.24 a 3.27, um exemplo de coluna a ser gerada nesta etapa pode ser representado por: 


$$
\left[\begin{array}{c}
C_{k} \\
A_{1 k} \\
A_{2 k} \\
A_{3 k} \\
A_{4 k} \\
A_{5 k} \\
A_{6 k} \\
0 \\
1 \\
0
\end{array}\right]
$$

Neste exemplo, o problema possui 6 atividades e 3 máquinas. Os coeficientes $A_{j k}$ se referem à quantidade de vezes que a atividade $j$ foi processada no programa de produção $k$, e irão compor as equações 3.25. A ordem de processamento não é uma informação armazenada na coluna. Os três últimos números se referem à máquina para qual este programa de produção foi criado, neste exemplo é a máquina 2 . O valor $C_{k}$ representa o custo total de atraso deste programa de produção, e é o coeficiente de $k$ que irá compor a função objetivo. Devido a quantidade de variáveis existentes no modelo apresentado na seção 3.2.1, é inviável listá-las para construir o modelo completo. Desta forma, um problema de otimização, chamado aqui de Sub-Problema, é construído para encontrar as variáveis, ou pseudo-soluções, que possuem o menor custo reduzido. Da teoria de Pesquisa Operacional, o custo reduzido pode ser calculado da seguinte maneira:

$$
c_{k}=\sum_{j=1}^{J} \sum_{t=1}^{C-P_{j m}+1}\left(c_{j t}^{k}-\pi_{j}\right) x_{j t}^{k}-\pi_{m} \quad \forall m=1 \ldots M
$$

Onde $\pi_{j}$ representa as variáveis duais das equações 3.25 e $\pi_{m}$ representa as variáveis duais da equação 3.26. Como é conhecido da teoria de Pesquisa Operacional, se o custo reduzido $c_{k}$ for menor do que 0 , ao inserirmos a variável correspondente no modelo a solução do problema de minimização será melhorada.

Para encontrar o programa de produção $k^{\prime}$ que possui o menor custo reduzido, Akker, Hurkens e Savelsbergh (2000) optaram por construir um problema de caminho mínimo, onde precisa-se encontrar o menor caminho entre o instante 1 e o instante $T$ através dos arcos constituídos pelo processamento das atividades. Em outras palavras, uma rede de $\operatorname{arcos} Q$ é construída por todos os possíveis arcos $Q_{t t^{\prime}}$, onde $t^{\prime}-t=p_{j}$ e o custo do arco é $c_{j t}^{k}-\pi_{j}$. Um exemplo de rede de arcos é mostrado na Figura 3. 


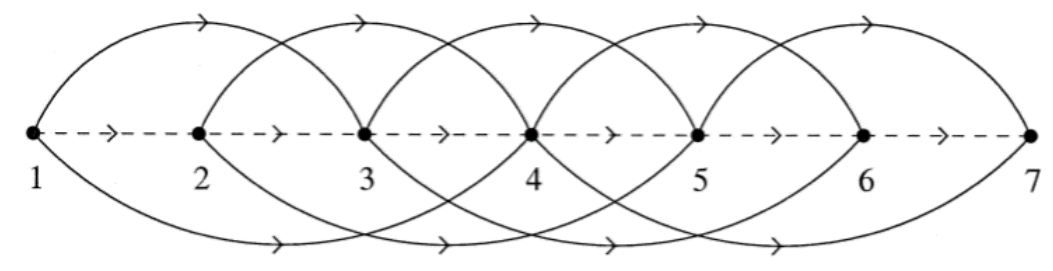

Figura 3: Neste exemplo, observa-se todas as maneiras possíveis de partir do instante 1 e chegar no instante 7 através de duas atividades com tempo de processamento igual a 2 e 3. Existe também a possibilidade de ter tempo ocioso (arcos tracejados).

A instância do exemplo possui duas atividades. Nesta instancia, os tempos de processamento de cada atividade são $p_{1}=2$ e $p_{2}=3$. Para representar uma solução, a variável $x_{j t}$ valerá 1 caso a atividade $j$ seja processada no instante $t$, e valerá 0 caso contrário. Assim, uma pseudo-solução possível é $x_{11}=x_{13}=x_{15}=1$. A coluna referente a esta pseudo-solução é $(3,0,1)^{T}$, o que significa que a atividade 1 foi processada 3 vezes, enquanto a atividade 2 não foi processada. O ultimo elemento deste vetor se refere ao coeficiente da restrição 3.25 .

Trabalhando com redes de arcos neste formado, é possível fazer uso de algoritmos otimizantes de baixo custo computacional. Uma vez que a rede de arcos é direta e acíclica, o problema pode ser resolvido em tempo $O(n T)$ (AKKER; HURKENS; SAVELSBERGH, 2000). Neste trabalho, $m$ redes de arcos foram construídas, uma para cada máquina, e utilizou-se algoritmo de Djikstra (DIJKSTRA et al., 1976) para resolver $m$ problemas de caminho mínimo conforme o algoritmo 1 mostrado abaixo. Todas as pseudo-soluções, ou colunas geradas, que possuem custo reduzido inferior a zero são adicionados no Problema Mestre.

Após a resolução do Problema Mestre apresentado na seção 3.2.1, verifica-se se existe ainda um programa de produção que melhoraria a função objetivo caso fosse incluído no conjunto considerado pelo modelo. Caso exista tal variável, esta é incluída no Problema mestre e uma nova iteração se inicia.

Este ciclo é repetido até que não exista mais um programa de produção, ou resultado do sub-problema, que possua custo reduzido menor do que zero. A Figura 4, abaixo, esquematiza o método.

Neste fluxograma, observa-se um pré-processamento do modelo que consiste na reformulação e decomposição de Dantzig-Wolfe e na geração da solução inicial. Logo após, o problema mestre é inicializado. Assim, o ciclo de seleção e adição da nova coluna no 


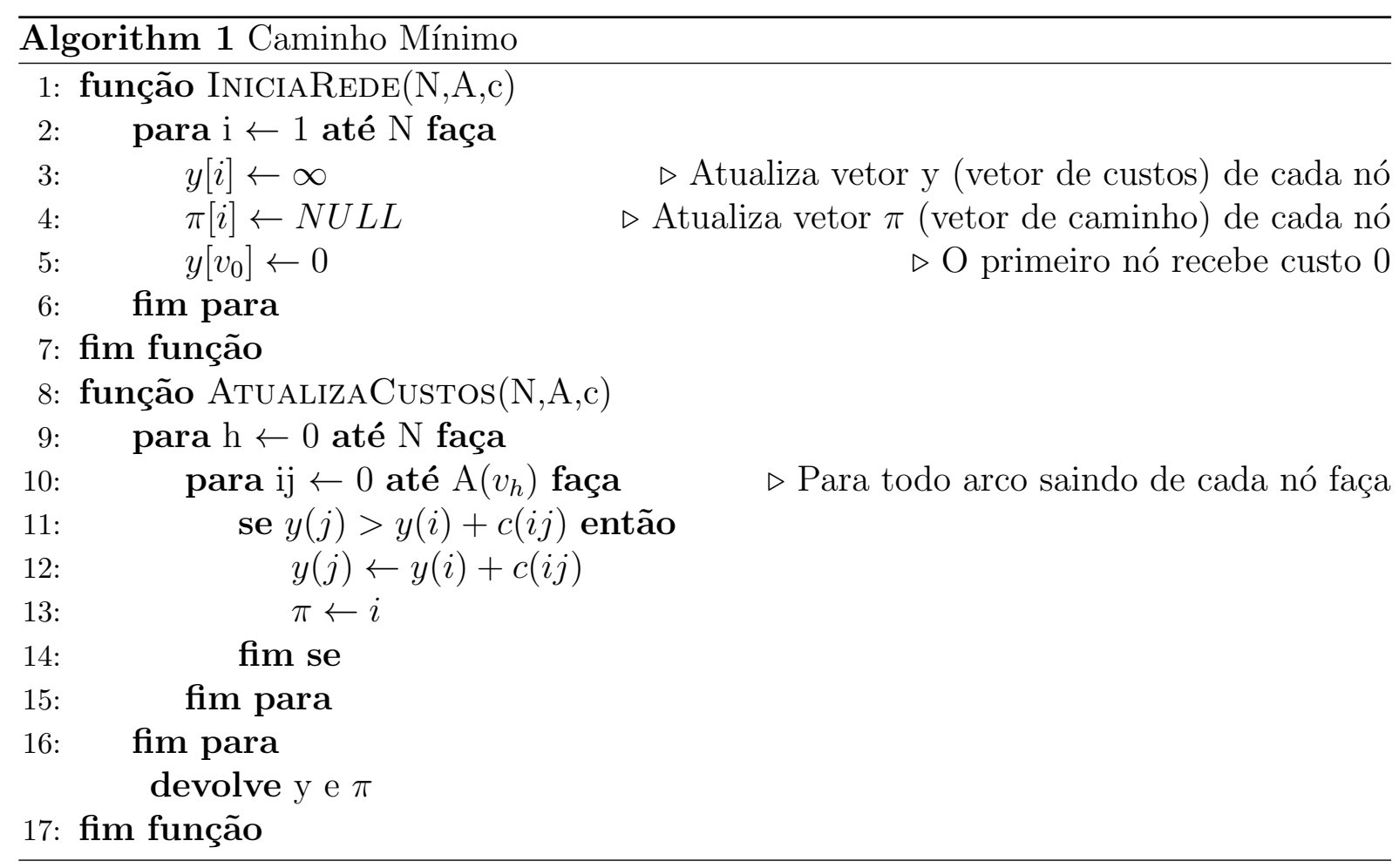

problema mestre se inicia. Estas etapas consistem na atualização da rede de arcos, ou seja, a subtração pelas variáveis duais do problema mestre e na resolução do subproblema. Desta forma, a solução do problema de caminho mínimo pode ser convertida em um formado de coluna e, então, adicionada no problema mestre. O algoritmo deste processo está apresentado no apêndice $\mathrm{C}$ deste trabalho.

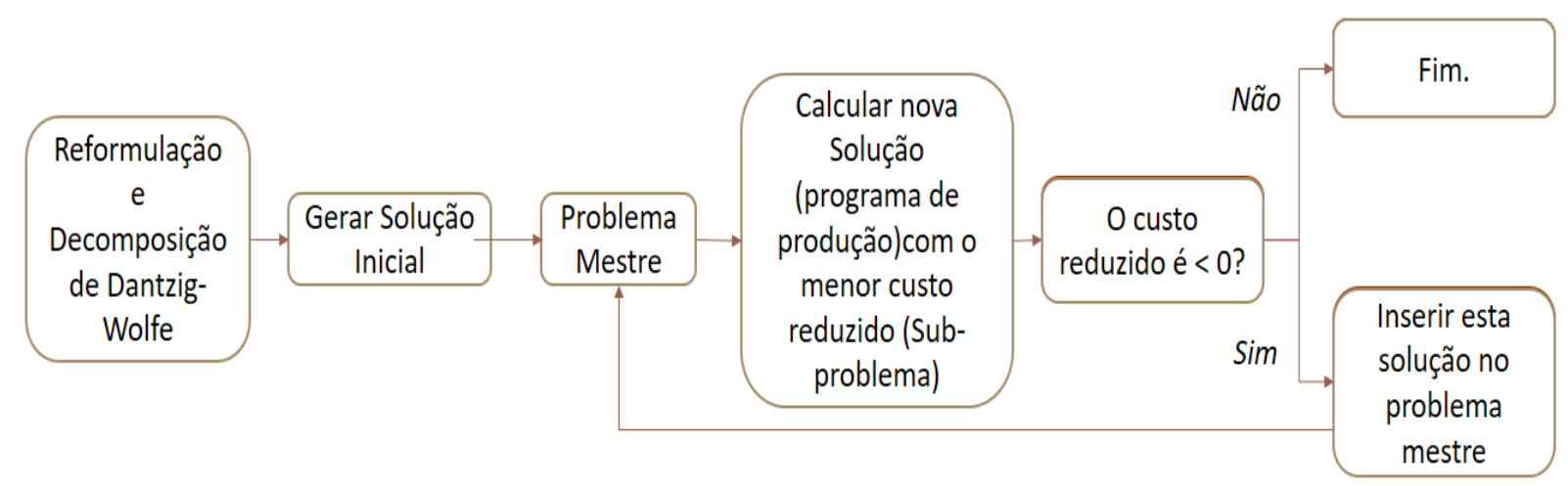

Figura 4: A geração de colunas acontece iterativamente até que o menor custo reduzido encontrado pelo sub-problema seja maior do que zero. 


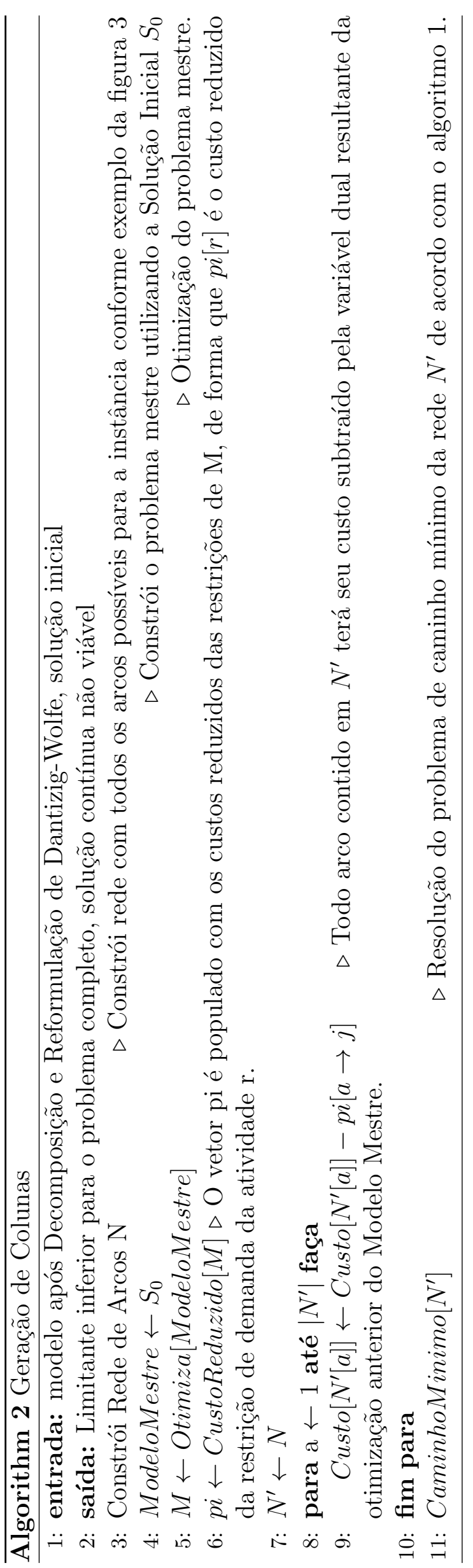




\subsubsection{Solução Inicial}

Como mencionado nas outras sessões deste capítulo, o algoritmo de geração de colunas parte da ideia de encontrar uma nova coluna que trará redução na função objetivo de um modelo matemático se adicionada ao problema.

Para isto, a partir da teoria de pesquisa operacional, esta coluna a ser adicionada precisa apresentar custo reduzido menor do que zero. O custo reduzido da coluna $k$, $c_{k}$, calculado conforme a equação 3.28, é uma função das variáveis duais do modelo matemático do problema mestre ( representados por $\pi$ na equação) e dos coeficientes da função objetivo dele (representados por $c$ na equação).

Portanto, percebe-se que para encontrar a primeira coluna a ser adicionada o modelo matemático do problema mestre precisa ser resolvido. Assim, é necessário que o modelo mestre seja inicializado com uma solução inicial viável do problema original.

A qualidade desta solução inicial poderá influenciar na velocidade do método de geração de colunas. Em outras palavras, quanto mais próxima do ótimo esta solução for, menos colunas serão necessárias para encontrar finalizar o algoritmo.

Desta forma, existe um balanço entre o tempo gasto para gerar uma boa solução inicial e o tempo gasto para que o algoritmo de geração de colunas encontre o limitante inferior do problema. Neste trabalho, decidiu-se utilizar uma heurística construtiva simples para gerar a solução inicial para o modelo do problema mestre.

Esta heurística será explicada e discutida na próxima seção.

\subsection{Método Heurístico}

Como componente importante do método de geração de colunas, a solução inicial do algoritmo pode influenciar na performance do mesmo. Em outras palavras, a qualidade da solução inicial para o algoritmo de geração de colunas irá influenciar na quantidade de colunas geradas, consequentemente no tempo gasto pelo algoritmo.

Com o objetivo de fornecer uma solução inicial adequada para o algoritmo de geração de colunas, será proposta neste trabalho uma heurística construtiva. Uma heurística construtiva foi escolhida pela sua facilidade de implementação e rapidez de execução, desta forma, a definição da solução inicial não impactará no tempo total de execução do método de geração de colunas. 
Como discutido no Capítulo 2, existe uma lacuna na bibliografia de métodos construtivos para o problema de máquinas diferentes em paralelo com tempos de liberação e elegibilidade. Devido a isto, a heurística construtiva deste trabalho será explorada também através do método proposto por Arcus (1965), onde o autor introduz o conceito de Heurística Construtiva Probabilística.

Nas próximas sessões a heurística construtiva será discutida, bem como a adaptação da mesma para uma heurística construtiva probabilística.

\subsubsection{Heurística Construtiva Determinística}

A proposta da Heurística construtiva determinística deste trabalho parte da ideia de uma regra de prioridade que envolve várias características da definição do problema tratado. O fator $c_{j m}$ calculado na equação 3.29 abaixo será utilizado para priorizar os pares $(j, m)$ na construção da solução.

$$
c_{j m}=\frac{t c_{j}}{P_{j m} * D_{j} * \sum_{j=1}^{J} \operatorname{Pjm}}
$$

O fator $c_{j m}$ foi proposto de forma que sejam explorados os custos de atraso, tempo de processamento, data de entrega e características das máquinas. Abaixo, serão explicados os fatores que compões $c_{j m}$.

- $\frac{t c_{j}}{P_{j m}}$ : Este fator representa o custo de atraso potencial por unidade de tempo alocada na máquina. Um valor alto de $t c_{j}$, ou custo de atraso da atividade $j$, indica que uma solução de boa qualidade para a instância provavelmente apresentará a atividade $j$ no início da programação. Porém, por se tratar de um problema que envolve máquinas diferentes e elegibilidade, o efeito de alocar a atividade $j$ pode mudar de acordo com o tempo da máquina que executar esta atividade. Por este motivo, o valor de $t c_{j}$ é dividido pelo tempo de processamento da atividade $j$ na máquina $m$ para cada par $(j, m)$. Em instâncias onde existe atraso, a escolha estratégica das atividades que irão atrasar versus as atividades que não irão atrasar está atrelada a este fator.

- $\frac{1}{D_{j}}$ : Este fator representa a tendencia de atraso de $j$. Quanto menor é $D_{j}$, ou a data de entrega da atividade $j$, maior é a chance de $j$ estar atrasado na solução e a expectativa é de um atraso total maior. Portanto, uma combinação de alto custo de atraso $\left(t c_{j}\right)$ e baixo $D_{j}$ representa um candidato forte para ser alocado no início 
da solução.

- $\frac{1}{\sum_{j=1}^{J} \text { Pjm }}$ : Este fator está relacionado com a eficiência e flexibilidade da máquina $m$. Uma máquina que possui tempos de processamento $P_{j m}$ relativamente baixos é dita eficiente, ao mesmo tempo que uma máquina que é capaz de processar todas as atividades da instância é dita uma máquina flexível. Assim, a soma $\sum_{j=1}^{J} P j m$ será menor para máquinas eficientes e menos flexíveis, resultando em pares $(j, m)$ com maior prioridade na construção da solução. em outras palavras, este fator busca utilizar melhor os recursos disponíveis na instância.

O fator resultante dos itens acima, como mostrado na equação 3.29, é estático. Ou seja, $c_{j m}$ será calculado apenas uma vez para todos os possíveis pares $(j, m)$.

A lista de pares $(j, m)$ é, então, ordenada por $c_{j m}$ decrescente e o primeiro par será alocado na solução em construção. Após esta etapa, uma rotina é responsável por apagar da lista de pares $(j, m)$ todos os pares compostos pelo $j$ que acabou de ser alocado. Desta forma, os próximos pares são escolhidos até a lista estar vazia.

Seja a instância i uma instância hipotética de 5 atividades e 2 máquinas, uma possível lista de pares $(j, m)$ é exemplificada na tabela 7 abaixo:

\begin{tabular}{c|c} 
Tabela 7: Instância Ex \\
\hline$(j, m)$ & $c_{j m}$ \\
\hline$j_{1}, m_{1}$ & 35 \\
$j_{2}, m_{1}$ & 11 \\
$j_{4}, m_{1}$ & 24 \\
$j_{5}, m_{1}$ & 62 \\
$j_{1}, m_{2}$ & 39 \\
$j_{2}, m_{2}$ & 0 \\
$j_{3}, m_{2}$ & 12 \\
$j_{5}, m_{2}$ & 37 \\
\hline
\end{tabular}

Perceba que na instância exemplo, os pares $\left(j_{3}, m_{1}\right)$ e $\left(j_{4}, m_{2}\right)$ não existem. Isto é devido à elegibilidade de máquina como característica do problema tratado neste trabalho.

Na continuidade da heurística, esta lista deve ser ordenada por $c_{j m}$ decrescente, como mostrado na tabela 8 abaixo. 
Tabela 8: Instância Exemplo - Lista de pares $(j, m)$ Ordenada por $c_{j m}$ decrescente

\begin{tabular}{c|c}
\hline$(j, m)$ & $c_{j m}$ \\
\hline$j_{5}, m_{1}$ & 62 \\
$j_{1}, m_{2}$ & 39 \\
$j_{5}, m_{2}$ & 37 \\
$j_{1}, m_{1}$ & 35 \\
$j_{4}, m_{1}$ & 24 \\
$j_{3}, m_{2}$ & 12 \\
$j_{2}, m_{1}$ & 11 \\
$j_{2}, m_{2}$ & 0 \\
\hline
\end{tabular}

Desta forma, é possível perceber que a atividade $j_{5}$ deverá ser alocada na máquina $m_{1}$ pela priorização definida por esta heurística. Ao ser alocada, seu instante de término de processamento na máquina escolhida é calculado como a seguir:

$$
C_{j}=\max \left(R_{m}, R j\right)+P_{j m}
$$

Onde $R_{m}$ e $R_{j}$ são os instantes de liberação da máquina e da atividade respectivamente. Desta forma, é possível calcular o custo de atraso desta atividade.

Após a alocação, todos os pares de $j_{5}$ são eliminados da lista, como na tabela 9 a seguir.

Tabela 9: Instância Exemplo - Lista após a alocação da primeira atividade

\begin{tabular}{c|c}
\hline$(j, m)$ & $c_{j m}$ \\
\hline$j_{1}, m_{2}$ & 39 \\
$j_{1}, m_{1}$ & 35 \\
$j_{4}, m_{1}$ & 24 \\
$j_{3}, m_{2}$ & 12 \\
$j_{2}, m_{1}$ & 11 \\
$j_{2}, m_{2}$ & 0 \\
\hline
\end{tabular}

De maneira similar, a próxima atividade a ser alocada é a atividade $j_{1}$ na máquina $m_{2}$. Seu custo de atraso será somado ao custo de atraso acumulado das atividades já alocadas. Este processo segue até todas as atividades das instâncias serem alocadas. O pseudo código deste processo está descrito abaixo, no algoritmo 3.3.1. 


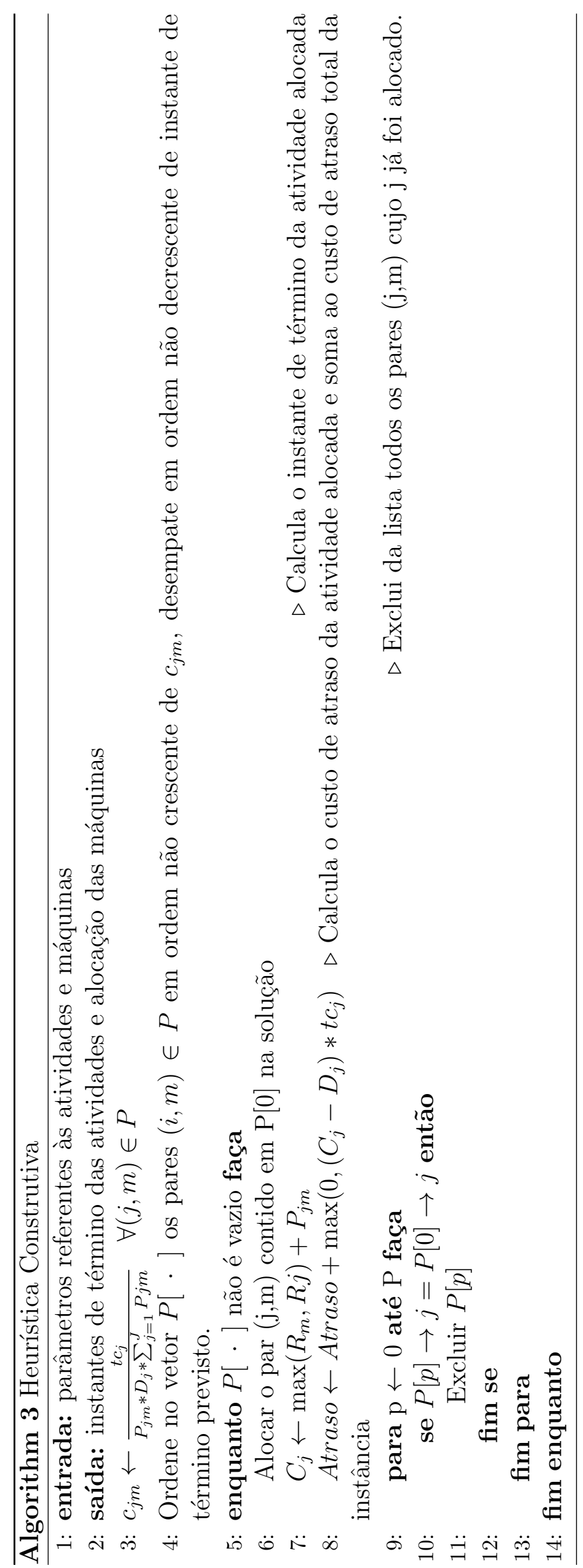




\subsubsection{Heurística Construtiva Probabilística}

A proposta da heurística probabilística consiste em selecionar os pares $(j, m)$ de maneira aleatória enviesada. O viés para sortear cada par é o fator descrito na equação 3.29. Ou seja, quanto maior é o fator $c_{j m}$, maior é a chance deste par ser sorteado e compor a solução naquele instante. Quando todas a atividades forem sorteadas, esta iteração foi finalizada e, assim, armazena-se a solução se esta for melhor do que a incumbente. Ao término de um número pré-definido de soluções, o método é finalizado para a instância.

A proposta de seleção aleatória para construir a solução é baseada em Arcus (1965). O pseudocódigo da heurística construtiva probabilística está no algoritmo 3.3.2.

O viés $\operatorname{prob}_{j m}$ de cada par é calculado por:

$$
\operatorname{prob}_{j m}=\alpha^{k+1}
$$

Onde $\alpha$ é um parâmetro pré-definido e $k$ é a posição do par $(j, m)$ no vetor $P$, ordenado em ordem não crescente de $c_{j m}$.

O fator $\alpha$ está compreendido entre 0 e 1 . Desta forma, quanto maior é o fator $k$, menor será $\operatorname{prob}_{j m}$. Na tabela 10 abaixo, o exemplo utilizado na seção anterior foi utilizado para demonstrar os valores de $\operatorname{prob}_{j m}$.

Tabela 10: Instância Exemplo - Lista de pares $(j, m)$ Ordenada por $p r o b_{j m}$, considerando $\alpha=0,8$

\begin{tabular}{c|c|c|c|c}
\hline$(j, m)$ & $c_{j m}$ & Posição $\operatorname{prob}_{j m}(\alpha=0,8)$ & $\operatorname{prob}_{j m}(\alpha=0,6)$ \\
\hline$j_{5}, m_{1}$ & 62 & 0 & 0,8 & 0,6 \\
$j_{1}, m_{2}$ & 39 & 1 & 0,64 & 0,41 \\
$j_{5}, m_{2}$ & 37 & 2 & 0,51 & 0,25 \\
$j_{1}, m_{1}$ & 35 & 3 & 0,41 & 0,15 \\
$j_{4}, m_{1}$ & 24 & 4 & 0,33 & 0,09 \\
$j_{3}, m_{2}$ & 12 & 5 & 0,26 & 0,05 \\
$j_{2}, m_{1}$ & 11 & 6 & 0,20 & 0,03 \\
$j_{2}, m_{2}$ & 0 & 7 & 0,16 & 0,02 \\
\hline
\end{tabular}

Após o cálculo de $\operatorname{prob}_{j m}$, os valores são normalizados. Para analisar o efeito do fator $\alpha$ na heurística, o gráfico abaixo foi gerado utilizando 0,6 e 0,8 . 


\section{Probabilidade}

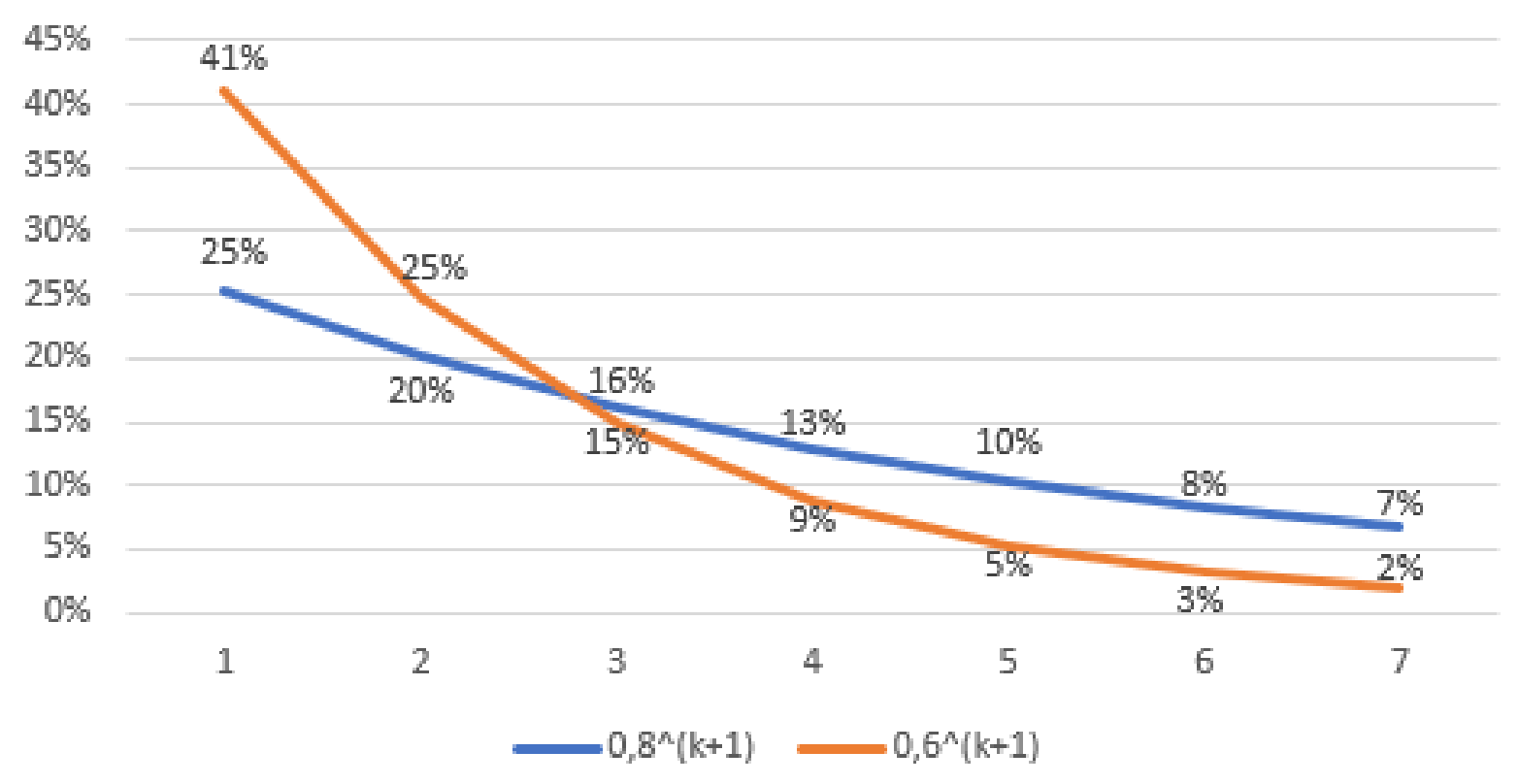

Figura 5: No eixo horizontal, a posição do par $(j, m)$, no eixo vertical a probabilidade deste par ser sorteado para compor a solução.

Desta forma, pretende-se inserir um viés na heurística que considera a natureza do problema como uma forma de intensificar ( $\alpha$ menor) ou diversificar ( $\alpha$ maior) a construção das soluções.

O pseudocódigo desta heurística construtiva probabilística está escrito abaixo, no algoritmo 3.3.2. Além disso, o código está exposto no apêndice B deste trabalho. 


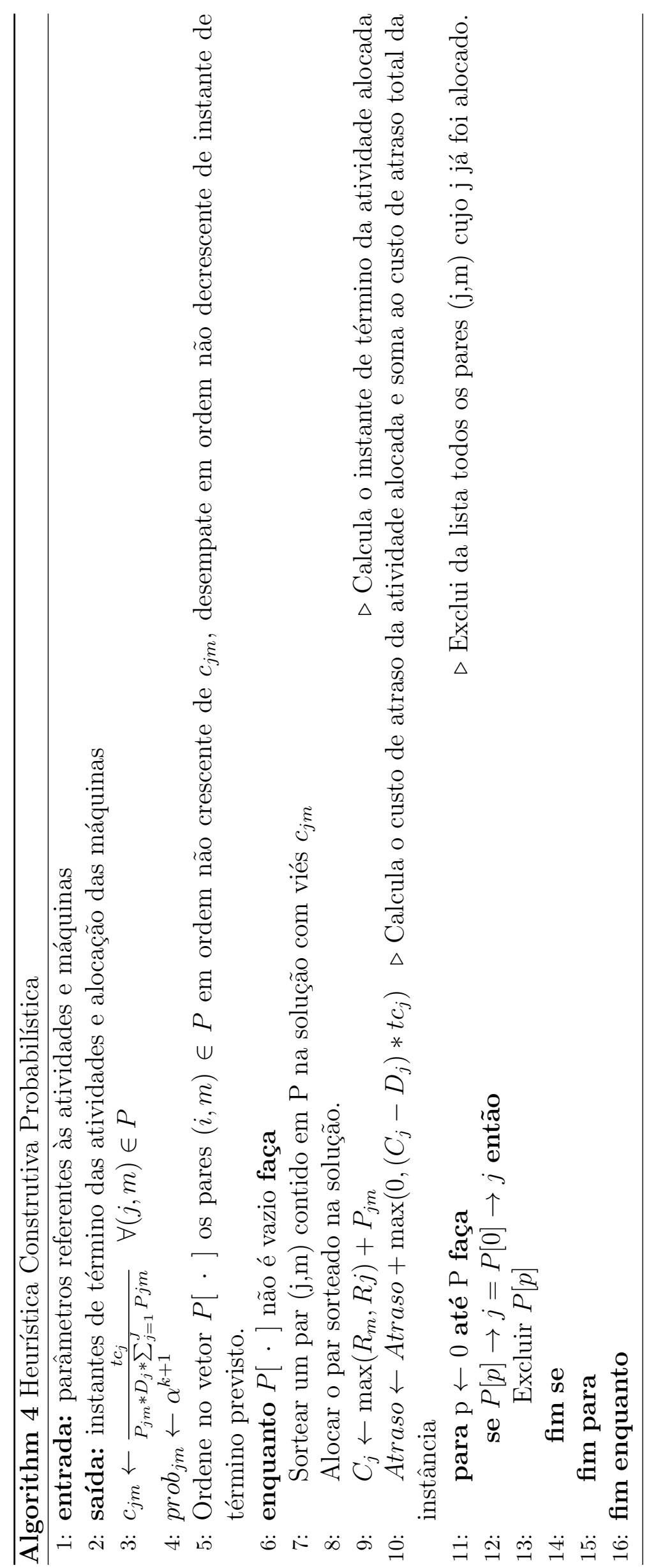




\section{IMPLEMENTAÇÃO}

O modelo de programação inteira mista foi implementado no IBM ILOG CPLEX 12.6, com suporte do Visual Basic for Applications do Excel 2013 para tratar os dados e exibir o resultado encontrado. Por outro lado, o algoritmo de Geração de Colunas foi implementado Python. O computador utilizado foi um Intel(R) Core(TM)i7-6500U CPU 2.50GHz.

\subsection{Validação do Método}

Para validar a aplicabilidade do método, buscou-se instâncias na literatura que fossem compatíveis com a proposta deste trabalho. Como foi discutido na revisão da literatura, existe uma lacuna de trabalhos que propõem métodos exatos de solução para o problema aqui apresentado, portanto houve dificuldade em encontrar instâncias adequadas.

Neste contexto, este trabalho prosseguirá com dois conjuntos distintos de instâncias. O primeiro conjunto, utilizado para validação do método e discutido nesta seção, foi gerado de maneira similar àquelas trabalhadas por Liaw et al. (2003). Ou seja, instâncias para o problema de minimização do atraso total ponderado em máquinas diferentes em paralelo. Estas instâncias não contemplam duas características importantes do problema aqui tratado: Elegibilidade de máquina e release time de máquina e de atividade. Para este propósito, o segundo conjunto de instâncias, chamado de Conjunto de Testes, foi gerado de acordo com o item 4.2 desta seção e seus resultados serão discutidos na seção de Resultados, no capítulo 5.4.

\subsubsection{Instâncias do conjunto de validação do Método}

Para uma instancia de $n$ atividades e $m$ máquinas, de acordo com Liaw et al. (2003), os tempos de processamento são gerados pela distribuição uniforme $U[1,100]$, as datas de entrega foram geradas por $U\left[\bar{P}\left(1-T-\frac{R}{2}\right), \bar{P}\left(1-T+\frac{R}{2}\right)\right]$, onde $T$ é o fator de atraso, $R$ 
é a amplitude e $\bar{P}$ é calculado como abaixo.

$$
\bar{P}=\sum_{i=1}^{n} \sum_{j=1}^{m} \frac{P_{i j}}{m^{2}}
$$

O valor de $\bar{P}$ pode ser interpretado como a data média de entrega que se deseja para a instancia a ser gerada. Como mostrado acima, as datas de entrega serão geradas a partir do valor de $\bar{P}$ considerando os fatores de aperto (T) e amplitude (R).

O valor de $t_{j}$ foi escolhido aleatoriamente por $U[1,10]$. Desta forma, quanto maior for o parâmetro $T$, mais apertado será o programa e quanto maior for o parâmetro $R$, mais espalhado serão as datas de entrega.

A tabela 11 abaixo lista os valores possíveis da cada parâmetro. Utilizando-se linguagem VBA, foram geradas 5 instâncias para cada combinação, resultando em um total de 405 instâncias.

Tabela 11: Parâmetros das instâncias do primeiro conjunto

\begin{tabular}{c|c}
\hline Parâmetros & Valores Adotados \\
\hline $\mathrm{n}$ & $14,16,18$ \\
$\mathrm{~m}$ & $2,3,4$ \\
$\mathrm{~T}$ & $0.2,0.6,1$ \\
$\mathrm{R}$ & $0.2,0.6,1$ \\
\hline
\end{tabular}

Para o método aqui apresentado, estas instâncias serão consideradas como instâncias cujos valores $R_{j}$ e $R_{m}$ são iguais a zero e a taxa de elegibilidade é igual a 100\%. Em outras palavras, todas as máquinas e todas as atividades estarão disponíveis no instante zero e todas as máquinas são capazes de executar todas as atividades. É importante mencionar que todos os valores de data prometida de entrega e tempo de processamento foram gerados de maneira a garantir uma discretização coerente com o modelo apresentado na seção 3.1.

\subsubsection{Resultados das instâncias do Conjunto de Validação do método}

Com a massa de dados geradas como descrito acima, o processo de solução seguiu para cada instância de acordo com os passos:

1. Execução do modelo MILP com um tempo limite de 1800 segundos; 
2. Caso uma solução com GAP inferior a 1\% (considerada ótima para este trabalho) seja encontrada, finaliza o processo para esta instância, caso contrário, segue para o próximo passo;

3. Executar o algoritmo de geração de colunas;

4. Calcular o GAP de acordo com a equação abaixo, onde $U P_{M I L P}$ representa o limitante superior fornecido pelo modelo de programação linear mista e $L B_{C G}$ representa o limitante inferior fornecido pelo algoritmo de geração de colunas:

$$
G A P=\frac{U P_{M I L P}-L B_{C G}}{U P_{M I L P}}
$$

5. Voltar para o passo 1 para a próxima instância

Seguindo este processo, $85 \%$ instâncias tiveram soluções ótimas encontradas no passo 1, enquanto outros $11 \%$ das instâncias tiveram soluções ótimas encontradas no passo 3. De maneira geral, foram encontradas soluções ótimas para $96 \%$ das instâncias geradas de acordo com Liaw et al. (2003).

As 17 instâncias cujas soluções ótimas não foram encontradas por este método são instâncias de e 2 ou 3 máquinas e, em sua maioria, apresentam parâmetros $\mathrm{T}=0,6$ e $\mathrm{R}$ $=0,2$. Estas instâncias finalizaram o processo com um GAP médio de $9 \%$.

O processo de geração de colunas teve uma duração média de 40 segundos por instância, com desvio padrão de 18 segundos.

No trabalho de Liaw et al. (2003), em que este conjunto de instancias foi proposto, os autores apresentaram um método para encontrar lower bounds para as soluções das mesmas. Este método foi desenvolvido a partir da de um modelo matemático indexado no tempo, no qual o valor do atraso de cada atividade era estimado através da premissa de que cada máquina processaria as atividades em ordem não decrescente de tempo de processamento. Este método resultou em um desvio médio de $42 \%$ com relação à solução ótima. Liaw et al. (2003) também propuseram um método para encontrar upper bounds para as soluções das instâncias através de uma heurística, resultando em um desvio médio de $65 \%$ da solução ótima.

Com estes resultados, observa-se que o método apresentado neste trabalho apresentou um bom desempenho para tratar as instancias encontradas na literatura.

Desta forma, como mencionado anteriormente, um novo conjunto de instâncias será gerado de maneira similar à apresentada aqui, porém algumas modificações serão im- 
plementadas para que as instancias contemplem características essenciais do problema aqui tratado, como elegibilidade de máquina e tempos de liberação das atividades e das máquinas.

\subsection{Instâncias do Conjunto de Teste}

Como mencionado, as instâncias encontradas na literatura não contemplavam dois parâmetros importantes do problema tratado neste problema. Um deles é a taxa de elegibilidade $(e)$. Este valor entre 0 e 1 representa a porcentagem de atividades que cada máquina poderá executar em média. Outros dois parâmetros não contemplados nas instâncias de Liaw et al. (2003) foram o tempo de liberação das máquinas e das atividades $\left(r_{m}\right.$ e $\left.r_{j}\right)$. Estes valores representam, respectivamente, o instante a partir do qual cada máquina $m$ e cada atividade $j$ estará disponível para ser programada.

Estas instâncias foram geradas da mesma maneira que Liaw et al. (2003) propôs, porém o fator elegibilidade $(e)$ foi considerado como a probabilidade de gerar-se um $P_{j m}$ para aquele par de atividade e máquina. Além disso, o valor de $e$ foi incluso no novo cálculo de $\bar{P}$, como abaixo:

$$
\bar{P}=\sum_{i=1}^{n} \sum_{j=1}^{m} \frac{P_{i j}}{m^{2} * e}
$$

Além disso, os valores de $r_{j}$ e $r_{m}$ foram gerados por $U[0,3]$, os tempos de processamento de cada atividade $\left(P_{j m}\right)$ foram gerados por $T[0,5,10]$ e os custos de atraso $\left(t c_{j}\right)$ foram gerados por $U[0,10]$. Novamente todos os valores que se referem a instantes de tempo foram gerados como números inteiros para que seja garantida a aderência do limitante inferior proposto sem onerar o tempo de processamento do método de geração de colunas.

Os parâmetros utilizados para estas instâncias estão listados na tabela 12, sendo que para cada conjunto de parâmetros, foram geradas 10 instâncias. Portanto, este conjunto possui 320 instâncias. Uma parte desta massa de dados está exposta no apêndice D deste trabalho. 
Tabela 12: Parâmetros das instâncias do segundo conjunto

\begin{tabular}{c|c}
\hline Parâmetros & Valores Adotados \\
\hline $\mathrm{n}$ & 20,25 \\
$\mathrm{~m}$ & 3,4 \\
$\mathrm{~T}$ & $0.2,1$ \\
$\mathrm{R}$ & $0.2,1$ \\
$\mathrm{e}$ & $0.7,0.4$ \\
\hline
\end{tabular}




\section{ANÁLISE DOS RESULTADOS}

Nesta seção, os resultados das instâncias do Conjunto de Teste serão apresentados. Para efeito de análises, estas instâncias foram submetidas às seguintes etapas:

1. Execução do modelo MILP com um tempo limite de 1800 segundos;

2. Cálculo do $G A P_{M I L P}$ de acordo com a equação, considerando-se $L B_{M I L P}$ e $U B_{M I L P}$ o limitante inferior e superior resultantes do MILP, simultaneamente:

$$
G A P_{M I L P}=\frac{U P_{M I L P}-L B_{M I L P}}{U P_{M I L P}}
$$

3. Executar o algoritmo de geração de colunas;

4. Calcular o $G A P_{G C}$ de acordo com a equação 5.2, onde $U P_{M I L P}$ representa o limitante superior fornecido pelo modelo de programação linear mista e $L B_{C G}$ representa o limitante inferior fornecido pelo algoritmo de geração de colunas:

$$
G A P_{G C}=\frac{U P_{M I L P}-L B_{C G}}{U P_{M I L P}}
$$

5. O GAP final da instância será calculado como abaixo:

$$
G A P=\min \left\{G A P_{M I L P}, G A P_{G C}\right\}
$$

6. Voltar para o passo 1 para a próxima instância

O resultado final do processo será medido pelo GAP resultante do passo 5 acima. Porém, com o propósito de analisar o comportamento do método, são gerados três valores diferentes ao longo do processo de acordo com as equações acima descritas. A seguir apresenta-se os três valores e o objetivo de cada um:

- GAP $P_{M L P}:$ O modelo de programação inteira mista proposto neste trabalho, como é de se esperar, fornece a cada instância resolvida limitantes superiores e inferiores. 
Tais limitantes são utilizados para calcular o $G A P_{M I L P}$. Este valor é utilizado para avaliar o resultado do modelo MILP;

- $G A P_{G C}$ : O algoritmo de geração de colunas, de acordo com sua definição, fornece limitantes superiores e inferiores para as instâncias após o problema sofrer uma relaxação linear. Estes limitantes não são adequados para o problema completo, de variáveis binarias e inteiras. Porém, a solução final do algoritmo de geração de colunas representa um limitante inferior para o problema completo. Tal limitante será utilizado para calcular o $G A P_{G C}$, juntamente com o limitante superior fornecido pelo MILP. O $G A P_{G C}$ será utilizado para avaliar o resultado do algoritmo de geração de colunas.

- GAP: Este é o valor de interesse do método. Ele representa a qualidade da solução final encontrada pelo processo, uma vez que o algoritmo de geração de colunas pode gerar limitantes inferiores de melhor qualidade do que o modelo matemático proposto. Este valor será utilizado para avaliar o resultado do processo como um todo.

Além disso, as instâncias foram submetidas ao algoritmo de heurística probabilística discutido na seção 3.3.2.

Nas próximas sessões, serão analisados separadamente os comportamentos do modelo MILP e do algoritmo de Geração de Colunas. Depois, será analisado o método como um todo, considerando o GAP como calculado no passo 5 acima. Por ultimo, os resultados da heurística probabilística proposta serão discutidos.

\subsection{Resultados do modelo matemático}

Individualmente, o modelo de programação inteira mista proposto neste trabalho foi capaz de encontrar soluções ótimas para 182 (56,8\%) das 320 instâncias geradas no conjunto de testes . A solução fornecida pelo MILP foi considerada ótima se o GAP resultante foi menor do que $1 \%$.

Estas instâncias são mostradas na Tabela 13, divididas por quantidade de máquinas e atividades.

É de se esperar que instâncias menores, ou seja, com 20 atividades, favoreçam o modelo matemático para encontrar melhores soluções. 
Tabela 13: Quantidade de instâncias que tiveram soluções ótimas encontradas em até 1800 segundos pelo MILP, por quantidade de máquinas e atividades.

\begin{tabular}{cccc}
\hline \multirow{2}{*}{$\mathrm{n}$} & \multicolumn{3}{c}{$\mathrm{m}$} \\
\cline { 2 - 4 } & 3 & 4 & Total \\
\hline 20 & 47 & 54 & 101 \\
25 & 40 & 41 & 81 \\
Total & 87 & 95 & 182 \\
\hline
\end{tabular}

Por outro lado, segundo a Tabela 14, fica claro que as instâncias resolvidas com maior facilidade pelo modelo matemático são instâncias com fator de atraso igual a 0,2. Em outras palavras, estas instâncias estavam pouco atrasadas de maneira geral.

Tabela 14: Quantidade de instâncias que foram resolvidas em até 1800 segundos pelo MILP, por R e $\mathrm{T}$.

\begin{tabular}{cccc}
\hline \multirow{2}{*}{$\mathrm{T}$} & \multicolumn{3}{c}{$\mathrm{R}$} \\
\cline { 2 - 4 } & 0,2 & 1 & Total \\
\hline 0,2 & 80 & 80 & 160 \\
1 & 9 & 13 & 22 \\
Total & 89 & 93 & 182 \\
\hline
\end{tabular}

Com relação às instâncias cujas soluções ótimas não foram encontradas, percebeu-se que o $G A P_{M I L P}$ resultante foi de baixa qualidade, como mostrado na Tabela 15.

Tabela 15: $G A P_{M I L P}$ resultante para instâncias que não tiveram soluções ótimas encontradas em até 1800 segundos pelo MILP.

\begin{tabular}{cccc}
\hline \multirow{2}{*}{$\mathrm{n}$} & \multicolumn{3}{c}{$\mathrm{m}$} \\
\cline { 2 - 4 } & 3 & 4 & Total \\
\hline 20 & $34,9 \%$ & $34,6 \%$ & $34,8 \%$ \\
25 & $60,4 \%$ & $50,3 \%$ & $55,4 \%$ \\
Total & $48,9 \%$ & $44,0 \%$ & $46,6 \%$ \\
\hline
\end{tabular}

Este resultado coloca em questionamento a qualidade do limitante superior ou inferior resultantes do MILP para instâncias com um alto fator de atraso. Porém, na seção posterior onde o algoritmo de geração de colunas é discutido, será mostrado que o limitante superior aqui encontrado é de boa qualidade.

Por agora, é possível notar que 100\% das instâncias que não tiveram soluções ótimas encontradas pelo modelo matemático são instâncias com limitantes inferiores maiores do que zero pois as atividades estão, de maneira geral, muito atrasadas. A Tabela 16 mostra o $G A P_{M I L P}$ resultante para todas as instâncias.

Em adição a isto, a Tabela 17 mostra que o tempo necessário para o modelo matemático encontrar uma solução comprovadamente ótima para instâncias com fator $\mathrm{T}$ 
Tabela 16: $G A P_{M I L P}$ resultante para todas a instâncias por T e R.

\begin{tabular}{cccc}
$\mathrm{T}$ & \multicolumn{3}{c}{$\mathrm{R}$} \\
\cline { 2 - 4 } & 0,2 & 1 & Total \\
\hline 0,2 & $0,0 \%$ & $0,0 \%$ & $0,0 \%$ \\
1 & $48,1 \%$ & $32,3 \%$ & $40,2 \%$ \\
\hline Total & $24,0 \%$ & $16,1 \%$ & $20,1 \%$
\end{tabular}

igual a 0,2 é muito pequeno.

Tabela 17: Tempo médio de processamento do MILP em segundos para todas as instâncias.

\begin{tabular}{cccc} 
& \multicolumn{3}{c}{$\mathrm{R}$} \\
\cline { 2 - 4 } $\mathrm{T}$ & 0,2 & 1 & Total \\
\hline 0,2 & 0,11 & 0,35 & 0,23 \\
1 & 1669,3 & 1570,68 & 1619,9 \\
\hline Total & 834,7 & 785,51 & 810,11
\end{tabular}

Percebeu-se, portanto, que o modelo de programação linear inteira mista proposto neste trabalho tem uma grande facilidade em encontrar bons limitantes superiores para as instâncias em um tempo curto. Porém, isto não é verdade para limitante inferiores.

É de se esperar, portanto, que caso a instância possua pelo menos uma solução cujo valor do objetivo é igual a zero, esta solução é rapidamente encontrada e classificada como solução ótima. Isto acontece devido à equação 3.12 apresentada no modelo matemático. Esta restrição define um limitante inferior oriundo da definição do problema. Em outras palavras, não existe atraso negativo.

Por outro lado, caso o modelo esteja tratando uma instância cuja solução ótima possui limitante inferior maior do que zero, o MILP tem dificuldades de comprovar a otimalidade da solução. Devido a isto, como é possível observar pela Tabela 16, todas as instâncias que o modelo não foi capaz de encontrar nenhuma solução ótima possuem fator de atraso 1, adicionalmente seus limitantes inferiores são maiores do que zero.

Na figura 6, temos a representação da solução ótima fornecida pelo modelo matemático em gráfico de Gantt. A instância do exemplo é a instância 21 e o menor atraso total ponderado possível para ela é 806,5. O $G A P_{M I L P}$ resultante para esta instância foi $0 \%$. 

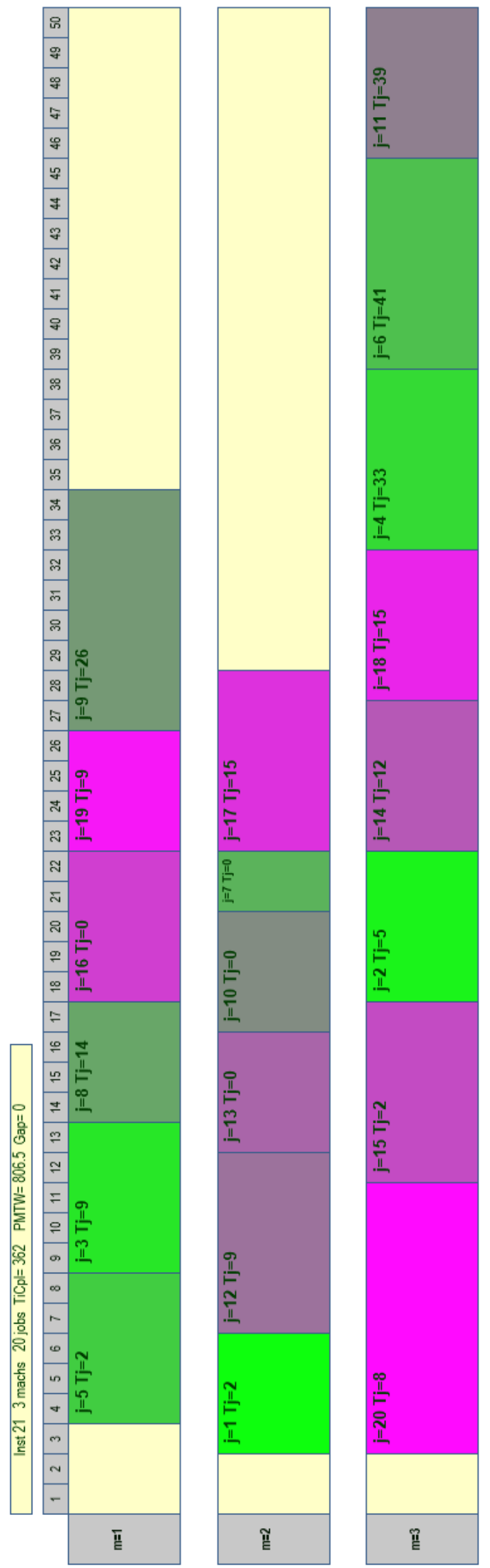

Figura 6: Gráfico de Gantt da solução fornecida pelo modelo matemático para a instância 21, na legenda, TiCpl representa o tempo total para o software apresentar uma solução ótima e PMTW representa o valor do objetivo da solução. 


\subsection{Resultados da geração de colunas}

Utilizando o limitante inferior fornecido pelo algoritmo de geração de colunas, foi possível comprovar a otimalidade das soluções de 261 instâncias que foram processadas pelo MILP, representando 81,5\% do total de instancias. Na Tabela 18, é apresentada a quantidade de instâncias que tiveram soluções ótimas comprovadas pelo algoritmo de geração de colunas por quantidade de máquinas $(m)$ e quantidade de atividades $(j)$.

Tabela 18: Quantidade de instâncias que tiveram soluções ótimas comprovadas pelo algoritmo de geração de colunas por quantidade de máquinas e atividades.

\begin{tabular}{cccc} 
& \multicolumn{3}{c}{$\mathrm{m}$} \\
\cline { 2 - 4 } & 3 & 4 & Total \\
\hline 20 & 66 & 72 & 138 \\
25 & 65 & 58 & 123 \\
Total & 131 & 130 & 261 \\
\hline
\end{tabular}

Novamente, instâncias menores possuem uma pequena vantagem devido ao numero reduzido de soluções possíveis. Porém, como mostra a Tabela 19, a influência do fator de atraso T no resultado do algoritmo é mais significativa assim como no modelo matemático.

Tabela 19: Quantidade de instâncias que tiveram soluções ótimas comprovadas pelo algoritmo de geração de colunas por fator $\mathrm{T}$ e R.

\begin{tabular}{cccc}
\hline $\mathrm{T}$ & \multicolumn{3}{c}{$\mathrm{R}$} \\
\cline { 2 - 4 } & 0,2 & 1 & Total \\
\hline 0,2 & 80 & 75 & 155 \\
1 & 55 & 51 & 106 \\
Total & 135 & 126 & 261 \\
\hline
\end{tabular}

Como é possível perceber, 59 instâncias (18,4\% do total) não tiveram soluções comprovadas como ótimas pelo algoritmo de geração de colunas. Apesar disso, como mostra a Tabela 20, estas instâncias finalizaram o processo com um $G A P_{G c}$ médio de 2,2\%. Isto demonstra que o limitante superior fornecido pelo modelo matemático discutido na seção 3.1 é de boa qualidade 
Tabela 20: $G A P_{G C}$ médio final das instâncias que não tiveram soluções ótimas comprovadas pelo algoritmo de geração de colunas por fator $\mathrm{T}$ e $\mathrm{R}$.

\begin{tabular}{cccc}
\hline \multirow{2}{*}{$\mathrm{T}$} & \multicolumn{3}{c}{$\mathrm{R}$} \\
\cline { 2 - 4 } & 0,2 & 1 & Total \\
\hline 0,2 & $*$ & $3,6 \%$ & $3,6 \%$ \\
1 & $2,0 \%$ & $2,1 \%$ & $2,1 \%$ \\
Total & $2,0 \%$ & $2,3 \%$ & $2,2 \%$ \\
\hline
\end{tabular}

A fim de analisar o comportamento do algoritmo ao longo do processo de geração de colunas, a instância 158 foi selecionada. A Figura 9 representa a solução viável fornecida pelo modelo matemático para esta instância.

Como podemos perceber, o modelo matemático não foi capaz de comprovar otimalidade desta solução em 1800 s, resultando em um GAP $P_{M L P}$ de 11,3\%. Esta solução representa um custo de atraso total de 490.7, já que 16 das 20 atividades que compõem a instância estão atrasadas nesta solução.

Para este caso, o limitante inferior encontrado pelo modelo matemático foi de um custo de atraso total 435.36, portanto existe uma necessidade de encontrar um limitante inferior de melhor qualidade para inferir a otimalidade da solução inteira fornecida.

Com este objetivo, o algoritmo de geração de colunas foi executado e, a cada coluna gerada, o valor dos limitantes superiores e inferiores foram colocados no gráfico da figura 8.

Como foi mencionado na seção 3.2.2, a reformulação que foi aplicada no problema para o processo de geração de colunas o transformou em um problema de soluções não inteiras. Em outras palavras, as soluções fornecidas pelo algoritmo de geração de colunas não são viáveis para o problema original, mas o valor do objetivo encontrado no algoritmo de geração de colunas funciona como um limitante inferior para ele.

No contexto do problema relaxado que foi mencionado, podemos encontrar seu limitante superior $\left(U B_{G C}\right)$ encontrando a solução ótima para o problema mestre definido na seção 3.2.2 (equação ??). Derivado do limitante superior, o limitante inferior $\left(L B_{G C}\right)$ pode ser calculado da seguinte forma:

$$
L B_{G C}=U B_{G C}+c_{k}
$$


Onde $c_{k}$, ou custo reduzido do subproblema, foi definido na equação ??.

Podemos perceber, pelo gráfico das Figuras 8 e 7, que o limitante inferior apresenta um comportamento instável ao longo do processo, diferentemente do limitante superior. Os dois gráficos são referentes à mesma massa de dados, porém com eixos diferentes para facilitar a visualização.

Estes dois valores, para esta instância, se encontraram no valor aproximado de 487 que representa um limitante inferior para o problema completo (inteiro) que resulta em um GAP de 0,7\%.

Assim, podemos concluir que a solução viável encontrada pelo modelo matemático cumpre o requisito de otimalidade definido para este trabalho.

É importante ressaltar que esta solução viável foi encontrada pelo modelo matemático em um tempo menor do que 1800 segundos, e a etapa de resolução deste modelo matemático poderia ter sido interrompida neste momento.

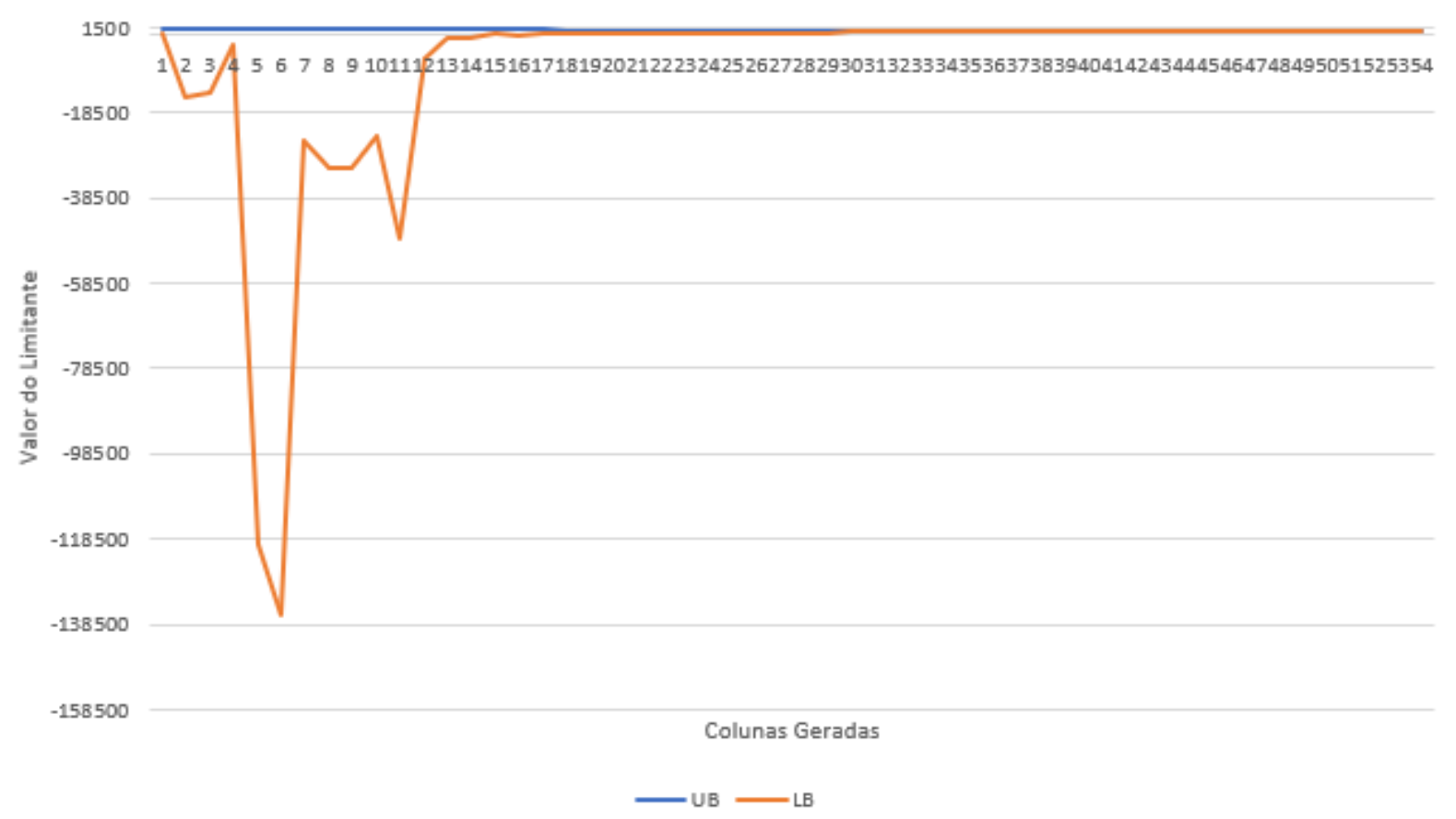

Figura 7: Gráfico da evolução do limitante superior e inferior do algoritmo de geração de colunas para a instância 158. 


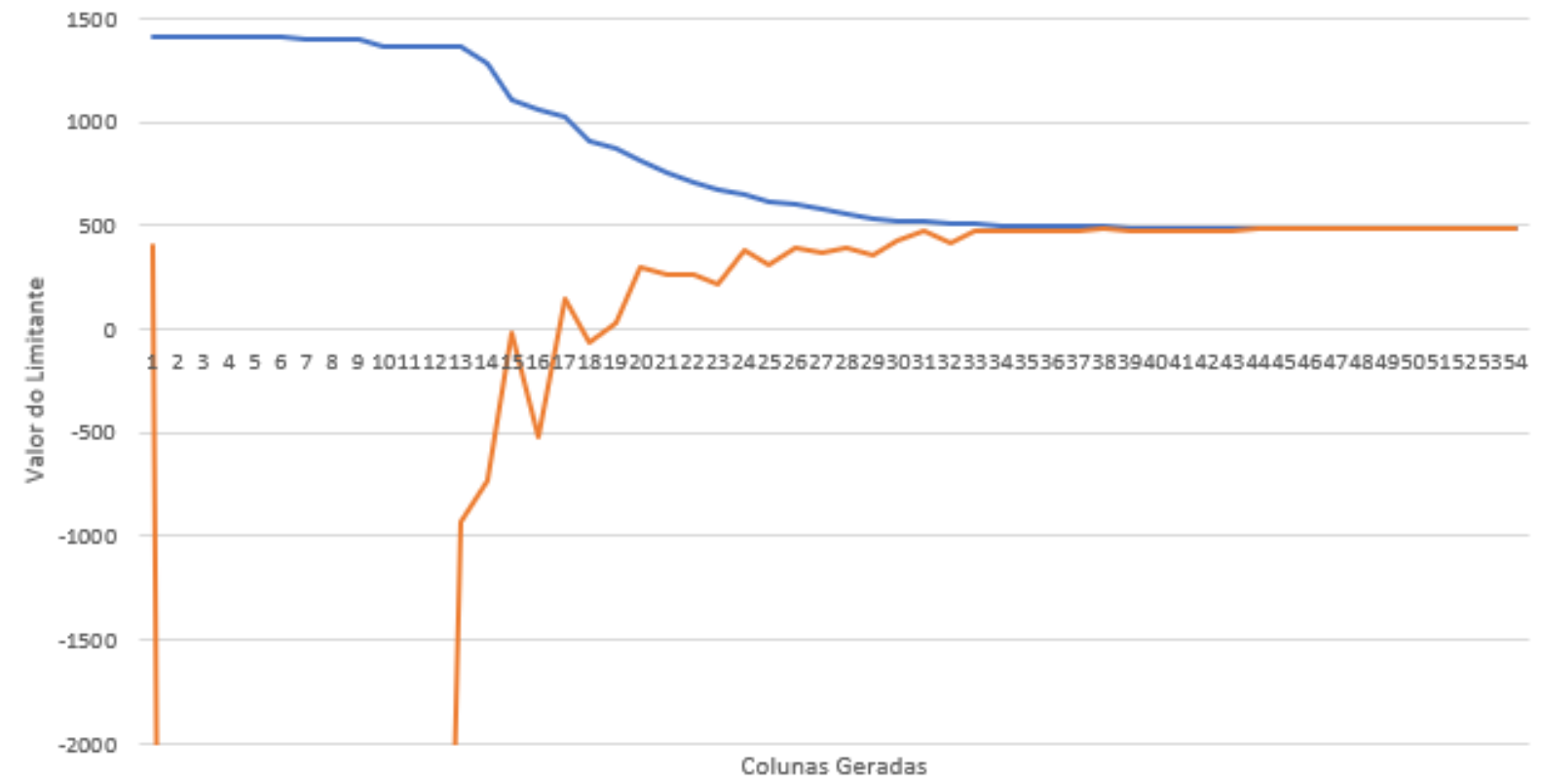

Figura 8: Gráfico da evolução do limitante superior e inferior do algoritmo de geração de colunas para a instância 158. A parte inferior do gráfico foi cortada para facilitar a visualização. 


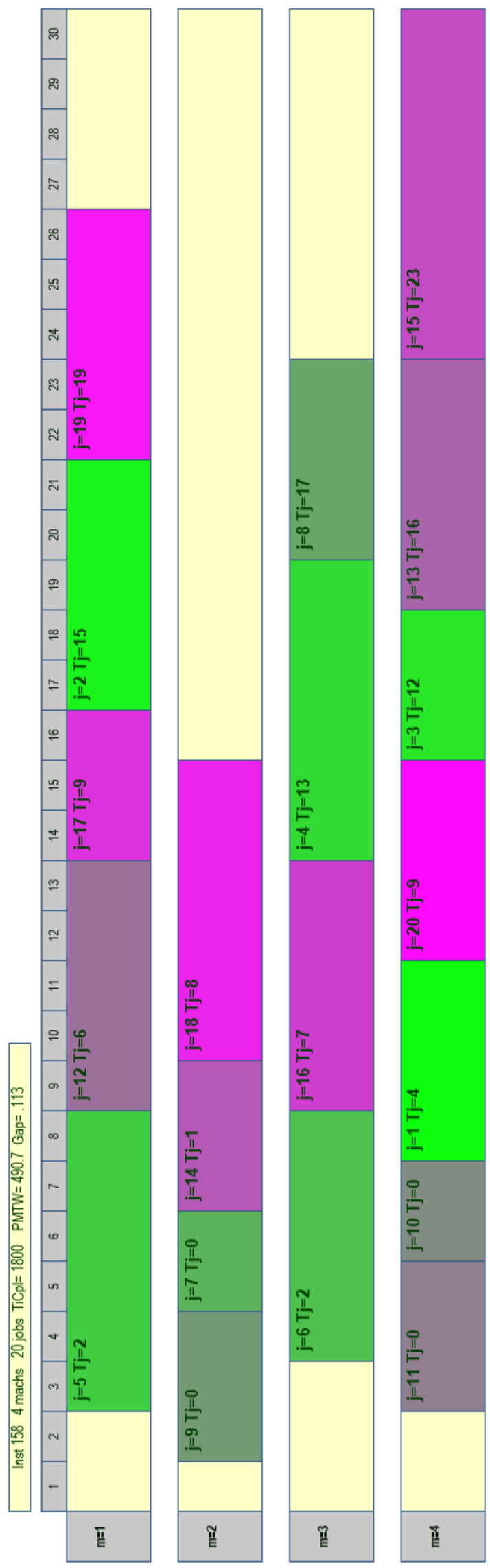

Figura 9: Gráfico de Gantt da solução fornecida pelo modelo matemático para a instância 158. 


\subsection{Resultados do método como um todo}

Nesta seção, será apresentado e discutido o resultado do método como um todo, considerando o GAP calculado no passo 5 do procedimento apresentado no início do capítulo. Este GAP é definido como o menor entre o $G A P_{M I L P}$ e o $G A P_{G C}$.

Como resultado, das 320 instâncias geradas, 57\% tiverem soluções ótimas encontradas no passo 1. Outros $27 \%$ das instâncias tiveram soluções ótimas confirmadas graças ao limitante inferior fornecido pelo algoritmo de Geração de Colunas.

Como é possível perceber na Figura 10, aproximadamente 76,3\% das instâncias tiveram GAP final menor do que $0,5 \%$.

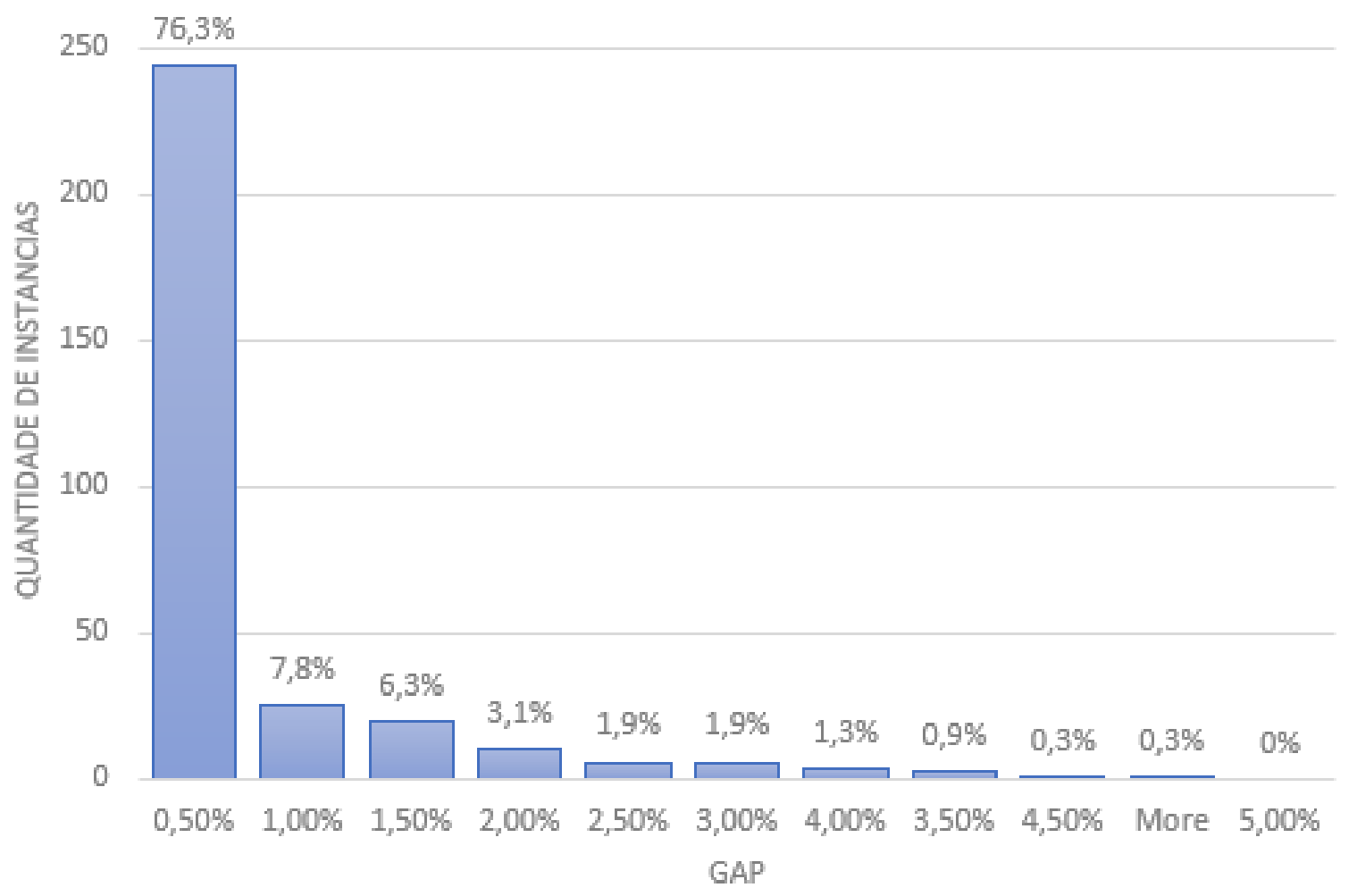

Figura 10: Histograma de GAPs das melhores soluções encontradas para as instancias do conjunto 2.

É possível observar um impacto do fator de elegibilidade $(e)$ no resultado. Como mostra a Tabela 21, instâncias com fator elegibilidade menor favorecem o método. Uma das razões encontradas para este comportamento aponta para o espaço de soluções menor que estas instâncias possuem, uma vez que as possibilidades de soluções são reduzidas com um menor fator de elegibilidade. 
Tabela 21: Quantidade de instâncias com solução ótima por fator de elegibilidade.

\begin{tabular}{c|c|c}
\hline Fator Elegibilidade & Quantidade & Porcentagem \\
\hline 0,4 & 148 & $55 \%$ \\
0,7 & 121 & $45 \%$ \\
Total & 269 & $100 \%$ \\
\hline
\end{tabular}

Ao contrário do fator de atraso $(\mathrm{T})$, o fator de amplitude $(\mathrm{R})$ não apresentou nenhum impacto na quantidade de soluções ótimas encontradas, como mostra a Tabela 22

Tabela 22: Quantidade de instâncias com solução ótima por fator amplitude (R).

\begin{tabular}{c|c|c}
\hline Fator Amplitude (R) & Quantidade & Porcentagem \\
\hline 0,2 & 134 & $50 \%$ \\
1 & 135 & $50 \%$ \\
Total & 269 & $100 \%$ \\
\hline
\end{tabular}

As 51 instâncias cujas soluções ótimas não foram encontradas, finalizaram o processo mencionado com um GAP médio de $2 \%$, sendo o maior GAP encontrado $5,7 \%$ para a instância 193. A Tabela 23 mostra o GAP final médio destas instâncias.

Tabela 23: GAP final médio das instâncias que não tiveram soluções ótimas encontradas pelo método por quantidade de máquinas e atividades.

\begin{tabular}{cccc}
\hline $\mathrm{n}$ & \multicolumn{3}{c}{$\mathrm{m}$} \\
\cline { 2 - 4 } & 3 & 4 & Total \\
\hline 20 & $1,5 \%$ & $1,7 \%$ & $1,6 \%$ \\
25 & $2,5 \%$ & $2,2 \%$ & $2,3 \%$ \\
Total & $2,1 \%$ & $2,2 \%$ & $2,1 \%$ \\
\hline
\end{tabular}

A tabela 24 abaixo mostra o tempo médio de processamento do método todo. Este tempo inclui apenas o tempo de processamento do MILP caso este tenha encontrado uma solução ótima para a instância, caso contrário, inclui o tempo do MILP mais o tempo do processo de geração de colunas.

Tabela 24: Tempo médio de execução do método em segundos, por fator R e T.

\begin{tabular}{cccc}
\hline \multirow{2}{*}{$\mathrm{T}$} & \multicolumn{3}{c}{$\mathrm{R}$} \\
\cline { 2 - 4 } & 0,2 & 1 & Total \\
\hline 0,2 & 0,1 & 0,3 & 0,23 \\
1 & 1675,4 & 1576,5 & 1625,9 \\
Média & 837,7 & 788,4 & 813,1 \\
\hline
\end{tabular}




\subsection{Resultados da Heurística Construtiva Probabilística}

O algoritmo da heurística construtiva probabilística foi executado na massa da dados considerando o fator $\alpha=0.7$ para as primeiras 500 iterações e $\alpha=0.8$ para as 1500 iterações finais. Totalizando, assim, 2000 soluções construídas. O processo foi interrompido caso o algoritmo encontrasse alguma solução com atraso total ponderado igual a zero. As soluções da heurística construtiva probabilística foram comparadas com o limitante inferior encontrado pelo método de geração de colunas, calculando-se o $G A P_{H E U}$ da seguinte maneira:

$$
G A P_{H E U}=\frac{U P_{H E U}-L B_{C G}}{U P_{H E U}}
$$

Onde $U P_{H E U}$ é o valor de atraso total ponderado da solução encontrada pela heurística construtiva probabilística depois de 2000 iterações, e o $L B_{C G}$ é o limitante inferior encontrado pelo método de geração de colunas como explicado anteriormente.

Na tabela 25, encontram-se os $G A P_{H E U}$ resultantes para esta massa de dados separados por quantidade de atividades e máquinas. Percebe-se que o número de atividades da instância tem um impacto negativo no resultado final da heurística construtiva probabilística. Ou seja, quanto maior é a quantidade de atividades $(j)$, pior será o resultado encontrado.

Tabela 25: $G A P_{H E U}$ médio das instâncias resultante da heurística construtiva probabilística, por quantidade de atividades e máquinas.

\begin{tabular}{cccc}
\hline \multirow{2}{*}{$\mathrm{n}$} & \multicolumn{3}{c}{$\mathrm{m}$} \\
\cline { 2 - 4 } & 3 & 4 & Total \\
\hline 20 & $7,6 \%$ & $7,1 \%$ & $7,3 \%$ \\
25 & $13,0 \%$ & $14,9 \%$ & $14,0 \%$ \\
Total & $10,3 \%$ & $11,0 \%$ & $10,7 \%$ \\
\hline
\end{tabular}

A tabela 26 mostra resultado separado pelos fatores $R$ e $T$, como explicado na seção 4.1.1. Como é possível perceber, instâncias com fator de amplitude e atraso pequenos tem um resultado excelente. Isto acontece porque estas instâncias possuem soluções cm zero atraso total ponderado, e a heurística construtiva probabilística é capaz de encontrar tais soluções facilmente. Por outro lado, soluções que possuem custo de atraso total maior do que zero, ou seja, instâncias cujos fatores $\mathrm{T}$ e R são maiores, obtiveram resultados piores pelo método.

Como o algoritmo executou 2000 iterações para cada instância, o tempo total por 
Tabela 26: $G A P_{H E U}$ médio das instâncias resultante da heurística construtiva probabilística, por fator $\mathrm{R}$ e $\mathrm{T}$.

\begin{tabular}{cccc}
\hline \multirow{2}{*}{$\mathrm{T}$} & \multicolumn{3}{c}{$\mathrm{R}$} \\
\cline { 2 - 4 } & 0,2 & 1 & Total \\
\hline 0,2 & $0,0 \%$ & $12,6 \%$ & $6,3 \%$ \\
1 & $9,4 \%$ & $20,6 \%$ & $15,0 \%$ \\
Total & $4,7 \%$ & $16,6 \%$ & $10,7 \%$ \\
\hline
\end{tabular}

instância variou. Assim, a instância com maior tempo de execução da heurística construtiva probabilística levou 252 segundos e foi uma instância com 25 atividades e 4 máquinas. Na tabela 27, observa-se que os tempos médios de execução do algoritmo da heurística construtiva probabilística é influenciado pela dimensão da instância. Como é de se esperar, quanto maior a instância maior será o tempo de execução do algoritmo da heurística construtiva probabilística.

Tabela 27: Tempo médio de execução da heurística construtiva probabilística em segundos, por quantidade de atividades e máquinas.

\begin{tabular}{cccc}
\hline \multirow{2}{*}{$\mathrm{j}$} & \multicolumn{3}{c}{$\mathrm{m}$} \\
\cline { 2 - 4 } & 3 & 4 & Total \\
\hline 20 & 148,45 & 144,0 & 146,22 \\
25 & 163,59 & 170,37 & 166,9 \\
Total & 156,0 & 157,2 & 156,6 \\
\hline
\end{tabular}

Por outro lado, como é possível observar na tabela 28, se a instância possui alguma solução com custo de atraso total igual a zero, o algoritmo da heurística construtiva probabilística é interrompido rapidamente pois encontra uma solução equivalente.

Tabela 28: Tempo médio de execução da heurística construtiva probabilística em segundos, por fator $\mathrm{R} \mathrm{e} \mathrm{T}$.

\begin{tabular}{cccc}
\hline \multirow{2}{*}{$\mathrm{T}$} & \multicolumn{3}{c}{$\mathrm{R}$} \\
\cline { 2 - 4 } & 0,2 & 1 & Total \\
\hline 0,2 & 1,2 & 178,9 & 90,5 \\
1 & 222,3 & 224,0 & 223,15 \\
Total & 111,7 & 201,4 & 156,6 \\
\hline
\end{tabular}

A figura 11 representa a solução da instância 158, a mesma utilizada anteriormente nos outros métodos, encontrada pela heurística construtiva probabilística. A heurística encontrou uma solução com valor de atraso total ponderado iguala 496,4 e a solução ótima para esta instância possui 490,7 de atraso total ponderado, como demonstrado anteriormente. 


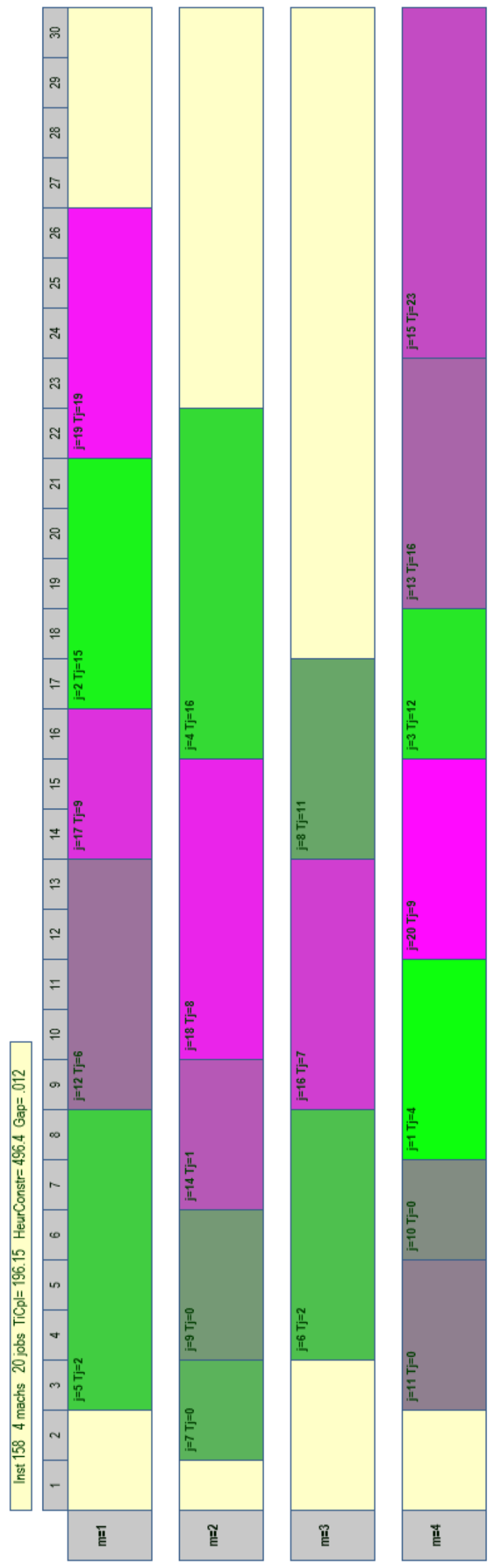

Figura 11: Gráfico de Gantt da solução fornecida pela heurística para a instância 158. 


\section{CONCLUSÃO}

Neste trabalho, foi abordado o problema de minimização do atraso total ponderado no sequenciamento de máquinas diferentes em paralelo com elegibilidade de máquina e tempos de liberação das máquinas e das atividades. Foi apresentado um modelo de programação inteira mista e proposto um método de geração de colunas para obtenção do limitante inferior, assim como foi apresentada uma proposta de heurística construtiva probabilística como discutido por Arcus (1965). O método foi aplicado em instâncias da literatura e em instâncias geradas para, então, exibir e discutir os resultados.

O modelo matemático proposto encontrou soluções com GAP menor do que $1 \%$ (consideradas ótimas neste trabalho) para 182 instâncias das 320 geradas em um tempo médio de 810 segundos. Para as 132 instâncias não resolvidas pelo modelo matemático proposto, um GAP médio de 46,6\% foi obtido. Observou-se que o modelo matemático proposto é eficiente para encontrar limitantes superiores das instâncias geradas sendo, porém, ineficiente para provar a otimalidade das soluções encontradas.

O método de geração de colunas foi executado nas instâncias após o modelo matemático fornecer o limitante superior de cada instância. O algoritmo conseguiu comprovar a otimalidade de 261 soluções das instâncias que foram processadas pelo MILP. As instâncias que não tiveram suas soluções comprovadas como ótimas finalizaram o processo com um GAP médio de 2,2\%. Isto demonstra que o limitante inferior fornecido pelo algoritmo de geração de colunas é de boa qualidade, sendo um importante complemento para o modelo matemático proposto.

O resultado encontrado pelo método combinando o modelo matemático e o algoritmo de geração de colunas demonstra que foi possível encontrar soluções ótimas para $84 \%$ das instâncias geradas, sendo que os $16 \%$ restante obtiveram um GAP final médio de boa qualidade $(2,1 \%)$. No processo como um todo, $57 \%$ das instâncias tiveram soluções ótimas comprovadas no modelo matemático proposto, enquanto outro $27 \%$ tiveram suas soluções comprovadas como ótimas pelo algoritmo de geração de colunas. 
Além disso, foi proposta uma heurística construtiva probabilística como uma extensão da heurística utilizada para gerar a solução inicial do algoritmo de geração de colunas. A heurística probabilística foi implementada de acordo com a proposta de Arcus (1965) e encontrou um GAP médio de 10,6\% para as instâncias em tempos menores do que 252 segundos.

Existem muitas oportunidades de avanço neste trabalho como pesquisas futuras. $\mathrm{O}$ modelo de programação inteira proposto e o método de geração de colunas podem ser facilmente modificados para tratar outros objetivos. Além disso, novas condições do problema podem ser consideradas, como setup dependente de sequência. Neste caso o sub-problema poderá ser tratado como um problema de caixeiro-viajante.

O algoritmo de geração de colunas tem sido implementado na literatura em conjunto com métodos de Branch $\&$ Prince, de maneira a evitar a utilização de dois modelos matemáticos diferentes para o mesmo problema como foi proposto neste trabalho. Outras técnicas para reduzir a quantidade de colunas geradas no algoritmo, como melhorar a solução inicial, e controlar o comportamento do limitante inferior ao longo do processo, como invólucro, também apresentam uma oportunidade de otimizar a execução do algoritmo.

Há também a possibilidade de transformar a solução do método de geração de colunas em soluções viáveis. Estas técnicas podem ser heurísticas ou modificações no próprio método. Por exemplo, as colunas geradas também podem ser tratadas andes de serem adicionadas ao problema mestre para que a solução final do processo de geração de colunas seja uma solução viável. 


\section{REFERÊNCIAS}

AFZALIRAD, M.; REZAEIAN, J. Resource-constrained unrelated parallel machine scheduling problem with sequence dependent setup times, precedence constraints and machine eligibility restrictions. Computers $\&$ Industrial Engineering, Elsevier, v. 98, p. 40-52, 2016.

AKKER, J. Van den; HURKENS, C. A.; SAVELSBERGH, M. W. Time-indexed formulations for machine scheduling problems: Column generation. INFORMS Journal on Computing, INFORMS, v. 12, n. 2, p. 111-124, 2000.

ALLAHVERDI, A.; GUPTA, J. N.; ALDOWAISAN, T. A review of scheduling research involving setup considerations. Omega, Elsevier, v. 27, n. 2, p. 219-239, 1999.

ALLAHVERDI, A. et al. A survey of scheduling problems with setup times or costs. European Journal of Operational Research, Elsevier, v. 187, n. 3, p. 985-1032, 2008.

ARCUS, A. A computer method of sequencing operations for assembly lines. International Journal of Production Research, Taylor \& Francis, v. 4, n. 4, p. 259-277, 1965.

AZIZOGLU, M.; KIRCA, O. On the minimization of total weighted flow time with identical and uniform parallel machines. European Journal of Operational Research, Elsevier, v. 113, n. 1, p. 91-100, 1999.

BARNHART, C. et al. Branch-and-price: Column generation for solving huge integer programs. Operations research, INFORMS, v. 46, n. 3, p. 316-329, 1998.

BEEZÃO, A. C. et al. Scheduling identical parallel machines with tooling constraints. European Journal of Operational Research, Elsevier, v. 257, n. 3, p. 834-844, 2017.

BILYK, A.; MÖNCH, L.; ALMEDER, C. Scheduling jobs with ready times and precedence constraints on parallel batch machines using metaheuristics. Computers $\&$ Industrial Engineering, Elsevier, v. 78, p. 175-185, 2014.

BLAZEWICZ, J.; DROR, M.; WEGLARZ, J. Mathematical programming formulations for machine scheduling: a survey. European Journal of Operational Research, Elsevier, v. 51, n. 3, p. 283-300, 1991.

CASTAÑO, F.; SEVAUX, M. Combining metaheuristics with column generation: Successful approaches to enhance column generation algorithms performance. In: Proceedings of the Sixth International Workshop on Model-based Metaheuristic (Matheuristics 2016). [S.l.: s.n.], 2016. p. 95-100.

CHAUDHRY, I. A.; DRAKE, P. R. Minimizing total tardiness for the machine scheduling and worker assignment problems in identical parallel machines using genetic algorithms. The International Journal of Advanced Manufacturing Technology, Springer, v. 42, n. 5, p. 581-594, 2009. 
CHENG, C.-Y.; HUANG, L.-W. Minimizing total earliness and tardiness through unrelated parallel machine scheduling using distributed release time control. Journal of Manufacturing Systems, Elsevier, v. 42, p. 1-10, 2017.

CHENG, T.; SIN, C. A state-of-the-art review of parallel-machine scheduling research. European Journal of Operational Research, Elsevier, v. 47, n. 3, p. 271-292, 1990.

DANTZIG, G. B.; WOLFE, P. Decomposition principle for linear programs. Operations research, INFORMS, v. 8, n. 1, p. 101-111, 1960.

DESROSIERS, J.; LÜBBECKE, M. E. A primer in column generation. In: Column generation. [S.1.]: Springer, 2005. p. 1-32.

DIJKSTRA, E. W. et al. A discipline of programming. [S.l.]: prentice-hall Englewood Cliffs, 1976. v. 1.

DYER, M. E.; WOLSEY, L. A. Formulating the single machine sequencing problem with release dates as a mixed integer program. Discrete Applied Mathematics, Elsevier, v. 26, n. 2-3, p. 255-270, 1990.

FANJUL-PEYRO, L.; PEREA, F.; RUIZ, R. Mip models and matheuristics for the unrelated parallel machine scheduling problem with additional resources. European Journal of Operational Research, Elsevier, 2017.

FENG, G.; LAU, H. C. Efficient algorithms for machine scheduling problems with earliness and tardiness penalties. Annals of Operations Research, Springer, v. 159, n. 1, p. 83-95, 2008.

G1. 2007. 〈http://g1.globo.com/Noticias/Economia_Negocios/0,,MUL28142-9356, 00-TOYOTA+LIDERA+MERCADO+COM+PRODUCAO+SEM+DESPERDICIOS. html $\rangle$.

GRAHAM, R. L. et al. Optimization and approximation in deterministic sequencing and scheduling: a survey. Annals of discrete mathematics, Elsevier, v. 5, p. 287-326, 1979.

HASSAN, M.-A. et al. Unrelated parallel machine scheduling problem with precedence constraints: Polyhedral analysis and branch-and-cut. In: SPRINGER. International Symposium on Combinatorial Optimization. [S.1.], 2016. p. 308-319.

KARP, R. M. Reducibility among combinatorial problems. In: Complexity of computer computations. [S.l.]: Springer, 1972. p. 85-103.

KUHN, H. W. The hungarian method for the assignment problem. Naval Research Logistics (NRL), Wiley Online Library, v. 52, n. 1, p. 7-21, 2005.

LEE, Y. H.; PINEDO, M. Scheduling jobs on parallel machines with sequence-dependent setup times. European Journal of Operational Research, Elsevier, v. 100, n. 3, p. 464-474, 1997.

LI, K.; YANG, S.-l. Non-identical parallel-machine scheduling research with minimizing total weighted completion times: Models, relaxations and algorithms. Applied mathematical modelling, Elsevier, v. 33, n. 4, p. 2145-2158, 2009. 
LIAW, C.-F. A branch-and-bound algorithm for identical parallel-machine total completion time scheduling problem with preemption and release times. Journal of Industrial and Production Engineering, Taylor \& Francis, v. 33, n. 6, p. 383-390, 2016.

LIAW, C.-F. et al. Scheduling unrelated parallel machines to minimize total weighted tardiness. Computers \& Operations Research, Elsevier, v. 30, n. 12, p. 1777-1789, 2003.

MENSENDIEK, A.; GUPTA, J. N.; HERRMANN, J. Scheduling identical parallel machines with fixed delivery dates to minimize total tardiness. European Journal of Operational Research, Elsevier, v. 243, n. 2, p. 514-522, 2015.

OZTURK, O.; BEGEN, M. A.; ZARIC, G. S. A branch and bound algorithm for scheduling unit size jobs on parallel batching machines to minimize makespan. International Journal of Production Research, Taylor \& Francis, v. 55, n. 6, p. 1815-1831, 2017.

POTTS, C. N.; KOVALYOV, M. Y. Scheduling with batching: A review. European journal of operational research, Elsevier, v. 120, n. 2, p. 228-249, 2000.

RAHMANI, N. et al. A column generation based heuristic for the dial-a-ride problem. In: International Conference on Information Systems, Logistics and Supply Chain (ILS). [S.l.: s.n.], 2016.

RAMBOD, M.; REZAEIAN, J. Robust meta-heuristics implementation for unrelated parallel machines scheduling problem with rework processes and machine eligibility restrictions. Computers \&5 Industrial Engineering, Elsevier, v. 77, p. 15-28, 2014.

RUIZ, R.; ANDRÉS-ROMANO, C. Scheduling unrelated parallel machines with resource-assignable sequence-dependent setup times. The International Journal of Advanced Manufacturing Technology, Springer, v. 57, n. 5, p. 777-794, 2011.

SCHALLER, J. E. Minimizing total tardiness for scheduling identical parallel machines with family setups. Computers 8 Industrial Engineering, Elsevier, v. 72, p. 274-281, 2014.

SIVRIKAYA-ŞERIFOğLU, F.; ULUSOY, G. Parallel machine scheduling with earliness and tardiness penalties. Computers \& Operations Research, Elsevier, v. 26, n. 8, p. 773-787, 1999.

VREDEVELD, T.; HURKENS, C. Experimental comparison of approximation algorithms for scheduling unrelated parallel machines. INFORMS Journal on Computing, INFORMS, v. 14, n. 2, p. 175-189, 2002.

WENG, M. X.; LU, J.; REN, H. Unrelated parallel machine scheduling with setup consideration and a total weighted completion time objective. International journal of production economics, Elsevier, v. 70, n. 3, p. 215-226, 2001.

WILHELM, W. E. A technical review of column generation in integer programming. Optimization and Engineering, Springer, v. 2, n. 2, p. 159-200, 2001.

YALAOUI, F.; CHU, C. Parallel machine scheduling to minimize total tardiness. International Journal of Production Economics, Elsevier, v. 76, n. 3, p. 265-279, 2002. 
ZHU, Z.; HEADY, R. B. Minimizing the sum of earliness/tardiness in multi-machine scheduling: a mixed integer programming approach. Computers $\&$ Industrial Engineering, Elsevier, v. 38, n. 2, p. 297-305, 2000. 


\section{APÊNDICE A - MODELO DE PROGRAMAÇÃO INTEIRA MISTA NO CPLEX}

//TUPLAS E RANGES INPUTS DA RODADA

// cria mRun

range $\mathrm{Rr}=1 \ldots 1$;

tuple Run \{

int iBeg;

int iEnd;

int TiLim;

Run $\operatorname{mRun}[\mathrm{Rr}]=\ldots$;

//TUPLAS E RANGES INPUTS DO OPL Global

// cria mQtdGl

range $\mathrm{Rq}=1 \ldots 1$;

tuple QtdGl \{

int iQtdGl;

int jQtdGl ;

int mQtdGl;

int jmQtdGl;\}

QtdGl mQtdGl $[\mathrm{Rq}]=\ldots$;

// cria ranges

range $R i=1 \ldots \operatorname{mQtdGl}[1] . \mathrm{iQtdGl} ; \quad$ range $\mathrm{Rj}=1 \ldots \operatorname{mQtdGl}[1] . j Q t d G l$;

range $\mathrm{Rm}=1 . . \mathrm{mQtdGl}[1] . \mathrm{mQtdGl} ; \quad$ range $\mathrm{Rjm}=1 . . \mathrm{mQtdGl}[1] . j \mathrm{mQtdGl}$; 
//TUPLAS INPUTS DAS INSTANCIAS

// cria moq

tuple oq \{

int Inst;

int QtdFx1;

int $\mathrm{bFx} 1$;

int eFx1;

int QtdFx2;

int $\mathrm{bFx} 2$;

int eFx2;

int QtdFx3;

int $\mathrm{bFx} 3$;

int eFx3;

int $\mathrm{QtdFx} 4$;

int $\mathrm{bFx}_{4}$;

int $\mathrm{eFx} 4 ;\}$

oq $\operatorname{moq}[\mathrm{Ri}]=\ldots$;

// cria moi

tuple oi \{

int Inst;

float $\mathrm{Mi} ;\}$

oi $\operatorname{moi}[\mathrm{Ri}]=\ldots$;

//cria oj

tuple oj \{

int Inst;

int $\mathrm{j}$;

float $\mathrm{Rj}$;

float $D_{j}$;

float $\operatorname{tcj} ;\}$

oj $\operatorname{moj}[R j]=\ldots$;

//cria om

tuple om \{

int Inst; 
int $\mathrm{m}$;

float $\mathrm{Rm} ;\}$

om mom $[\mathrm{Rm}]=\ldots$;

// cria ojm

tuple ojm \{

int Inst;

int $\mathrm{j}$;

int $\mathrm{m}$;

float Pjm;

float CjmMin;

int $\operatorname{Linm} ;\}$

ojm $\operatorname{mojm}[\operatorname{Rjm}]=\ldots$;

/ /PARAMETROS DO CPLEX

execute PARAMS $\{$ cplex.tilim=mRun $[1]$. TiLim $;\}$

\section{/ /DADOS GLOBAIS}

//passa instancia para o Mod

int Insts $[1 \ldots 1]=\ldots ; \quad$ int $\operatorname{viBeg}=\operatorname{mRun}[1]$. iBeg;

int InstLin=Insts[1]-viBeg +1 ;

\section{/ /DADOS DA INSTANCIA}

float $v M i=m o i[$ InstLin $] . M i$;

//VARIAVEIS DE DECISAO

dvar boolean Z[Rjm];

dvar boolean $\mathrm{Z1}[\mathrm{Rj}][\mathrm{Rj}]$;

dvar boolean Z2[Rj][Rj];

dvar float $+\mathrm{T}[\mathrm{Rj}]$;

dvar float $C[R j]$;

dvar float $\mathrm{P}[\mathrm{Rj}]$;

dvar float TW;

dvar float CT;

/ /FUNCAO OBJETIVO

minimize TW;

/ /RESTRICOES

subject to \{ 
forall( Linj in $R j: \operatorname{moj}[\operatorname{Linj}] . \operatorname{Inst}=\operatorname{Insts}[1])$

$\operatorname{sum}(\operatorname{Linjm}$ in Rjm: $\operatorname{mojm}[\operatorname{Linjm}]$. Inst=Insts [1] \&\& -

$\operatorname{mojm}[\operatorname{Linjm}] \cdot \mathrm{j}=\operatorname{moj}[\operatorname{Linj}] \cdot \mathrm{j}) \mathrm{Z}[\operatorname{Linjm}]==1$;

forall(Linim in Rjm, Linjm in Rjm: mojm[Linim]. Inst==Insts [1] \&\&_

$\operatorname{mojm}[\operatorname{Linjm}]$. Inst $=\operatorname{Insts}[1] \& \& \operatorname{mojm}[\operatorname{Linim}] . \mathrm{m}=\operatorname{mojm}[\operatorname{Linjm}] . \mathrm{m})$

$\mathrm{Z} 1[\operatorname{mojm}[\operatorname{Linim}] \cdot \mathrm{j}][\operatorname{mojm}[\operatorname{Linjm}] \cdot \mathrm{j}]+_{-}$

$\mathrm{Z} 2[\operatorname{mojm}[\operatorname{Linim}] \cdot \mathrm{j}][\operatorname{mojm}[\operatorname{Linjm}] \cdot \mathrm{j}]>=\mathrm{Z}[\operatorname{Linim}]+\mathrm{Z}[\operatorname{Linjm}]-1$;

forall(Lini in $\mathrm{Rj}$, Linj in $\mathrm{Rj}: \operatorname{Lini}<\operatorname{Linj} \& \& \operatorname{moj}[\operatorname{Lini}$. Inst=Insts [1] \&\&_ $\operatorname{moj}[\operatorname{Linj}] . \operatorname{Inst}=\operatorname{Insts}[1])\{$

$\mathrm{C}[\operatorname{moj}[\operatorname{Linj}] . \mathrm{j}]>=\mathrm{C}[\operatorname{moj}[\operatorname{Lini}] . \mathrm{j}]+\mathrm{P}[\operatorname{moj}[\operatorname{Linj}] . \mathrm{j}]-$

$-(1-\mathrm{Z} 1[\operatorname{moj}[\mathrm{Lini}] \cdot \mathrm{j}][\operatorname{moj}[\operatorname{Linj}] \cdot \mathrm{j}]) * \mathrm{vMi}$

$\mathrm{C}[\operatorname{moj}[\operatorname{Lini}] \cdot \mathrm{j}]>=\mathrm{C}[\operatorname{moj}[\operatorname{Linj}] \cdot \mathrm{j}]+\mathrm{P}[\operatorname{moj}[\operatorname{Lini}] \cdot \mathrm{j}]-$

$-(1-\mathrm{Z} 2[\operatorname{moj}[\operatorname{Lini}] \cdot \mathrm{j}][\operatorname{moj}[\operatorname{Linj}] \cdot \mathrm{j}]) * \mathrm{vMi} ;\}$

forall(Linjm in Rjm: $\operatorname{mojm}[\operatorname{Linjm}]$. Inst=Insts [1])

$\mathrm{C}[\operatorname{mojm}[\operatorname{Linjm}] \cdot \mathrm{j}]>=\operatorname{mojm}[\operatorname{Linjm}] . \operatorname{CjmMin} * \mathrm{Z}[\operatorname{Linjm}]$;

forall(Linj in $\mathrm{Rj}: \operatorname{moj}[\operatorname{Linj}]$. Inst=Insts [1]) \{

$\mathrm{P}[\operatorname{moj}[\operatorname{Linj}] . \mathrm{j}]==\operatorname{sum}(\operatorname{Linjm}$ in $\operatorname{Rjm}: \operatorname{mojm}[\operatorname{Linjm}]$. Inst=Insts [1]

$\& \& \operatorname{mojm}[\operatorname{Linjm}] \cdot j=\operatorname{moj}[\operatorname{Linj}] \cdot j)$

$\operatorname{mojm}[\operatorname{Linjm}]$. Pjm*Z[Linjm ];

$\mathrm{T}[\operatorname{moj}[\operatorname{Linj}] . j]>=\mathrm{C}[\operatorname{moj}[\operatorname{Linj}] \cdot \mathrm{j}]-\operatorname{moj}[\operatorname{Linj}] . \operatorname{Dj} ;$

$\mathrm{CT}>=\mathrm{C}[\operatorname{moj}[\operatorname{Linj}] \cdot \mathrm{j}] ;\}$

$\operatorname{TW}=\operatorname{sum}(\operatorname{Linj}$ in $\operatorname{Rj}: \operatorname{moj}[\operatorname{Linj}]$. Inst=Insts[1])

$\operatorname{moj}[\operatorname{Linj}] . \operatorname{tcj} * \mathrm{~T}[\operatorname{moj}[\operatorname{Linj}] . j] ;\}$ 


\title{
APÊNDICE B - CÓDIGO FONTE DA HEURÍSTICA CONSTRUTIVA PROBABILÍSTICA
}

\author{
import pandas as pd \\ import threading \\ import time \\ import DataReader as dr \\ from numpy import $\mathrm{NaN}$ \\ import numpy as np
}

pd.options.mode.chained_assignment = None \# default='warn'

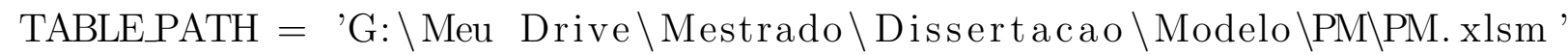

def Heuristica(inst, Qnt_jobs, Qnt_maq, candidatos, vies, it):

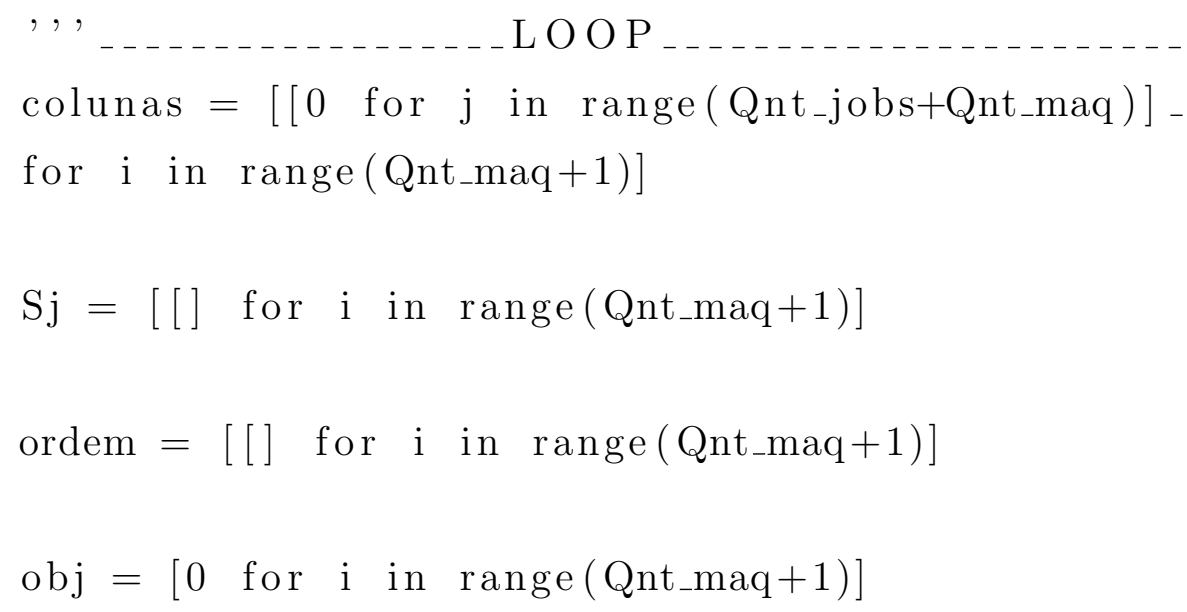


while candidatos. size $>0$ :

np. random. RandomState

try :

sorteado =candidatos.sample $(\mathrm{n}=1$, weights=candidatos ['vies '] $)$ except :

print (candidatos)

raise

$\operatorname{maq}=\operatorname{int}($ sorteado.index. labels $[0]+1)$

job $=$ int ( sorteado.index. labels $[1]+1)$

t0 $=\operatorname{int}($ sorteado [ ['Tm', 'Rm', ' Rj'] ] . $\max ($ axis $=1))$

$\operatorname{ordem}[\mathrm{maq}]$. append (job)

colunas [maq] [job+Qnt_maq-1] $=1$

colunas $[\mathrm{maq}][\mathrm{maq}-1]=1$

$\mathrm{Sj}[\mathrm{maq}]$. append ( to )

$\operatorname{atraso}=\max \left(0, \operatorname{int}\left(\mathrm{t} 0+\operatorname{sorteado}\left[\right.\right.\right.$ 'Pjm'] $-\operatorname{sorteado}\left[{ }^{\prime} \mathrm{Dj}\right.$ '] $\left.)\right)$

$\operatorname{obj}[\mathrm{maq}]=\operatorname{obj}[\mathrm{maq}]+\operatorname{atraso} * \mathrm{float}\left(\operatorname{sorteado}\left[{ }^{\prime} \operatorname{tcj}{ }^{\prime}\right]\right)$

,,,

ATUALIZA DADOS ,,,

candidatos $=$ -

candidatos.drop(candidatos [candidatos.index . labels $[1]+1==$ job ] . index)

candidatos ['Tm'] [ candidatos.index. labels $[0]+1==$ maq $]=$ t0 $+_{-}$ int ( sorteado['Pjm'])

if (candidatos ['Tm']. size > 1) and vies $>1$ :

candidatos ['Cj'] $=($ candidatos ['Pjm']) + candidatos ['Tm']

if vies $=2$ :

candidatos ['vies '] $=($ candidatos ['cjm'])

elif vies $=3$ : 


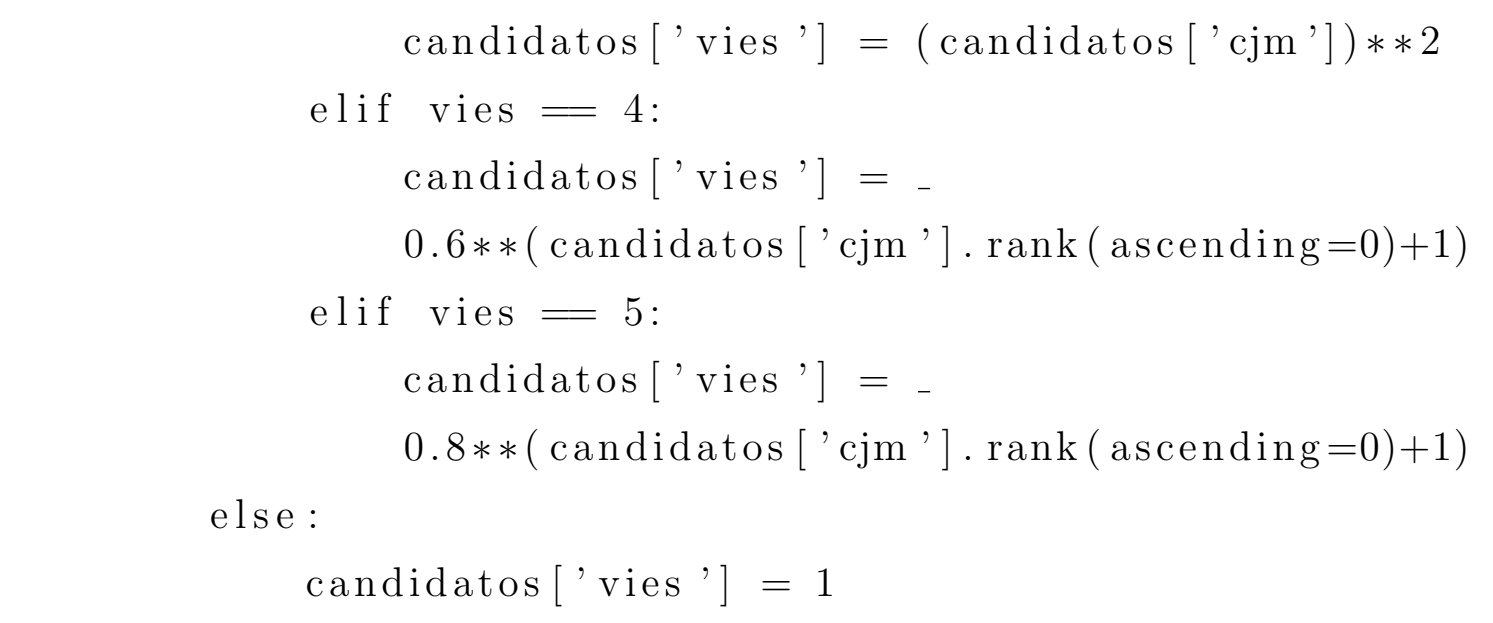

return colunas, $\mathrm{Sj}, \mathrm{obj}$, ordem

\section{,,,$\ldots \ldots$ L R D A D O S}

def HeuristicaLoop ( ):

matriz_ii_Global, matriz_ij_Global, matriz_im_Global , _ matriz_ijm_Global $=$ dr. DataRead $($ TABLEPATH $)$

vies $=4$

iteracoes $=2000$

, , _..........Seleciona dados da instancia_...................,

for inst in matriz_ii_Global['Inst'] :

matriz_ij= matriz_ij_Global [( matriz_ij_Global. Inst=inst)]

matriz_im = matriz_im_Global [( matriz_im_Global.Inst=inst)]

matriz_ijm = matriz_ijm_Global [( matriz_ijm_Global.Inst=inst)]

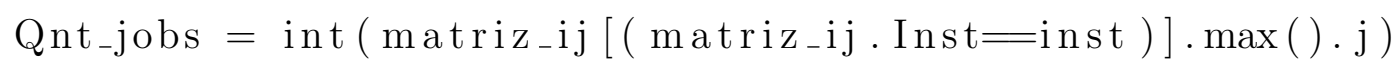

Qnt_maq $=\operatorname{int}($ matriz_im $[($ matriz_im $\cdot$ Inst=inst $)] \cdot \max () \cdot m)$

,,,$\ldots$ C A L C U L OS

candidatos $=$ PreparaCandidatos (matriz_ij, matriz_im , matriz_ijm, vies )

,,,

HEUR IS T I C A

start_heuristicainicial = time.time ()

incumbente $=999999$

for i in range(iteracoes):

candidatos_iteracao $=$ pd. DataFrame(candidatos) 


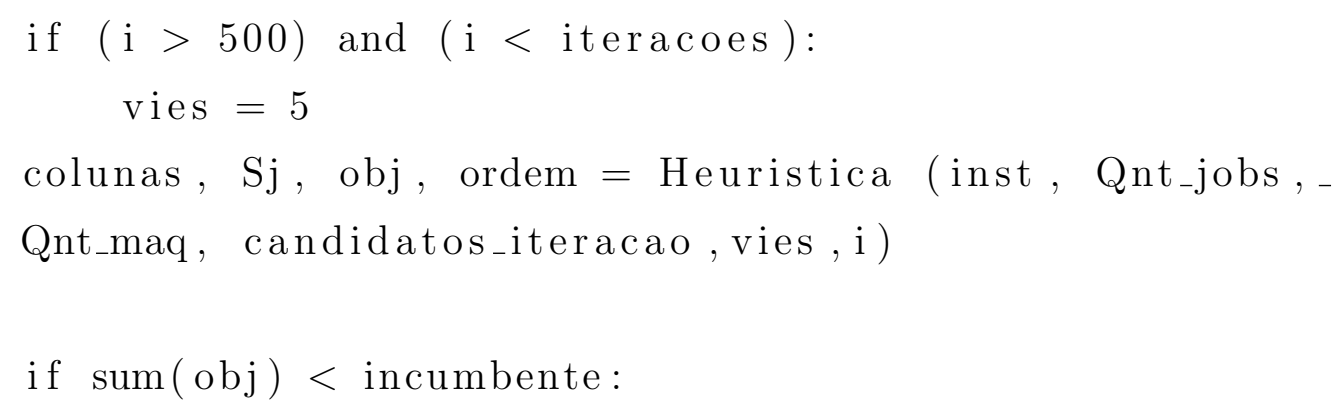

def PreparaCandidatos(matriz_ij, matriz_im, matriz_ijm, vies ):

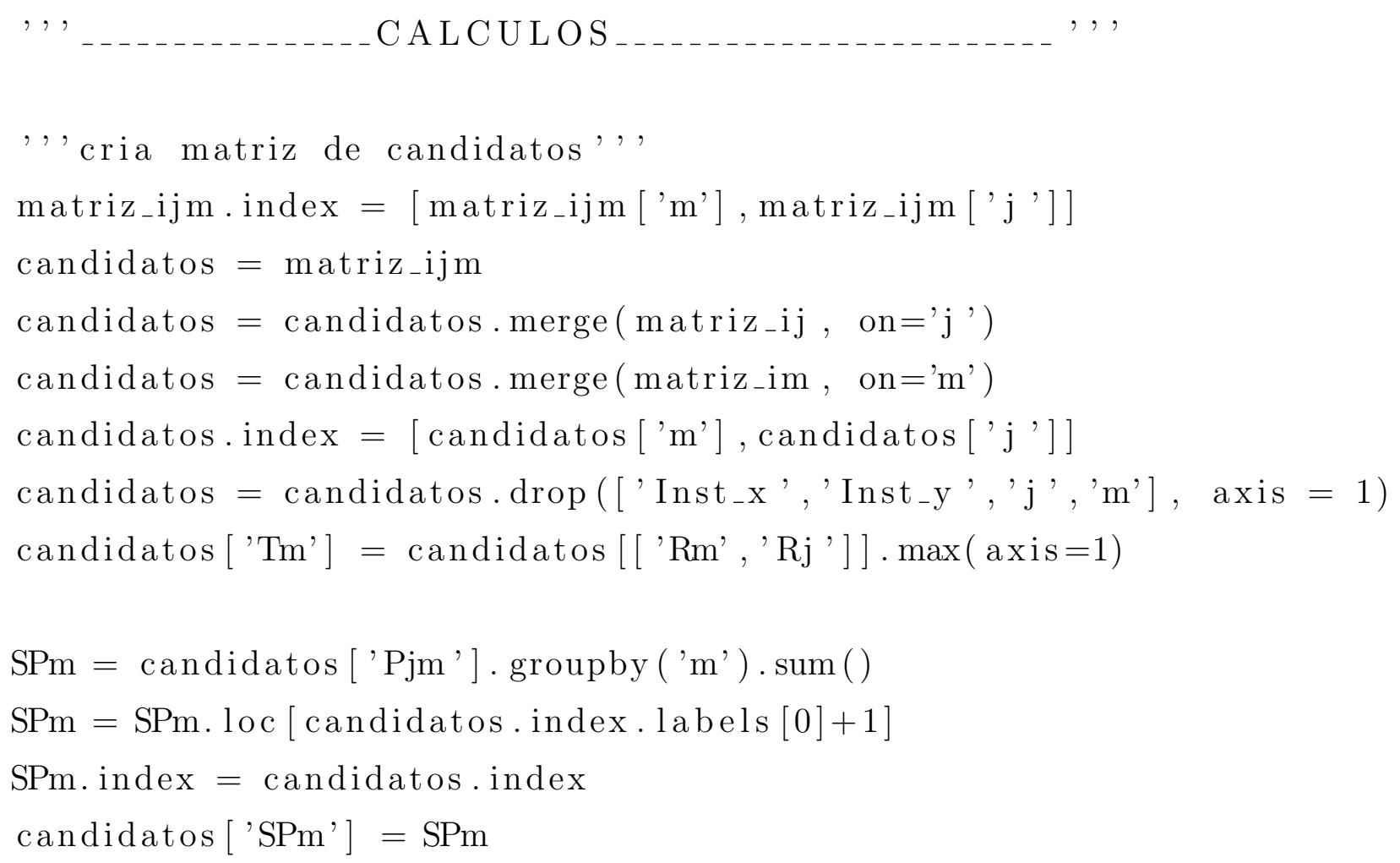




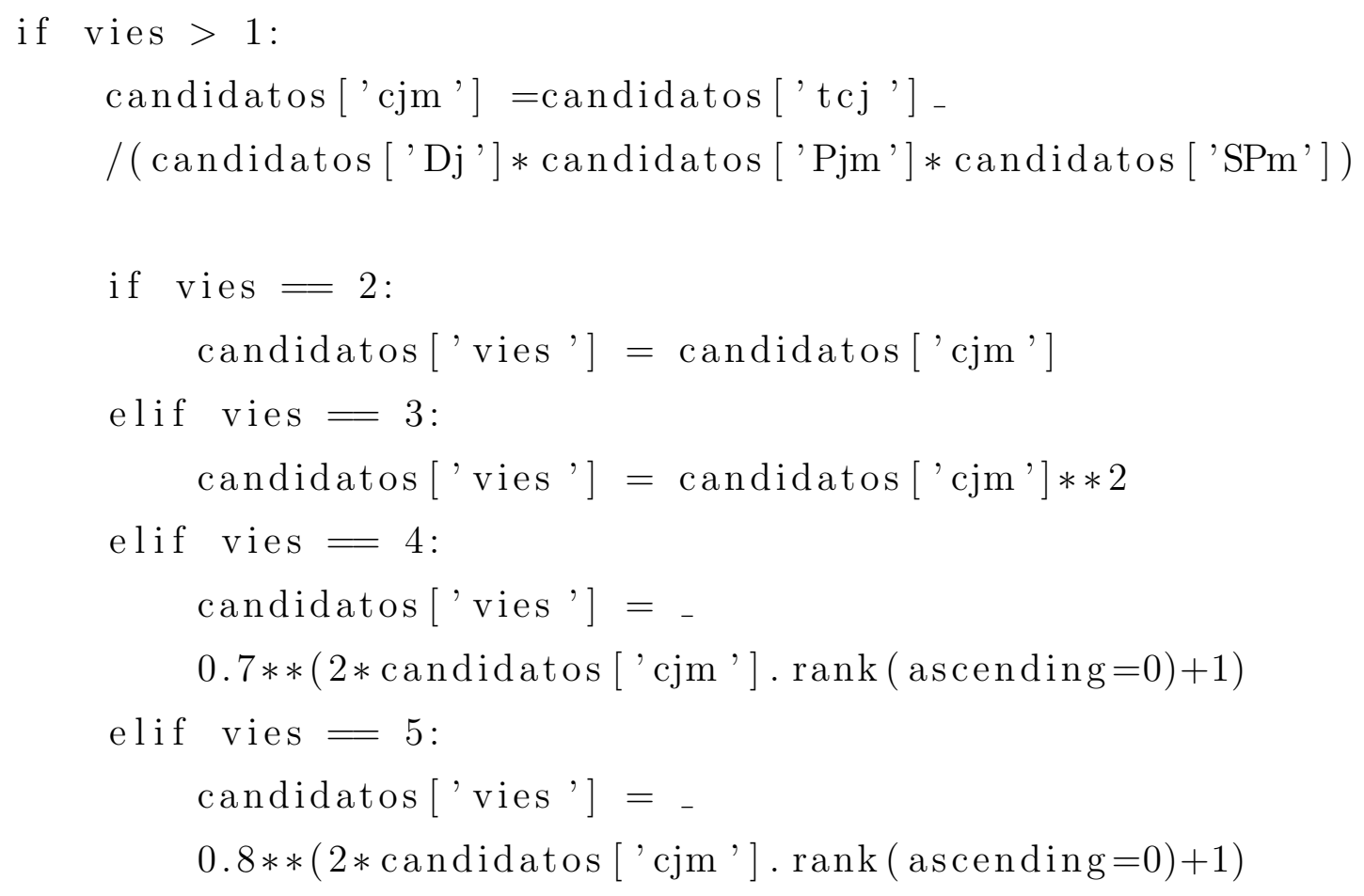

else:

candidatos ['vies'] $=1$

return candidatos

def GravaSolucao(incumbente, ordem, Sj, matriz_ij, matriz_im, matriz_ijm):

Oui $=$ pd. DataFrame (columns $=$ ['Inst ', 'jQtd' , 'mQtd' , 'jmQtd' , 'Mode', 'Tilim , , 'TiCpl ', 'UBVal' , 'LBVal' _

, 'Gap', 'Status', 'tQtd'], index $=[1]$ )

Oui.loc $[1]=$ -

[ matriz_ij ['Inst'] [1], matriz_ij ['j']. size, matriz_im ['m'] -

. size, matriz_ijm ['j']. size ,-

'HeurConstr' , 0,0 , incumbente , $0,0,0,0]$

Ouijm $=$ pd. DataFrame (columns $=$ ['Inst ', ' j ', ' $m$ ', ' $\mathrm{Sj}$ ', , $\mathrm{Pj}$ '

, ' $\left.\mathrm{Cj}{ }^{\prime},{ }^{\prime} \mathrm{Dj},{ }^{\prime}, \mathrm{Tj}^{\prime}\right]$ )

Ouijm [' ${ }^{\prime}$ '] $=$ matriz_ij $\left[{ }^{\prime} j^{\prime}\right]$

Ouijm ['Inst'] = matriz_ij ['Inst'][1]

for $m$ in range $(1$, len (ordem $))$ : 


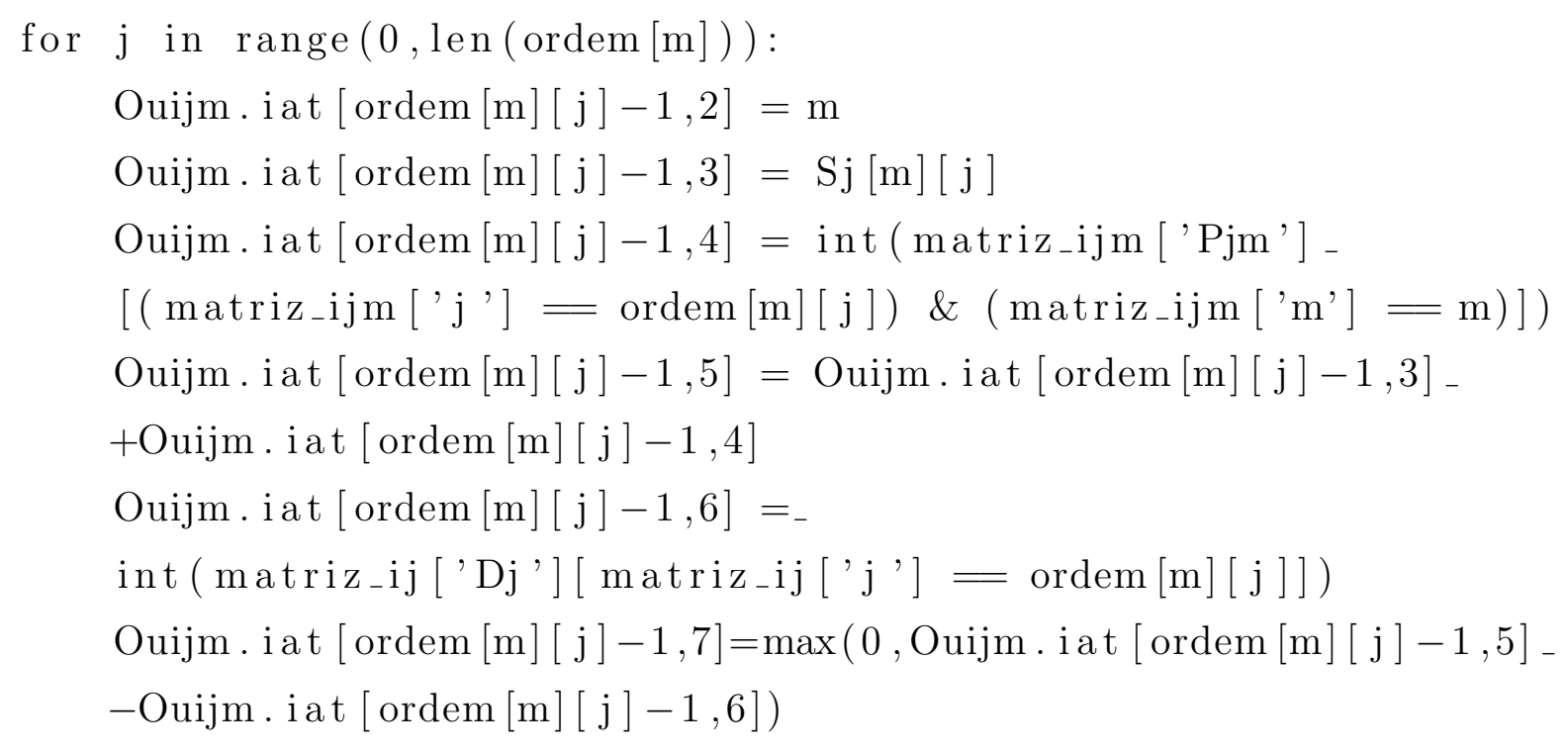

Oui.to_csv ( r 'G: \Meu Drive $\backslash$ Mestrado $\backslash$ Dissertacao $\backslash$ Modelo $\backslash P M \backslash$ Oui . txt ' , sep $=$ ';', index $=$ False, header $=$ False )

Ouijm.to_csv ( r 'G: \Meu Drive $\backslash$ Mestrado $\backslash$ Dissertacao $\backslash$ Modelo $\backslash P M \backslash$ Oujm.txt, sep $=$ ';', index $=$ False, header $=$ False)

if _-_name_- ' '-_main_- ':

HeuristicaLoop () 


\section{APÊNDICE C - CODIGO FONTE DO MÉTODO DE GERAÇÃO DE COLUNAS}

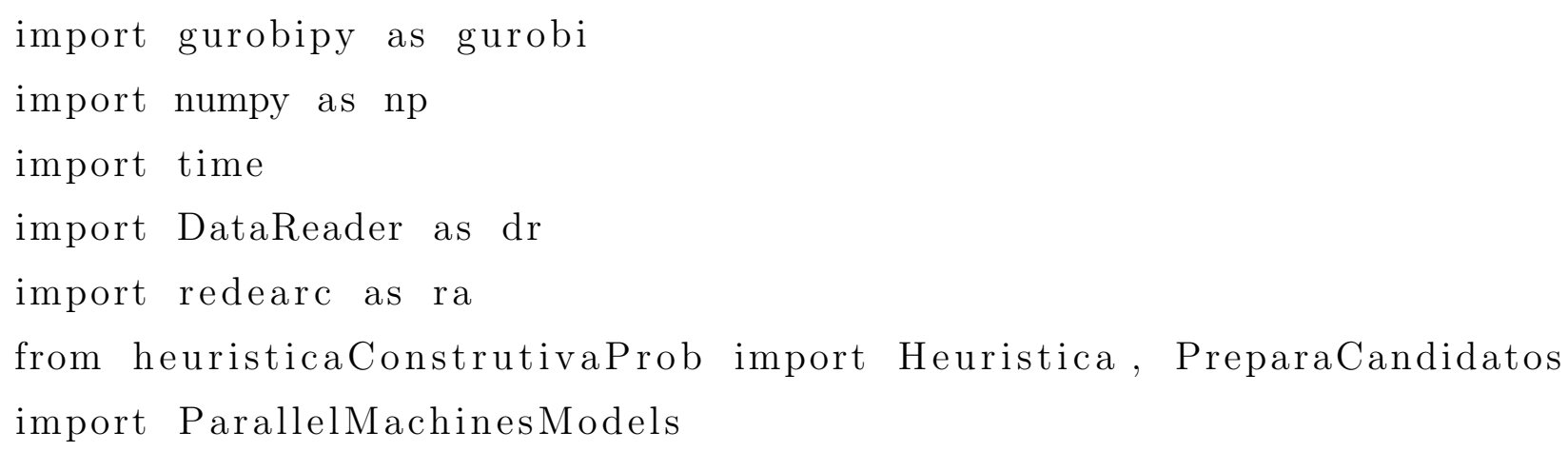




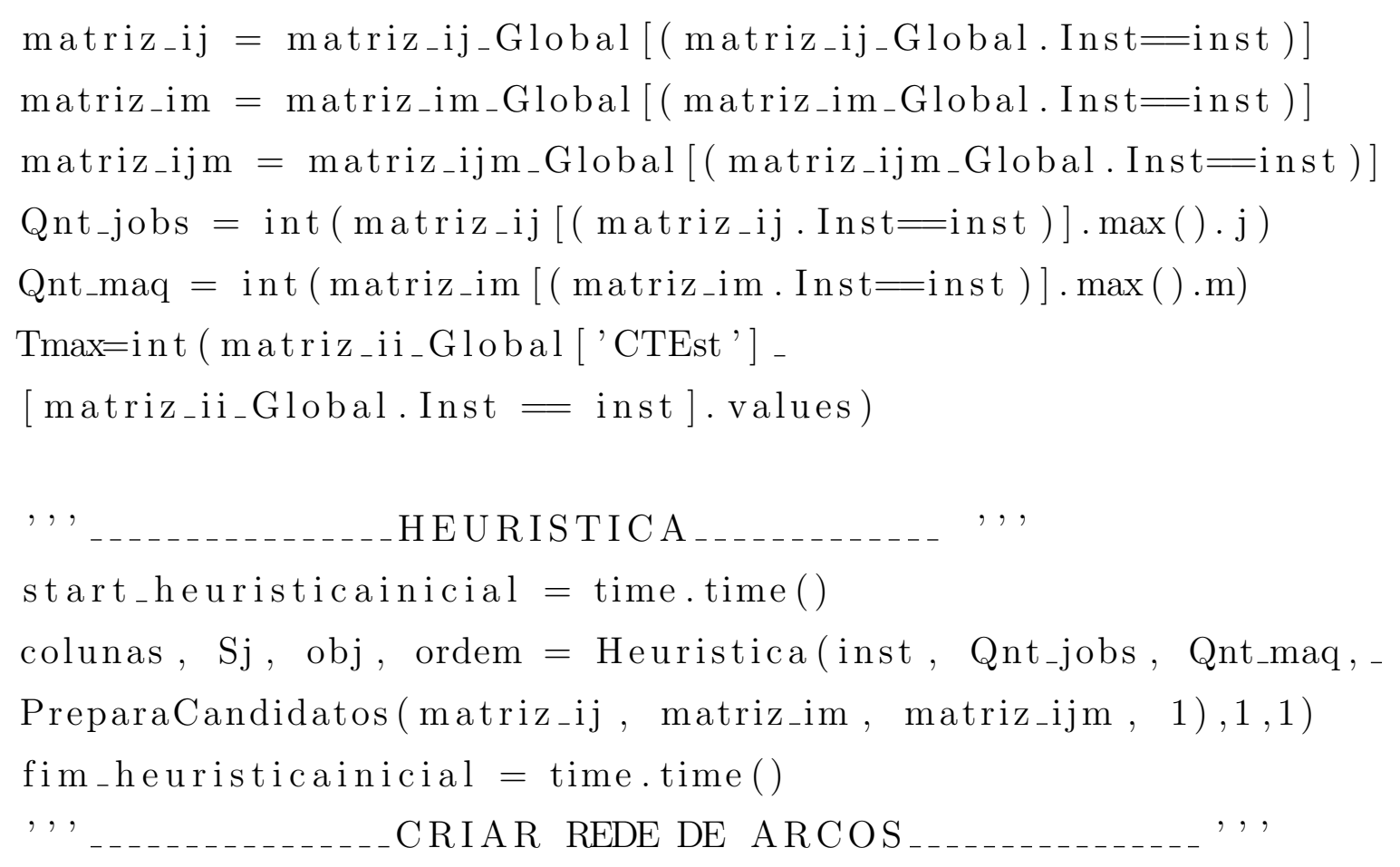

start_redeArc $=$ time.time ()

ArcNetwork = ra. CreateNetwork (Qnt_maq, Qnt_jobs, Tmax, inst , matriz_im, matriz_ij, matriz_ijm)

fim_redearc $=$ time.time ()

,, PROBLEMA MESTRE ,,

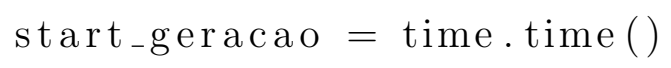

pi, contador_colunas, $m$, lamb, constr_cap , -

$\mathrm{c} 1$ = ParallelMachinesModels. MasterProb(colunas, obj , Qnt_maq, Qnt_jobs )
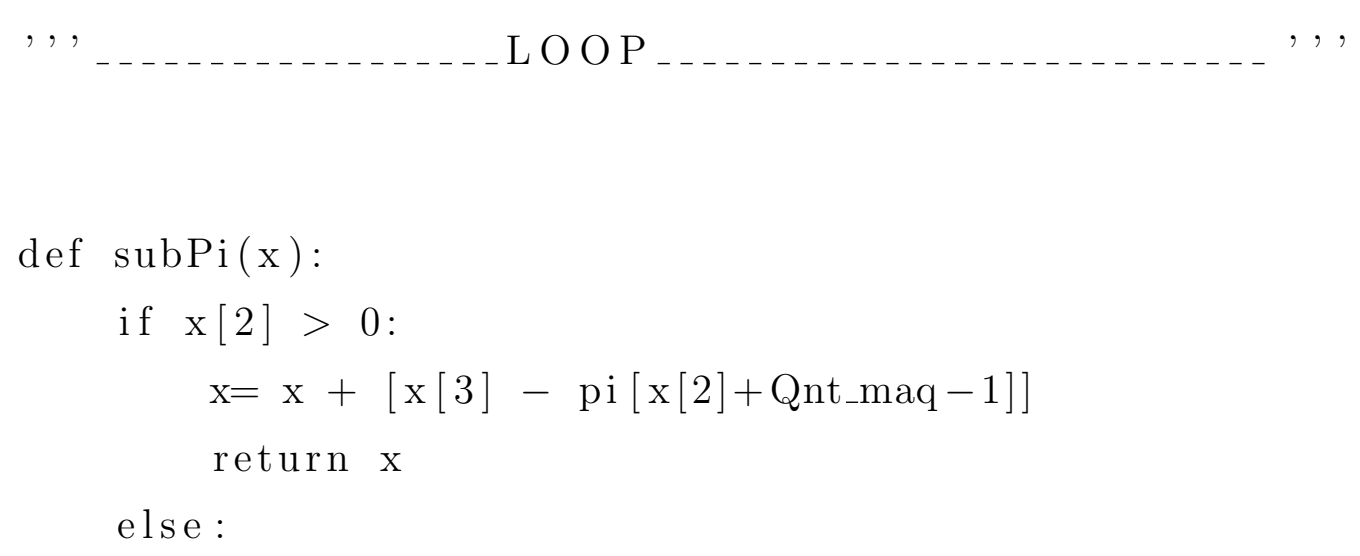


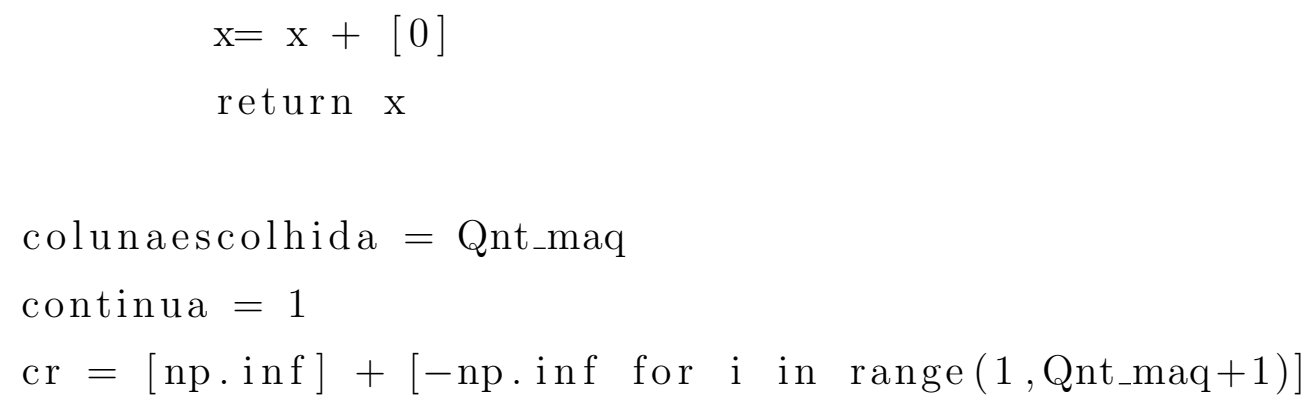

while len (unvisited) $>0$ :

vizinhos $=\operatorname{set}([(\mathrm{t} 0, \mathrm{t} 1, \mathrm{j}, \mathrm{c}, \mathrm{cr})$ for $\mathrm{t} 0$, $\mathrm{t} 1, \mathrm{j}, \mathrm{c}, \mathrm{cr}$ in redeCaminhoMinimo[maquina] if $(\mathrm{t} 0=\mathrm{current})])$

for $v$ in vizinhos: 


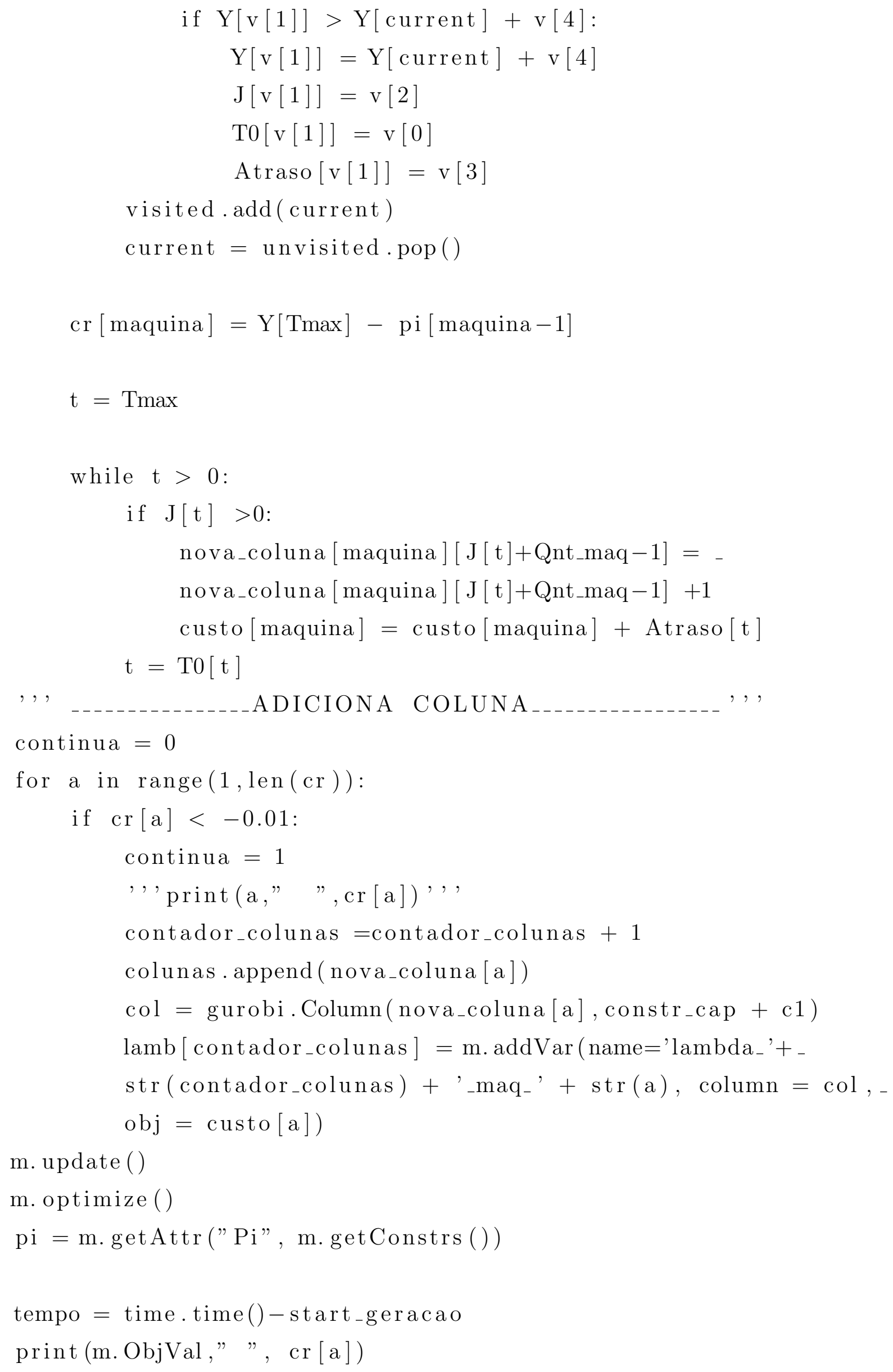




\section{APÊNDICE D - EXEMPLO DE ESTRUTURA DE DADOS}

\begin{tabular}{|c|c|c|c|c|c|c|c|}
\hline Inst & $\mathrm{j}$ & $\mathrm{Rj}$ & $\mathrm{Dj}$ & $\mathrm{tcj}$ & Inst & $\mathrm{m}$ & $\mathrm{Rm}$ \\
\hline 1 & 1 & 2 & 10 & 5,3 & 1 & 1 & 1 \\
\hline 1 & 2 & 2 & 31 & 7,1 & 1 & 2 & 0 \\
\hline 1 & 3 & 1 & 31 & 9,6 & 1 & 3 & 2 \\
\hline 1 & 4 & 2 & 64 & 0,5 & 2 & 1 & 2 \\
\hline 1 & 5 & 1 & 34 & 8,3 & 2 & 2 & 0 \\
\hline 1 & 6 & 1 & 23 & 7 & 2 & 3 & 2 \\
\hline 1 & 7 & 2 & 32 & 0,2 & 3 & 1 & 1 \\
\hline 1 & 8 & 1 & 72 & 3,8 & 3 & 2 & 1 \\
\hline 1 & 9 & 0 & 74 & 1,6 & 3 & 3 & 2 \\
\hline 1 & 10 & 1 & 35 & 1,9 & & & \\
\hline 1 & 11 & 1 & 70 & 2,9 & & & \\
\hline 1 & 12 & 2 & 58 & 6,9 & & & \\
\hline 1 & 13 & 3 & 60 & 4,3 & & & \\
\hline 1 & 14 & 1 & 40 & 0,6 & & & \\
\hline 1 & 15 & 0 & 40 & 4,7 & & & \\
\hline 1 & 16 & 2 & 58 & 5,1 & & & \\
\hline 1 & 17 & 2 & 40 & 8,3 & & & \\
\hline 1 & 18 & 0 & 24 & 5,4 & & & \\
\hline 1 & 19 & 2 & 27 & 4,5 & & & \\
\hline 1 & 20 & 2 & 71 & 0,9 & & & \\
\hline 2 & 1 & 1 & 24 & 9,3 & & & \\
\hline 2 & 2 & 1 & 26 & 6,7 & & & \\
\hline 2 & 3 & 1 & 36 & 2,4 & & & \\
\hline
\end{tabular}




\begin{tabular}{|c|c|c|c|c|}
\hline 2 & 4 & 3 & 33 & 5,9 \\
\hline 2 & 5 & 0 & 58 & 6,3 \\
\hline 2 & 6 & 0 & 42 & 4,8 \\
\hline 2 & 7 & 3 & 41 & 5,4 \\
\hline 2 & 8 & 3 & 33 & 3,4 \\
\hline 2 & 9 & 2 & 25 & 5,4 \\
\hline 2 & 10 & 3 & 27 & 3,7 \\
\hline 2 & 11 & 1 & 69 & 8,8 \\
\hline 2 & 12 & 0 & 27 & 8,1 \\
\hline 2 & 13 & 1 & 70 & 4,6 \\
\hline 2 & 14 & 2 & 70 & 5,6 \\
\hline 2 & 15 & 1 & 49 & 9 \\
\hline 2 & 16 & 0 & 11 & 4,3 \\
\hline 2 & 17 & 2 & 48 & 4,2 \\
\hline 2 & 18 & 0 & 46 & 6,5 \\
\hline 2 & 19 & 2 & 11 & 4,9 \\
\hline 2 & 20 & 2 & 2 & 1,4 \\
\hline 3 & 1 & 2 & 85 & 5 \\
\hline 3 & 2 & 2 & 74 & 8 \\
\hline 3 & 3 & 3 & 67 & 4,2 \\
\hline 3 & 4 & 0 & 26 & 1,7 \\
\hline 3 & 5 & 3 & 5 & 5 \\
\hline 3 & 6 & 1 & 8 & 4,5 \\
\hline 3 & 7 & 2 & 63 & 9,3 \\
\hline 3 & 8 & 1 & 47 & 3,5 \\
\hline 3 & 9 & 1 & 21 & 8,1 \\
\hline 3 & 10 & 2 & 6 & 3,1 \\
\hline 3 & 11 & 1 & 34 & 9,4 \\
\hline 3 & 12 & 2 & 83 & 2,5 \\
\hline 3 & 13 & 1 & 84 & 3,8 \\
\hline 3 & 14 & 3 & 28 & 1,1 \\
\hline 3 & 15 & 1 & 63 & 4,9 \\
\hline 3 & 16 & 1 & 3 & 4,1 \\
\hline 3 & 17 & 1 & 67 & 9,9 \\
\hline 3 & 18 & 3 & 84 & 8,2 \\
\hline 3 & 19 & 3 & 80 & 8,7 \\
\hline
\end{tabular}




$\begin{array}{lllll}3 & 20 & 2 & 41 & 7,9\end{array}$

\begin{tabular}{|c|c|c|c|}
\hline Inst & $\mathrm{j}$ & $\mathrm{m}$ & Pjm \\
\hline 1 & 1 & 1 & 4 \\
\hline 1 & 2 & 1 & 5 \\
\hline 1 & 4 & 1 & 5 \\
\hline 1 & 7 & 1 & 3 \\
\hline 1 & 8 & 1 & 8 \\
\hline 1 & 9 & 1 & 5 \\
\hline 1 & 10 & 1 & 3 \\
\hline 1 & 13 & 1 & 5 \\
\hline 1 & 14 & 1 & 9 \\
\hline 1 & 15 & 1 & 6 \\
\hline 1 & 16 & 1 & 3 \\
\hline 1 & 17 & 1 & 4 \\
\hline 1 & 18 & 1 & 5 \\
\hline 1 & 19 & 1 & 3 \\
\hline 1 & 1 & 2 & 7 \\
\hline 1 & 3 & 2 & 8 \\
\hline 1 & 4 & 2 & 6 \\
\hline 1 & 5 & 2 & 9 \\
\hline 1 & 6 & 2 & 5 \\
\hline 1 & 7 & 2 & 7 \\
\hline 1 & 9 & 2 & 6 \\
\hline 1 & 10 & 2 & 8 \\
\hline 1 & 11 & 2 & 6 \\
\hline 1 & 13 & 2 & 5 \\
\hline 1 & 14 & 2 & 5 \\
\hline 1 & 15 & 2 & 3 \\
\hline 1 & 17 & 2 & 3 \\
\hline 1 & 20 & 2 & 5 \\
\hline 1 & 1 & 3 & 7 \\
\hline 1 & 3 & 3 & 5 \\
\hline 1 & 4 & 3 & 4 \\
\hline 1 & 6 & 3 & 10 \\
\hline
\end{tabular}




\begin{tabular}{|c|c|c|}
\hline 1 & 7 & 3 \\
\hline 1 & 8 & 3 \\
\hline 1 & 9 & 3 \\
\hline 1 & 10 & 3 \\
\hline 1 & 11 & 3 \\
\hline 1 & 12 & 3 \\
\hline 1 & 13 & 3 \\
\hline 1 & 14 & 3 \\
\hline 1 & 16 & 3 \\
\hline 1 & 17 & 3 \\
\hline 1 & 18 & 3 \\
\hline 1 & 20 & 3 \\
\hline 2 & 1 & 1 \\
\hline 2 & 2 & 1 \\
\hline 2 & 3 & 1 \\
\hline 2 & 5 & 1 \\
\hline 2 & 6 & 1 \\
\hline 2 & 7 & 1 \\
\hline 2 & 8 & 1 \\
\hline 2 & 9 & 1 \\
\hline 2 & 10 & 1 \\
\hline 2 & 11 & 1 \\
\hline 2 & 12 & 1 \\
\hline 2 & 13 & 1 \\
\hline 2 & 14 & 1 \\
\hline 2 & 16 & 1 \\
\hline 2 & 18 & 1 \\
\hline 2 & 20 & 1 \\
\hline 2 & 1 & 2 \\
\hline 2 & 2 & 2 \\
\hline 2 & 3 & 2 \\
\hline 2 & 5 & 2 \\
\hline 2 & 6 & 2 \\
\hline 2 & 8 & 2 \\
\hline 2 & 9 & 2 \\
\hline 2 & 10 & 2 \\
\hline
\end{tabular}




\begin{tabular}{|c|c|c|}
\hline 2 & 11 & 2 \\
\hline 2 & 12 & 2 \\
\hline 2 & 13 & 2 \\
\hline 2 & 15 & 2 \\
\hline 2 & 17 & 2 \\
\hline 2 & 18 & 2 \\
\hline 2 & 19 & 2 \\
\hline 2 & 20 & 2 \\
\hline 2 & 3 & 3 \\
\hline 2 & 4 & 3 \\
\hline 2 & 5 & 3 \\
\hline 2 & 6 & 3 \\
\hline 2 & 7 & 3 \\
\hline 2 & 8 & 3 \\
\hline 2 & 9 & 3 \\
\hline 2 & 10 & 3 \\
\hline 2 & 11 & 3 \\
\hline 2 & 17 & 3 \\
\hline 2 & 18 & 3 \\
\hline 2 & 19 & 3 \\
\hline 2 & 20 & 3 \\
\hline 3 & 1 & 1 \\
\hline 3 & 2 & 1 \\
\hline 3 & 3 & 1 \\
\hline 3 & 4 & 1 \\
\hline 3 & 5 & 1 \\
\hline 3 & 6 & 1 \\
\hline 3 & 7 & 1 \\
\hline 3 & 8 & 1 \\
\hline 3 & 11 & 1 \\
\hline 3 & 13 & 1 \\
\hline 3 & 14 & 1 \\
\hline 3 & 16 & 1 \\
\hline 3 & 17 & 1 \\
\hline 3 & 18 & 1 \\
\hline 3 & 19 & 1 \\
\hline
\end{tabular}




\begin{tabular}{|c|c|c|}
\hline 3 & 20 & 1 \\
\hline 3 & 1 & 2 \\
\hline 3 & 4 & 2 \\
\hline 3 & 5 & 2 \\
\hline 3 & 6 & 2 \\
\hline 3 & 9 & 2 \\
\hline 3 & 10 & 2 \\
\hline 3 & 11 & 2 \\
\hline 3 & 12 & 2 \\
\hline 3 & 13 & 2 \\
\hline 3 & 14 & 2 \\
\hline 3 & 16 & 2 \\
\hline 3 & 17 & 2 \\
\hline 3 & 18 & 2 \\
\hline 3 & 19 & 2 \\
\hline 3 & 20 & 2 \\
\hline 3 & 1 & 3 \\
\hline 3 & 2 & 3 \\
\hline 3 & 3 & 3 \\
\hline 3 & 4 & 3 \\
\hline 3 & 6 & 3 \\
\hline 3 & 7 & 3 \\
\hline 3 & 8 & 3 \\
\hline 3 & 9 & 3 \\
\hline 3 & 13 & 3 \\
\hline 3 & 15 & 3 \\
\hline 3 & 16 & 3 \\
\hline 3 & 18 & 3 \\
\hline 3 & 19 & 3 \\
\hline 3 & 20 & 3 \\
\hline
\end{tabular}




\section{APÊNDICE E - RESULTADO DAS INSTÂNCIAS PARA OS TRÊS MÉTODOS (MILP, GERAÇÃO DE COLUNAS E HEURÍSTICA CONSTRUTIVA PROBABILÍSTICA)}

$\begin{array}{llll}\text { Inst } & \text { MILP } & \text { CG } & \text { HEU } \\ 1 & 0,0 & 0,0 & 0,0 \\ 2 & 7,0 & 7,0 & 7,0 \\ 3 & 52,6 & 52,6 & 52,6 \\ 4 & 53,7 & 53,7 & 53,7 \\ 5 & 42,4 & 42,4 & 57,5 \\ 6 & 0,0 & 0,0 & 0,0 \\ 7 & 0,0 & 0,0 & 0,0 \\ 8 & 0,0 & 0,0 & 0,0 \\ 9 & 27,2 & 27,2 & 27,2 \\ 10 & 41,3 & 41,3 & 52,1 \\ 11 & 0,0 & 0,0 & 0,0 \\ 12 & 0,0 & 0,0 & 0,0 \\ 13 & 0,0 & 0,0 & 0,0 \\ 14 & 0,0 & 0,0 & 0,0 \\ 15 & 0,0 & 0,0 & 0,0 \\ 16 & 0,0 & 0,0 & 0,0\end{array}$




\begin{tabular}{|c|c|c|c|}
\hline 17 & 0,0 & 0,0 & 0,0 \\
\hline 18 & 0,0 & 0,0 & 0,0 \\
\hline 19 & 0,0 & 0,0 & 0,0 \\
\hline 20 & 0,0 & 0,0 & 0,0 \\
\hline 21 & 806,5 & 806,5 & 914,1 \\
\hline 22 & 378,9 & 378,9 & 439,5 \\
\hline 2 & 557,9 & 547,9 & 663,0 \\
\hline 2 & 551,2 & 545,3 & 607,8 \\
\hline 25 & 709,4 & 707,9 & 914,1 \\
\hline 20 & 319,9 & 313,1 & 453,9 \\
\hline 27 & 436,2 & 430,1 & 576,2 \\
\hline 28 & 803,2 & 803,2 & 945,8 \\
\hline 29 & 566,7 & 565,6 & 663,1 \\
\hline 3 & 697,8 & 690,6 & 873,0 \\
\hline 31 & 680,2 & 676,0 & 725,8 \\
\hline 32 & 454,0 & 452,0 & 469,1 \\
\hline 33 & 885,8 & 875,9 & 921,4 \\
\hline 34 & 788,4 & 788,4 & 839,1 \\
\hline 3 & 308,8 & 300,8 & 352,9 \\
\hline 30 & 398,5 & 397,3 & 441,0 \\
\hline 37 & 498,0 & 497,8 & 536,3 \\
\hline 3 & 529,7 & 529,7 & 584,3 \\
\hline 3 & 532,9 & 528,9 & 586,3 \\
\hline 40 & 523,8 & 523,8 & 568,4 \\
\hline 41 & 0,0 & 0,0 & 0,0 \\
\hline 42 & 55,0 & 54,2 & 55,0 \\
\hline 43 & 6,9 & 6,9 & 6,9 \\
\hline 44 & 20,1 & 20,1 & 20,1 \\
\hline 45 & 162,8 & 162,8 & 186,5 \\
\hline 46 & 127,6 & 127,6 & 127,6 \\
\hline 47 & 71,3 & 71,3 & 71,9 \\
\hline 48 & 96,5 & 96,5 & 96,5 \\
\hline 49 & 11,0 & 11,0 & 11,0 \\
\hline 50 & 3,5 & 3,5 & 3,5 \\
\hline 51 & 0,0 & 0,0 & 0,0 \\
\hline 52 & 0,0 & 0,0 & 0,0 \\
\hline
\end{tabular}




\begin{tabular}{|c|c|c|c|}
\hline 53 & 0,0 & 0,0 & 0,0 \\
\hline 54 & 0,0 & 0,0 & 0,0 \\
\hline 5 & 0,0 & 0,0 & 0,0 \\
\hline 0 & 0,0 & 0,0 & 0,0 \\
\hline 57 & 0,0 & 0,0 & 0,0 \\
\hline 5 & 0,0 & 0,0 & 0,0 \\
\hline 59 & 0,0 & 0,0 & 0,0 \\
\hline 60 & 0,0 & 0,0 & 0,0 \\
\hline 61 & 939,5 & 938,1 & 1072,6 \\
\hline 62 & 752,6 & 744,4 & 846,6 \\
\hline 63 & 599,5 & 589,6 & 666,3 \\
\hline 64 & 339,3 & 336,1 & 364,4 \\
\hline 65 & 359,8 & 345,1 & 439,1 \\
\hline 66 & 927,5 & 927,5 & 997,9 \\
\hline 67 & 1090,5 & 1086,0 & 1218,6 \\
\hline 68 & 693,7 & 691,6 & 765,3 \\
\hline 69 & 669,7 & 659,3 & 773,2 \\
\hline 70 & 609,0 & 608,5 & 718,5 \\
\hline 71 & 459,1 & 459,1 & 491,1 \\
\hline 72 & 456,1 & 454,1 & 488,0 \\
\hline 73 & 449,2 & 444,6 & 491,5 \\
\hline 74 & 907,6 & 906,7 & 937,1 \\
\hline 75 & 653,3 & 646,4 & 672,1 \\
\hline 76 & 825,5 & 825,5 & 889,0 \\
\hline 77 & 397,2 & 397,0 & 428,7 \\
\hline 78 & 880,7 & 874,8 & 895,5 \\
\hline 79 & 814,1 & 814,1 & 877,4 \\
\hline 80 & 678,1 & 672,6 & 709,1 \\
\hline 81 & 0,0 & 0,0 & 4,8 \\
\hline 82 & 0,0 & 0,0 & 0,0 \\
\hline 83 & 3,9 & 3,9 & 3,9 \\
\hline 84 & 32,0 & 32,0 & 32,0 \\
\hline 85 & 9,0 & 9,0 & 9,0 \\
\hline 86 & 55,7 & 55,7 & 55,7 \\
\hline 87 & 34,5 & 34,5 & 34,5 \\
\hline 88 & 34,2 & 34,2 & 34,2 \\
\hline
\end{tabular}




$\begin{array}{llll}89 & 17,0 & 17,0 & 17,0 \\ 90 & 26,8 & 26,7 & 27,2 \\ 91 & 0,0 & 0,0 & 0,0 \\ 92 & 0,0 & 0,0 & 0,0 \\ 93 & 0,0 & 0,0 & 0,0 \\ 94 & 0,0 & 0,0 & 0,0 \\ 95 & 0,0 & 0,0 & 0,0 \\ 96 & 0,0 & 0,0 & 0,0 \\ 97 & 0,0 & 0,0 & 0,0 \\ 98 & 0,0 & 0,0 & 0,0 \\ 99 & 0,0 & 0,0 & 0,0 \\ 100 & 0,0 & 0,0 & 0,0\end{array}$

$\begin{array}{llll}101 & 706,1 & 704,5 & 865,7\end{array}$

$102 \quad 501,4 \quad 499,0 \quad 582,2$

$103 \quad 493,6 \quad 487,7 \quad 545,8$

$104 \quad 488,8 \quad 488,8 \quad 577,7$

$105 \quad 432,9 \quad 423,8 \quad 535,6$

$106 \quad 308,8 \quad 308,0 \quad 365,5$

$107 \quad 881,9 \quad 881,4 \quad 1102,9$

$108 \quad 434,9 \quad 429,6 \quad 548,6$

$109 \quad 506,1 \quad 504,3 \quad 605,3$

$110 \quad 306,0 \quad 306,0 \quad 448,8$

$111 \quad 333,2 \quad 333,2 \quad 358,4$

$112 \quad 491,6 \quad 491,6 \quad 529,5$

$113 \quad 797,0 \quad 797,0 \quad 857,6$

$114 \quad 476,5 \quad 467,5 \quad 523,3$

$115 \quad 435,9 \quad 435,9 \quad 464,8$

$116 \quad 289,3 \quad 284,2 \quad 318,7$

$117 \quad 368,7 \quad 368,7 \quad 417,9$

$118 \quad 501,3 \quad 490,1 \quad 546,8$

$119 \quad 466,9 \quad 455,3 \quad 508,8$

$120 \quad 417,1 \quad 417,1 \quad 486,3$

$121 \quad 81,0 \quad 81,0 \quad 87,5$

$122 \quad 4,3 \quad 4,3 \quad 4,3$

$123 \quad 57,9 \quad 57,9 \quad 57,9$

$\begin{array}{llll}124 & 22,8 & 22,8 & 22,8\end{array}$ 


$\begin{array}{llll}125 & 111,7 & 111,7 & 111,7 \\ 126 & 82,2 & 82,2 & 83,2 \\ 127 & 224,3 & 224,3 & 224,3 \\ 128 & 19,2 & 19,2 & 19,2 \\ 129 & 42,2 & 42,2 & 50,1 \\ 130 & 6,1 & 6,1 & 6,1 \\ 131 & 0,0 & 0,0 & 0,0 \\ 132 & 0,0 & 0,0 & 0,0 \\ 133 & 0,0 & 0,0 & 0,0 \\ 134 & 0,0 & 0,0 & 0,0 \\ 135 & 0,0 & 0,0 & 0,0 \\ 136 & 0,0 & 0,0 & 0,0 \\ 137 & 0,0 & 0,0 & 0,0 \\ 138 & 0,0 & 0,0 & 0,0 \\ 139 & 0,0 & 0,0 & 0,0 \\ 140 & 0,0 & 0,0 & 0,0 \\ 141 & 801,9 & 801,6 & 846,6 \\ 142 & 707,2 & 707,2 & 768,4 \\ 143 & 679,7 & 676,4 & 745,4 \\ 144 & 511,1 & 511,1 & 596,4 \\ 145 & 627,8 & 627,0 & 752,4 \\ 146 & 285,5 & 283,7 & 369,2 \\ 147 & 587,5 & 587,5 & 679,2 \\ 148 & 695,7 & 690,4 & 715,5 \\ 149 & 432,8 & 432,8 & 481,8 \\ 150 & 538,4 & 533,7 & 594,0 \\ 151 & 303,7 & 301,1 & 326,2 \\ 152 & 646,5 & 646,5 & 660,5 \\ 153 & 534,9 & 534,9 & 559,2 \\ 154 & 520,5 & 516,0 & 545,8 \\ 155 & 379,5 & 375,7 & 423,3 \\ 156 & 596,4 & 596,3 & 610,5 \\ 157 & 318,3 & 316,0 & 356,8 \\ 1516,7 & 514,2 & 555,7\end{array}$




$\begin{array}{llll}161 & 0,0 & 0,0 & 0,3 \\ 162 & 0,0 & 0,0 & 0,0 \\ 163 & 7,2 & 7,2 & 11,4 \\ 164 & 42,0 & 42,0 & 56,5 \\ 165 & 3,7 & 3,7 & 3,7 \\ 166 & 0,0 & 0,0 & 0,0 \\ 167 & 0,0 & 0,0 & 0,0 \\ 168 & 0,0 & 0,0 & 0,0 \\ 169 & 24,8 & 24,8 & 24,8 \\ 170 & 30,5 & 30,5 & 30,5 \\ 171 & 0,0 & 0,0 & 0,0 \\ 172 & 0,0 & 0,0 & 0,0 \\ 173 & 0,0 & 0,0 & 0,0 \\ 174 & 0,0 & 0,0 & 0,0 \\ 175 & 0,0 & 0,0 & 0,0 \\ 176 & 0,0 & 0,0 & 0,0 \\ 177 & 0,0 & 0,0 & 0,0 \\ 178 & 0,0 & 0,0 & 0,0 \\ 179 & 0,0 & 0,0 & 0,0 \\ 180 & 0,0 & 0,0 & 0,0 \\ 181 & 1071,2 & 1063,3 & 1293,1 \\ 182 & 1079,8 & 1072,2 & 1381,2 \\ 183 & 649,6 & 633,0 & 709,6 \\ 184 & 810,6 & 794,6 & 1016,2 \\ 185 & 740,3 & 738,2 & 970,6 \\ 186 & 658,0 & 634,6 & 837,4 \\ 187 & 684,5 & 682,8 & 928,3 \\ 188 & 752,7 & 725,4 & 908,4 \\ 189 & 911,6 & 880,1 & 1002,1 \\ 190 & 1028,4 & 1002,8 & 1106,0 \\ 191 & 792,0 & 782,5 & 877,3 \\ 192 & 868,6 & 867,7 & 990,5 \\ 193 & 846,6 & 797,9 & 912,6 \\ 194 & 873,6 & 868,3 & 970,0 \\ 195 & 685,8 & 685,8 & 728,7 \\ 165,7 & 655,9 & 744,1\end{array}$




$\begin{array}{llll}197 & 1313,2 & 1299,2 & 1391,5 \\ 198 & 850,9 & 848,5 & 961,6 \\ 199 & 1175,9 & 1133,4 & 1233,7 \\ 200 & 580,6 & 579,6 & 662,0 \\ 201 & 91,5 & 91,5 & 102,1 \\ 202 & 0,0 & 0,0 & 0,0 \\ 203 & 0,0 & 0,0 & 0,0 \\ 204 & 30,5 & 30,5 & 30,5 \\ 205 & 53,0 & 53,0 & 57,8 \\ 206 & 0,0 & 0,0 & 0,0 \\ 207 & 0,4 & 0,4 & 1,6 \\ 208 & 1,0 & 1,0 & 1,0 \\ 209 & 4,1 & 4,1 & 4,1 \\ 210 & 48,0 & 48,0 & 48,0 \\ 211 & 0,0 & 0,0 & 0,0 \\ 212 & 0,0 & 0,0 & 0,0 \\ 213 & 0,0 & 0,0 & 0,0 \\ 214 & 0,0 & 0,0 & 0,0 \\ 215 & 0,0 & 0,0 & 0,0 \\ 216 & 0,0 & 0,0 & 0,0 \\ 217 & 0,0 & 0,0 & 0,0 \\ 218 & 0,0 & 0,0 & 0,0 \\ 219 & 0,0 & 0,0 & 0,0 \\ 220 & 0,0 & 0,0 & 0,0 \\ 221 & 740,7 & 733,9 & 945,1 \\ 222 & 735,9 & 731,5 & 830,3 \\ 223 & 918,1 & 918,1 & 1159,7 \\ 224 & 1447,0 & 1414,1 & 1692,2 \\ 225 & 946,0 & 946,0 & 1108,7 \\ 226 & 967,2 & 954,3 & 1072,7 \\ 227 & 1113,8 & 1102,8 & 1264,2 \\ 230 & 917,5 & 917,5 & 1031,5 \\ 23 & 1196,3 & 1195,3 & 1423,0 \\ 230 & 1420,6 & 1414,7 & 1615,7 \\ 20 & 705,6 & 705,6 & 789,4 \\ 269,3 & 559,4 & 652,2\end{array}$




$\begin{array}{llll}233 & 910,9 & 908,9 & 976,8 \\ 234 & 1084,6 & 1075,6 & 1136,6 \\ 235 & 572,9 & 567,4 & 642,8 \\ 236 & 784,8 & 780,6 & 843,3 \\ 237 & 803,6 & 801,7 & 858,5 \\ 238 & 1448,5 & 1422,5 & 1512,8 \\ 239 & 1176,4 & 1174,7 & 1243,7 \\ 240 & 968,5 & 959,8 & 1100,2 \\ 241 & 32,4 & 32,4 & 32,4 \\ 242 & 103,4 & 103,4 & 116,7 \\ 243 & 19,6 & 19,6 & 19,6 \\ 244 & 19,4 & 19,4 & 24,7 \\ 245 & 30,9 & 29,3 & 57,6 \\ 246 & 8,0 & 7,8 & 16,5 \\ 247 & 147,8 & 147,8 & 170,1 \\ 248 & 168,1 & 164,0 & 175,3 \\ 249 & 0,0 & 0,0 & 0,0 \\ 250 & 31,0 & 29,1 & 71,1 \\ 251 & 0,0 & 0,0 & 0,0 \\ 252 & 0,0 & 0,0 & 0,0 \\ 253 & 0,0 & 0,0 & 0,0 \\ 254 & 0,0 & 0,0 & 0,0 \\ 255 & 0,0 & 0,0 & 0,0 \\ 256 & 0,0 & 0,0 & 0,0 \\ 257 & 0,0 & 0,0 & 0,0 \\ 258 & 0,0 & 0,0 & 0,0 \\ 259 & 0,0 & 0,0 & 0,0 \\ 260 & 0,0 & 0,0 & 0,0 \\ 261 & 723,7 & 698,0 & 845,6 \\ 262 & 556,5 & 556,5 & 801,6 \\ 263 & 786,9 & 777,8 & 922,4 \\ 264 & 571,4 & 547,5 & 794,9 \\ 265 & 926,7 & 915,4 & 1201,8 \\ 257 & 710,3 & 707,2 & 881,6 \\ 23,5 & 961,8 & 1122,7\end{array}$




$\begin{array}{llll}269 & 502,9 & 486,7 & 659,9 \\ 270 & 452,3 & 452,3 & 620,2 \\ 271 & 884,9 & 868,0 & 928,2 \\ 272 & 796,1 & 793,5 & 895,0 \\ 273 & 521,2 & 503,9 & 606,5 \\ 274 & 485,8 & 473,2 & 526,3 \\ 275 & 706,6 & 688,6 & 850,3 \\ 276 & 539,7 & 525,5 & 570,9 \\ 277 & 613,9 & 609,6 & 683,4 \\ 278 & 602,4 & 587,0 & 695,6 \\ 279 & 807,2 & 807,2 & 904,0 \\ 280 & 345,0 & 341,5 & 381,6 \\ 281 & 11,4 & 11,4 & 11,4 \\ 282 & 0,0 & 0,0 & 0,0 \\ 283 & 55,2 & 55,2 & 72,0 \\ 284 & 27,6 & 27,6 & 27,6 \\ 285 & 48,6 & 48,6 & 48,6 \\ 286 & 72,4 & 72,4 & 73,5 \\ 287 & 0,0 & 0,0 & 0,0 \\ 288 & 0,0 & 0,0 & 0,0 \\ 289 & 9,1 & 9,1 & 12,4 \\ 290 & 23,0 & 23,0 & 23,0 \\ 291 & 0,0 & 0,0 & 0,0 \\ 292 & 0,0 & 0,0 & 0,0 \\ 293 & 0,0 & 0,0 & 0,0 \\ 294 & 0,0 & 0,0 & 0,0 \\ 295 & 0,0 & 0,0 & 0,0 \\ 296 & 0,0 & 0,0 & 0,0 \\ 297 & 0,0 & 0,0 & 0,0 \\ 298 & 0,0 & 0,0 & 0,0 \\ 304 & 0,0 & 0,0 & 0,0 \\ 302 & 0,0 & 0,0 & 0,0 \\ 299 & 984,1 & 984,1 & 1104,8 \\ 286,4 & 281,2 & 352,7 \\ 245,8 & 996,8\end{array}$




$\begin{array}{llll}305 & 511,5 & 509,8 & 571,5 \\ 306 & 647,3 & 641,9 & 737,9 \\ 307 & 445,6 & 445,0 & 532,8 \\ 308 & 970,3 & 969,5 & 1105,6 \\ 309 & 680,3 & 678,6 & 760,3 \\ 310 & 448,9 & 446,7 & 565,2 \\ 311 & 644,9 & 644,9 & 701,9 \\ 312 & 950,0 & 939,6 & 986,8 \\ 313 & 947,7 & 942,1 & 969,3 \\ 314 & 756,2 & 756,2 & 815,6 \\ 315 & 877,8 & 871,5 & 938,2 \\ 316 & 759,2 & 755,1 & 812,1 \\ 317 & 750,3 & 749,7 & 835,9 \\ 318 & 612,7 & 607,7 & 647,3 \\ 319 & 693,1 & 690,7 & 773,5 \\ 320 & 913,3 & 899,6 & 987,9\end{array}$

